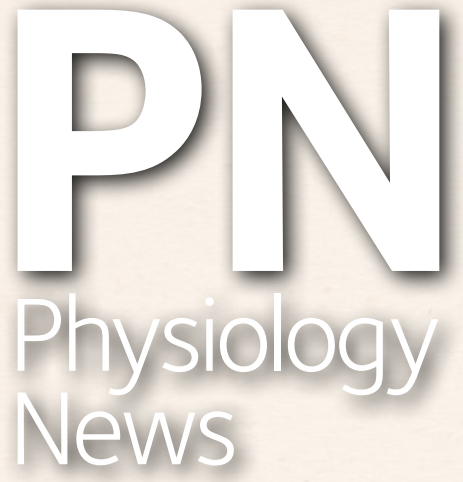

Issue 124/ Winter 2021
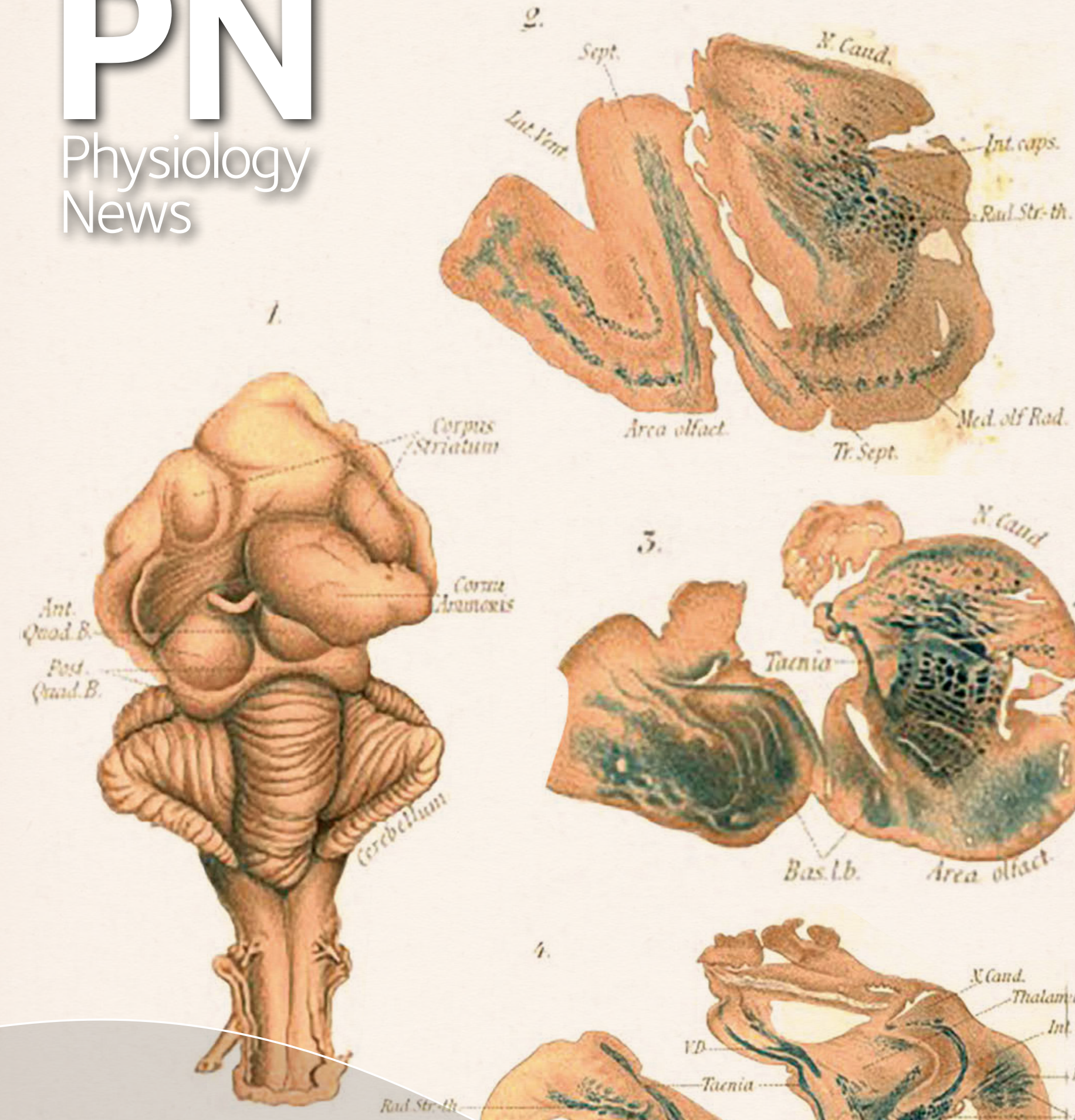


\section{Read Physiology News}

on the go

Did you know that

Physiology News

and its archives can

be accessed online?

physoc.org/magazine

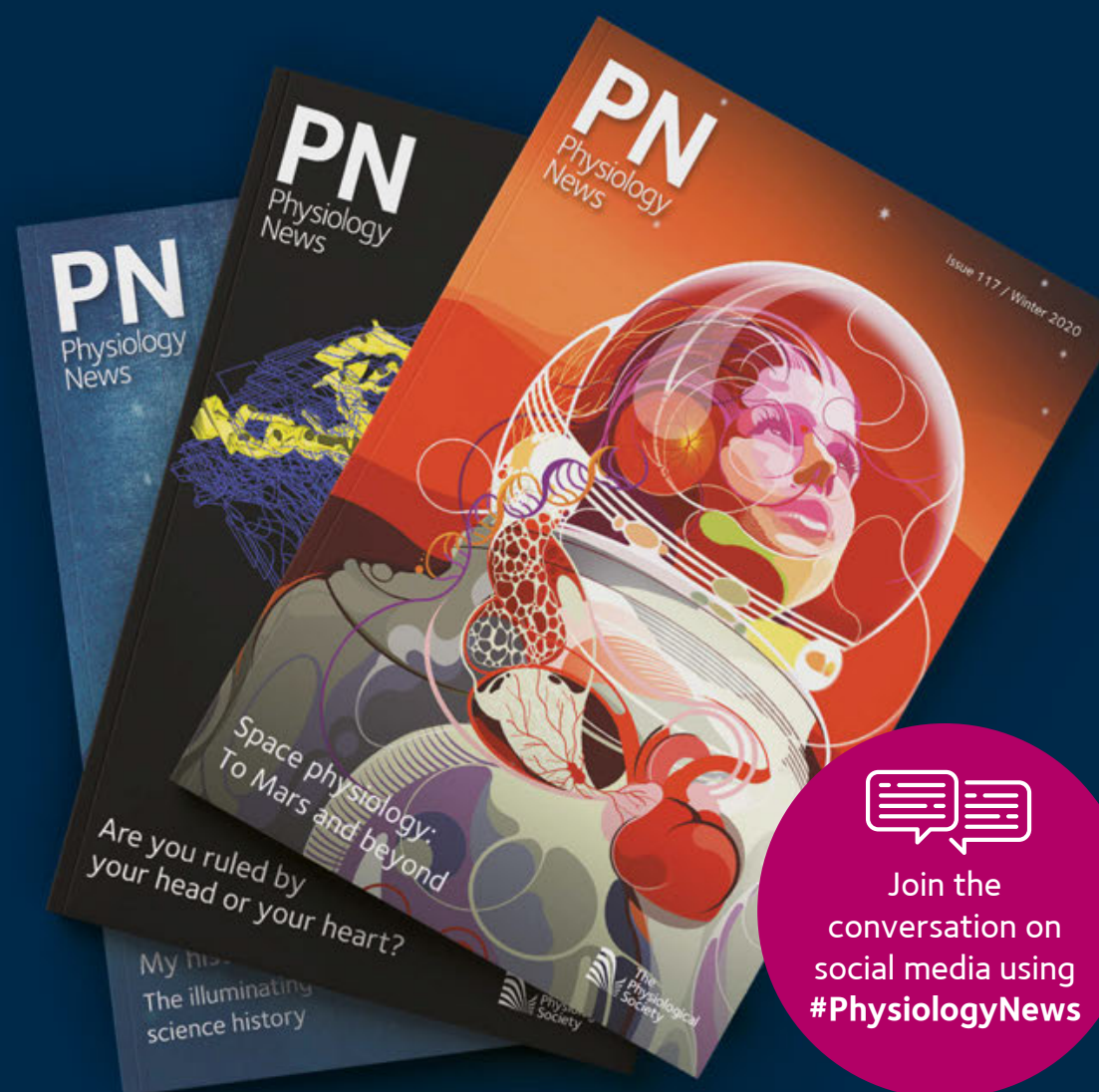

\section{Physiology News}

We welcome feedback on our membership magazine, or letters and suggestions for articles for publication, including book reviews, from our members.

Please email Julia Turan at magazine@physoc.org.

Physiology News is one of the benefits of membership, along with reduced registration rates for our high-profile events, free online access to our leading journals, The Journal of Physiology, Experimental Physiology and Physiological Reports, and travel grants to attend scientific meetings. Membership offers you access to the largest network of physiologists in Europe.

Join now to support your career in physiology:

Visit www.physoc.org/membership or call 02072695721.

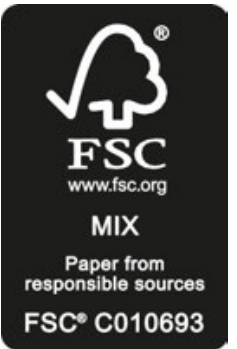

\begin{tabular}{l} 
Membership fees for 2021 \\
Undergraduate or \\
Master's Member \\
Postgraduate Member \\
Full Member \\
\hline Fellow Member \\
\hline Retired Member
\end{tabular}

FEES

Free (first year of membership) $£ 10$ per year (subsequent years)

$£ 30$ per year

$£ 100$ per year (standard rate) $£ 50$ per year (concessionary rate)

$£ 15$ per year
$£ 120$ per year

Opinions expressed in articles and letters submitted by, or commissioned from, members or outside bodies are not necessarily those of The Physiological Society. Physiology News is a member magazine and therefore is not subject to peer review and authors are advised to not include unpublished hard scientific data. Except where otherwise noted, content is licensed under a Creative Commons Attribution-ShareAlike 4.0 International (CC BY-SA 4.0) licence (creativecommons. org/licenses/by-sa/4.0/), which permits reuse, redistribution and reproduction, as well as remixing, transformation, and building upon the material for any purpose, in any medium, provided the original work is properly cited.

๑) 2021 The Physiological Society ISSN 1476-7996 (Print) ISSN 2041-6512 (Online). The Physiological Society is registered in England as a company limited by guarantee: No. 323575. Registered office: Hodgkin Huxley House, 30 Farringdon Lane, London EC1R 3AW. Registered charity: No. 211585. "The Physiological Society" and the Physiological Society logo are trademarks belonging to The Physiological Society and are registered in the UK and in the EU Community, respectively.
Scientific Editor

Dr Keith Siew University College London

Managing Editor

Julia Turan

\section{Editorial Board}

Dr Ronan Berg University Hospital Rigshospitalet

Dr Havovi Chichger Anglia Ruskin University

Dr Lalarukh Haris Shaikh Palantir Technologies

Dr Wendy Hempstock University of Shizuoka, Japan

Dr Alexander Carswell University of East Anglia

Dr Richard Hulse Nottingham Trent University

Dr Philip Lewis University Hospital of Cologne

Dr Dervla O'Malley University College Cork

Dr Michael Preedy Yale University School of Medicine, US

Dr Christopher Torrens RCSI, Ireland

Dr Katherine Rogers Queen's University Belfast

magazine@physoc.org

www.physoc.org

Y

@ThePhySoc

I 1 physoc

in /company/The-Physiological-Society

You /physoctv

(O) @thephysoc

Designed and printed in the UK by The Lavenham Press Ltd. 


\section{Introduction}

5 Editorial

6 President's view: Nobel Prizes, blue plaques, and interdisciplinary research

8 CEO's view: Climate change, The Society's COP26 Hub and physiology

\section{News and Views}

9 Reports of The Society's recent committee meetings

10 Interdisciplinary working and the Research Excellence Framework (REF): How can we recognise and reward research collaboration?

12 The Doctor Who Fooled The World: Andrew Wakefield's war on vaccines by Brian Deer

14 Physiology and climate change: The Society's new booklet showcasing the relevance of physiological research to climate change

16 Journal insights

\section{Features}

18 Diminishing returns

23 The highs of endocannabinoid physiology

28 The role of exercise physiology in 2021

32 Sir Gordon Morgan Holmes

\section{Events}

38 Looking ahead to The Society's exciting 2022 conference programme: The outgoing Conference Committee Chair passes the baton

39 Our first online Annual Conference Physiology 2021: Members give testimonials from the event

\section{Membership}

41 Physiology News Editorial Board welcome two new members

42 The Society honours its newly elected Fellow Members

46 From exercise physiology to the Olympics, England Athletics and beyond: A Fellow Member tells the story of her illustrious career 


\section{Apply for one of}

The Society's new

grants this winter

M. Conference Attendance Award
으음 Funding to attend a Society and/or
Society-sponsored conference Deadline: 31 January

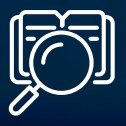

Accelerator Fellowship

Funding for projects within research, teaching, and outreach

Deadline: 1 March

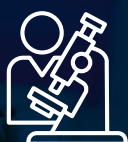

Professional Development Award Funding for professional training such as a laboratory visit or a workshop Deadline: 1 March

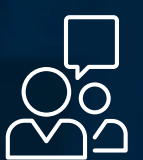

Momentum Fellowship

Funding to change the balance in your career between research, teaching, and outreach

Deadline: 1 March

$\kappa \hat{\imath}$ Research Springboard Studentship $\leftarrow \mathrm{O}^{\pi} \rightarrow$ Funding to support undergraduates

$\checkmark \downarrow \downarrow$ in experiencing the entire life-cycle of research

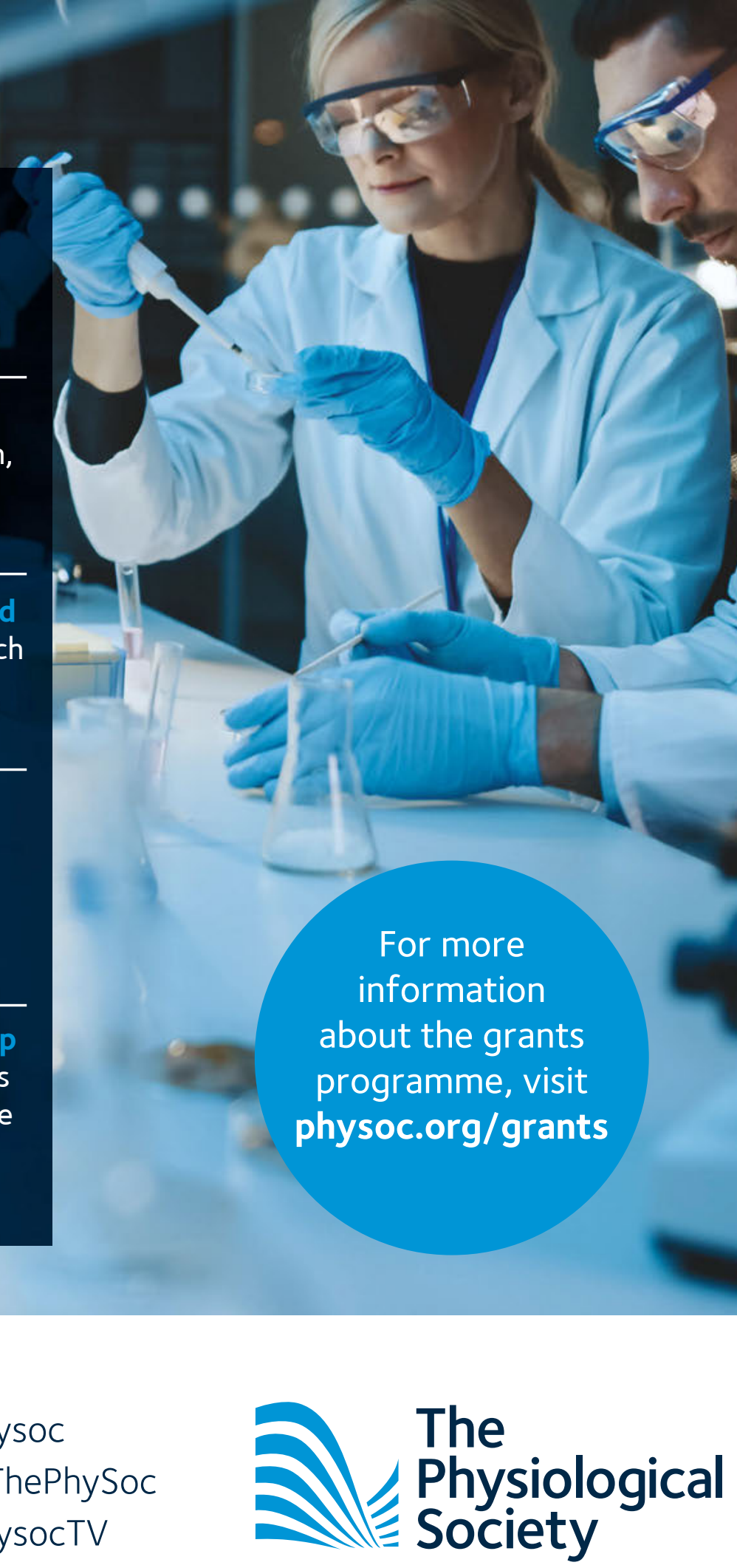
Deadline: 1 March

grants@physoc.org

+44 (0)2072695710 www.physoc.org f physoc

y @ThePhySoc

$\checkmark$ PhysocTV
The Physiological Society 


\section{Saying thank you, goodbye, and telling a bit of my story}

\author{
Julia Turan \\ Managing Editor, \\ Physiology News
}

To those Physiology News readers I haven't met yet this is a chance to say hello, and to say farewell as Managing Editor.

I joined The Society staff just over five years ago and have been Managing Editor of Physiology News, as well as Communications Manager, ever since. During my time at The Society, I've worked on 20 issues of the magazine (including this one) and the web version has had over 100,000 unique views.

I also led on a professional development webinar series during the first lockdown of COVID-19 last year, established a clear and consistent blog that gets several thousand views each month.

A career in communications would not come as a surprise to people who have known me for a long time. As a kid, I always had a propensity for writing, filling dozens of diaries, and I find that expressing myself in words massively helps me organise my thoughts (read: I love a chat). With hindsight, my initial decision to pursue science communication makes perfect sense. Allow me to explain.

For my undergraduate degree, I studied neurobiology and was initially aiming to be a lab-based scientist, focusing on basic research. For my undergraduate honour's thesis, I worked in the fabulous lab of the late Professor Ben Barres, developing a technique to study the role of actin in the ability of oligodendrocytes to form myelin. The aim of this was to understand the basic physiology that is disrupted in the disease multiple sclerosis.
Multiple sclerosis is a prime example of physiology; while it most directly impacts the brain, the knock-on consequences of the illness can affect many aspects of physiology (vision, movement, memory and many other systems).

In my final year of university, I discovered the field of science communication and was immediately hooked. While I dabbled in radio initially, I pivoted towards a focus on writing, and have expanded out professionally from there.

Writing and editing stories for a variety of audiences has been a focus of my role at The Society. Sharing the lives of fascinating physiologists, helping to amplify their voices, has been something I've thoroughly enjoyed.

In a twisted, yet also circular, turn of events two years ago, I was diagnosed with relapsing-remitting multiple sclerosis, making my honours thesis research seem fated and fuelling my passion for science communication further.

Alongside science communication, my twin passion, so to speak, is equity, diversity and inclusion (EDI) work. In addition to running an innovative magazine that showcases Society members and the latest physiology, Dr Keith Siew (Scientific Editor of Physiology News) and I worked to promote EDI as much as possible within the magazine.

Of course, this isn't me asking for a pat on the back! Quite the contrary. I'd like to echo messages we've published in previous magazines, calling for continued work, by everyone, and especially allies of all underrepresented communities.

This is a deliberately vague statement because the form that work takes, will vary widely whether we are talking about a charity, a research institute, a lab group, an individual, or other entities within the scientific sector.

An important step in The Society's EDI work is currently underway: a strategy is being drafted that will guide The Society's work in the area going forward. The Society has also done a range of important work in this area to date, which you can read about on our website: physoc.org/diversity.

I am proud that Keith, the Editorial Board, and I have published two EDI Special Issues in my time at The Society (and hopefully there will be more such Special Issues to come). These featured physiological research aiming to make our scientific knowledge base more equitable, diverse, and inclusive, as well as featuring profiles of people and organisations in this area.

While this magazine issue does not have a theme, it does include the usual exciting range of physiological topics. The feature articles focus on the importance of using large animal models, the medicinal effects of endocannabinoids, an update from the Human, Environmental and Exercise Early Career Theme Lead, and a historical profile of Gordon Morgan Holmes, including his studies of brain damage in British soldiers wearing a specific type of helmet called the Brodie.

Before I go, I want to say a huge thank you to my colleagues past and present on the Society staff, the Editorial Board of this magazine, and to Dr Keith Siew. I also want to thank Dr Karen Doyle who stepped down from the Editorial Board after six great years with us, and Dr Angus Brown who has also stepped down but will still be involved with the magazine as Chair of History and Archives.

You've all helped make me learn so much while at The Society and we've done great work together. 


\section{President's View}

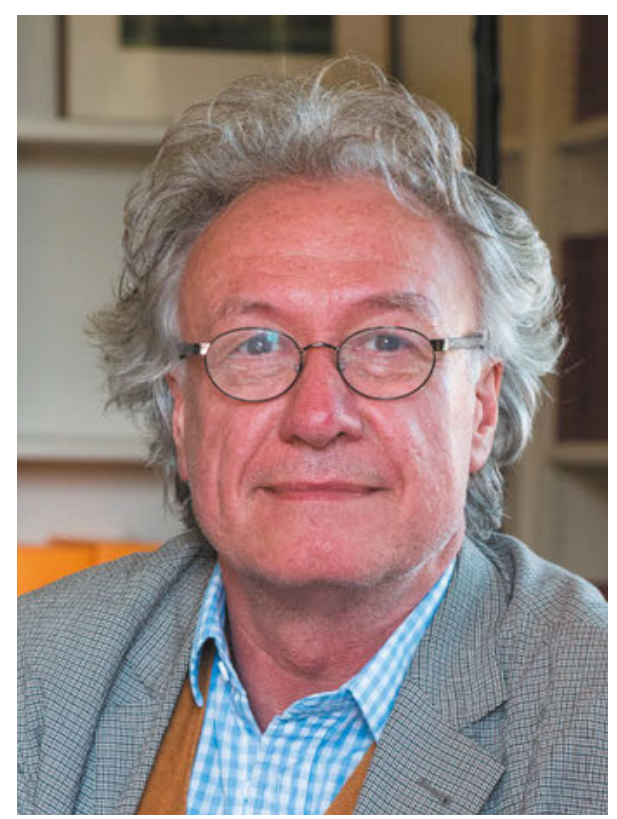

\section{Professor David Paterson}

President, The Physiological Society

In October I was delighted to congratulate Professor David Julius and Professor Ardem Patapoutian on behalf of The Physiological Society for their Nobel Prize in Physiology or Medicine. Their discoveries of receptors for temperature and touch is a great example of the ground-breaking work of physiologists. How we sense temperature, touch and movement are some of the great questions for humanity, and this research sheds light on how we sense and interact with the environment around us. It will be vital to develop treatments for chronic pain and other disease conditions and is a showcase for the vital contribution physiology makes to our lives.

As well as congratulating this year's Nobel Prize winners, I have been pleased to celebrate Nobel Prize winners of the past over the last few weeks, as we continue to erect Society blue plaques across the country. ${ }^{1}$ In September we unveiled blue plaques for Archibald Vivian Hill (known as AV Hill) in Manchester and Sir Charles Scott Sherrington in Liverpool. The blue plaques honour outstanding physiologists who have contributed to the advancement of the discipline through their discoveries while leaving a legacy beyond their lifetime, while celebrating and recognising institutions where distinguished physiologists have made significant contributions to the discipline alongside raising the visibility of physiology and giving the wider public an insight into the positive role that 'the science of life' plays in their everyday lives.

\section{Nobel Prizes, blue plaques, and interdisciplinary research} disciplines of biophysics and operations research. He was the Brackenbury Professor of Physiology at Manchester University from 1920 to 1923, and was awarded the Nobel Prize in 1922, aged just 36, for his studies on the production of heat and mechanical work in muscles. It was particularly special to unveil the blue plaque on the University of Manchester's Coupland Building 3, which was the old medical school at Victoria University of Manchester, where AV Hill worked. A lifelong humanitarian, Hill worked with Ernest Rutherford and William Beveridge to establish the Academic Assistance Council, which helped scientist victims of Nazi persecution at a time when the events in Germany were not known to many people in the UK. This organisation helped a thousand scientists escape, including 18 who went on to win Nobel Prizes.

At the University of Liverpool, I was delighted to recognise the tremendous achievements of Sir Charles Sherrington by unveiling a blue plaque to him on the University of Liverpool's Sherrington Building. Sherrington was awarded the Nobel Prize in 1932 with Edgar Adrian for their work on the functions of neurons. Prior to their research, it was thought that reflexes occurred as isolated activity within a reflex arc; they showed that instead, reflexes require integrated activation and showed reciprocal innervation of muscles, a principle now called Sherrington's Law.
AV Hill was one of the founders of the
In Edinburgh, we unveiled a blue plaque for Professor Mary Pickford, who started her career when there were few women doctors and considerable prejudice against women scientists. She went on to make her mark on medicine and physiological science.

Alongside the unveiling of our blue plaques, we have held Member Roadshows for members to meet Trustees and their local Society Representative. Following 18 months of COVID-19 and lockdowns, I have really enjoyed getting out around the country speaking to members face to face. We have many more roadshows planned over the next few months and I hope to meet many more members.

In November we have two prominent Society events taking place. We are holding an event in Parliament to launch our new report called The Future of Interdisciplinary Research Beyond REF2021. Physiology, by its nature, is a quintessential interdisciplinary science. From the immediate crisis of COVID-19 to longterm challenges such as our ageing society and climate change, the major issues facing the world require an interdisciplinary approach to solve.

Therefore, our project sought to consider how the UK's research system can better recognise and foster interdisciplinary research. We commissioned Research Consulting to carry out 1-1 interviews and focus groups

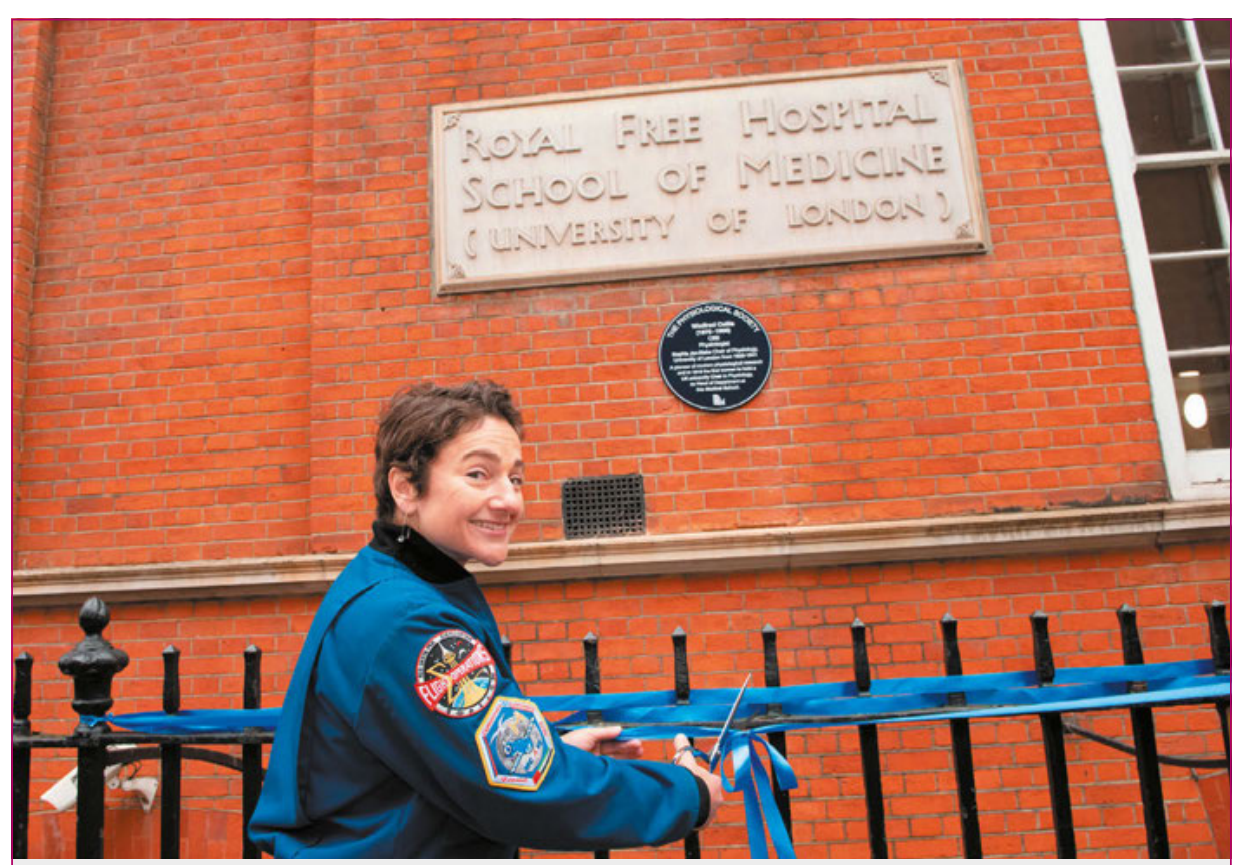

Dr Jessica Meir unveiling The Society's blue plaque for Professor Winifred Cullis. 


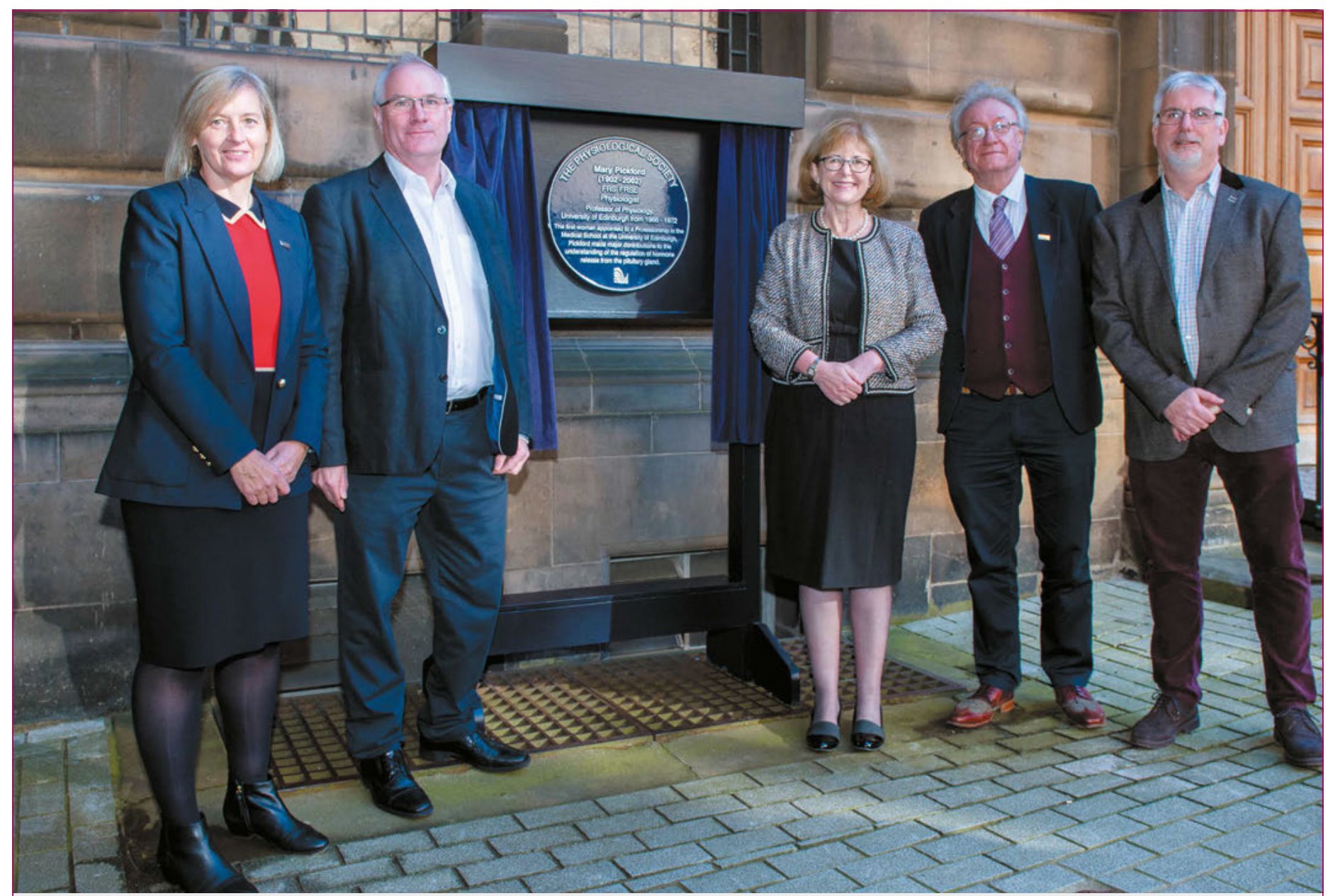

Dariel Burdass, Prof Mike Shipston, Professor Moira Whyte, Professor David Paterson and Prof David Wyllie (left to right) unveiling Professor Mary Pickford's plaque. Credit: Neil Hanna.

with a range of experts across the sector. We have brought together a Steering Group, chaired by Professor David Eisner, comprising representatives from across the research landscape, including The Royal Society, Royal Society of Chemistry, Institute of Physics, Campaign for Science and Engineering, Royal Society of Biology, Russell Group and GuildHE. The report makes recommendations on how we can increase the quantity of interdisciplinary research and address current barriers within the research ecosystem. You can read more about the report on page 10 and access the full report on our website. ${ }^{2}$

\section{In November we also have our 2021}

Member Forum and President's Lecture. The President's Lecture is the most prestigious event of The Society's calendar, and this year will be delivered by Dr Jessica Meir. Meir is a NASA astronaut and physiologist and, prior to becoming an astronaut, her career as a scientist focused on the physiology of animals in extreme environments. In 2019, while on the International Space Station, Jessica took part in NASA's first all-female spacewalk.
Finally, I am delighted to congratulate our 2021 Honorary Members, who will officially be appointed at our President's Lecture:

- Professor Dame Kay Davies CBE DBE FMedSci FRS, University of Oxford, UK

- Professor Maria Fitzgerald FMedSci FRS, University College London, UK

- Professor Christine Holt FRSB FMedSci FRS, University of Cambridge, UK

- Professor Carla J. Shatz PhD ForMemRS, Stanford University, California, US

- Professor Fiona Watt FRS FMedSci, King's College London, UK

- Professor Melanie Welham FRSB, Biotechnology and Biological Sciences Research Council (BBSRC)

- Rt Hon. Lord David Willetts FRS, Resolution Foundation
I am particularly pleased that, given The Society's focus on improving diversity and inclusion in science, that so many of our Honorary Members this year are women.

From congratulating this year's Nobel Prize winners, celebrating distinguished physiologists of the past, or ensuring the voices of our members are heard in the corridors of power, The Society's activities continue to go from strength to strength. I do hope you see you at one of our upcoming Member Roadshows or events around the country.

\section{References}

1. The Physiological Society (2021). The Physiological Society's blue plaques. Available at: https://www. physoc.org/about-us/our-blue-plaques/

2. The Physiological Society (2021). The Future of Interdisciplinary Research Beyond REF 2021. Available at: https://www.physoc.org/interdisciplinary 


\section{Climate change, The Society's COP26 Hub and physiology}

\section{Dariel Burdass}

\author{
Chief Executive, \\ The Physiological Society
}

Climate change, environmental damage and dwindling natural resources are significant and escalating problems which affect us all. The threat that climate change poses to the health of humans, other animals and plants cannot be ignored. This is being demonstrated globally by the melting of the polar ice sheets and locally by the milder winters we are having, coupled with more extreme weather such as heavy rain and flooding. The Atlas of Mortality and Economic Losses from Weather, Climate and Water Extremes (1970-2019)1 presented new data that between 1970 and 2019, there were more than 11000 disasters attributed to weather, climate, and waterrelated hazards, which accounted for just over 2 million deaths and US\$3.64 trillion in losses.

As noted by the World Health Organization ${ }^{2}$ the overall health effects of a changing climate are overwhelmingly negative. Climate change affects many of the social and environmental determinants of health and hygiene. These evolving health risk include:

- Temperature-related mortality and morbidity

- Air quality deterioration which exacerbates cardiovascular and respiratory disease

- Impacts of extreme events such as higher rainfall and rising sea levels which impact for example water-borne diseases such as cholera

- Food safety and nutrition

- Mental health and well-being

Physiology is an essential part of the scientific response as it helps us understand the consequences of climate change on the human body. As the science of how the body works, physiologists explain the impact of climate change on our health and productivity, and therefore the very future of our species.

COP26 is the 2021 United Nations climate change conference, and this year will be the 26th annual summit. It will bring together countries from across the world in what many believe to be the world's best last chance to get climate change under control. Physiology is essential to finding solutions for people facing hotter temperatures, extreme weather, fires, and floods and air pollution.
For example, physiologists use their specific expertise to look at how humans respond and cope with extreme heat to develop proposals for physiological adaptation (or acclimatisation), behavioural, infrastructure, and technological adaptation which can also inform public health guidance

In preparation for this event The Society has launched its COP26 Hub. This hub highlights how physiologists, and their research are playing a key role in delivering on the mitigation and adaption goals for COP $26^{3}$. From furthering our understanding of adaption to heat and extreme weather, to maximising human health while reducing food and agricultural emissions, physiological research is helping the fight against climate change.

Explore our COP26 hub which contains:

- A collection of videos from our conferences and meetings on topics related to a changing climate.

- Research articles published in our journals around the topic of a changing climate.

- Articles from Physiology News such as 'Ecophysiology and climate change, Shaping our understanding of animal form and function'.

- Projects and resources that our members are involved with

- Air pollution has long been one of the most severe forms of environmental damage. Air pollutants like Carbon Dioxide are causing the planet to heat up.

The Society has committed to an approach that seeks to incorporate environmental, social and governance into its business modelling. The Society has prepared a Responsible Investment Policy in line with guidance to asset owners provided by the UN Principles of Responsible Investment. The Policy aims to meet the expectations of The Society's members regarding key ethical considerations related to investing, and how The Society should respond to challenges observed in the world today. At a minimum, and where feasible, The Society expects the Portfolio to be invested in enterprises that have credible and target-based plans to reduce their most materially harmful impacts on people and the planet. ('Act to Avoid Harm'). The Society's preference, however, is to strongly favour investing in enterprises that not only act to avoid harm, but also generate various effects on positive outcomes for people and the planet.

The Society believes there are some enterprises and industries that it would be incompatible for the Portfolio to invest into. Therefore, The Society is committed to excluding any investee enterprises that derive more than $5 \%$ of their revenues from the following sectors:

- Thermal coal

- Oil sand extraction

- Arms and weapons

- Retail of threatened species

- Tobacco

- Enterprises subject to severe environmental controversies related to pollution with no evidence of remedial action

- Palm Oil and Wood Pulp companies that do NOT adhere to such minimum social and environmental standards

- Production of drift nets $>2.5 \mathrm{~km}$

- Companies found to have violated one or more of the ten Principles of the UN Global Compact

The Society has already started to evolve and embrace new ways of working to remain relevant and sustainable. In the office we are reducing the environmental impact of The Society through the following measures

- Our electricity comes from $100 \%$ renewable sources

- Our lighting will be $100 \%$ LED, including office, communal and emergency lighting.

- Where possible, all stationary is from recycled sources (i.e., pens, paper).

- We have moved all our business processes to paperless.

- We operate the Cycle to Work schedule, which encourages green commuting

- In 2018 we improved the building energy efficiency and insulation with the new roof and window secondary glazing.

- We recycle our waste

- We are opting for vegetarian

We are on a path to a net-zero future as we begin to develop The Society's new strategy which sets out a framework to increase the Visibility of Physiology in an Inclusive and Sustainable manner.

\section{References}

1. World Meteorological Organization (2021). WMO Atlas of Mortality and Economic Losses from Weather, Climate, and Water Extremes (1970-2019). Available at: library. wmo.int/doc_num.php?explnum_id=10769

2. World Health Organization (2018). Climate change and health. Available at: https://www.who.int/news-room/ fact-sheets/detail/climate-change-and-health

3. UN Climate Change Conference UK 2021 (2021). COP26 Goals. Available at: ukcop26.org/cop26-goals/ 


\section{Reports of The Society's recent committee meetings}

The purpose of these short updates is to keep you informed about the work of our committees. The following summaries detail the meetings of the past few months.

\section{The Board}

\section{June 2021}

The President, David Paterson, reported that the inaugural blue plaque unveiling and Sherrington lecture had gone well, and this the event could be used as a blueprint for future unveilings.

The Honorary Treasurer, Frank Sengpiel, reported that the new auditors Buzzacott LLP had completed their first audit of The Society and the process had gone smoothly. The auditors performed a full audit of the financial statements of The Society for the year ending 31 December 2020 and stated the audit found no significant deficiencies in the accounting and internal control systems and an unqualified opinion, without modification, would be issued on the 2020 financial statements. The Board approved the Trustee Annual Report and gave consent for the President and Honorary Treasurer to sign the Trustee Annual Report and balance sheet on behalf of the Board.

The Chief Executive, Dariel Burdass, updated The Board that the Member Community area of the website had launched, showcasing member-specific content. She added that the Theme Leads had engaged with this platform, but it was a slow burn and encouraged Trustees to help think of ways to engage the membership with it.

The Director of Scientific Publishing, Simon Rallison, and Chair of Publications Committee, Debbie Baines, spoke to the paper called Open Access, Plan S and The Society's strategy for The Journal of Physiology and Experimental Physiology and answered questions. A discussion followed the presentation which generated robust dialogue around the potential future publishing landscape The Society would be operating in, and it was agreed to keep this under review.

The Board approved the recommendations for Honorary Membership and Honorary Treasurer. The Board also approved the results of the General Trustee election. Read more about our newly appointed Trustees here: physoc.org/news_article/the-societywelcomes-our-new-trustees/

\section{Finance Committee}

\section{June 2021}

The Committee received and discussed the first quarter Management Accounts and reforecast narrative, which reflected the continued impact of the pandemic on the planned programme of events.

The Society's new audit manager from Buzzacott LLP updated the committee on the completed audit process and their intention to issue an unqualified opinion in the auditor's report. The Committee agreed to recommend the Letter of Representation and the Annual Report and Accounts to the Board for approval.

The Committee supported the recommendation that The Society used the COVID-19 fund to underpin the budget deficit for the next two to three years (2022, 2023 , 2024) while The Society undertook its next strategic review, starting in November 2021, which would enhance the visibility of physiology in an inclusive and sustainable manner.

The Honorary Treasurer introduced the Committee to the revised Investment Policy Statement and Responsible Investment Policy developed in collaboration with the Ethical Investment Working Group and the external consultant PWC. It was also agreed to put the recently vacated second floor of $\mathrm{HHH}$ on the rental market.

\section{Education, Public}

\section{Engagement and Policy}

\section{October 2021}

The second meeting of EPEP in 2021 was held in hybrid format and chaired by Dr Lucy Green, University of Southampton, UK.
The Committee agreed that the large and varied workload of the Committee limited the time available for discussion and analysis of projects within its remit. As such, the Committee agreed that a separate Policy Committee should be formed with oversight and accountability for The Society's work in this area.

The Committee noted the success of the recent animations and short explainer videos and agreed to feed in topic suggestions and members to be approached for these and the second series of the podcast, which is due to launch soon.

The Committee received an update from the Prizes Review Group, which had been convened to review the portfolio of Education and Teaching Prizes. The recommendation to increase recognition for the breadth of individuals that contribute to excellence in teaching was welcomed, and the Group was asked to develop these ideas further for presentation at the next meeting of EPEP.

The Committee also received an overview of proposed projects for 2022 from both the Head of Professional Development and Engagement Chrissy Stokes and the Head of Policy and Communications Andrew Mackenzie.

The Committee also welcomed a presentation and project overview from $\mathrm{Dr}$ Nick Freestone on his work to decolonise the curriculum and looked forward to supporting the aims of this project in future.

The Committee also gave thanks to Dr Elizabeth Sheader, Dr Charlotte Haigh, Dr Jo Lewis and Dr Nick Freestone for all their hard work on the Committee as they stand down as members.

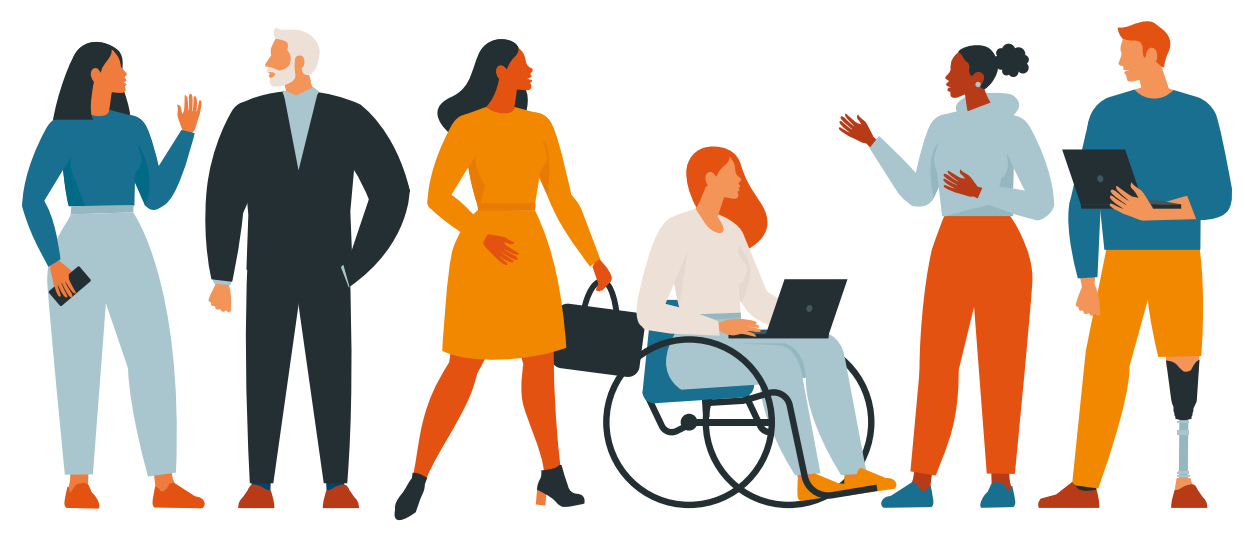




\section{Interdisciplinary working and the Research Excellence Framework (REF): How can we recognise and reward research collaboration?}

Professor David Eisner

University of Manchester, UK

\author{
Dr Dan King \\ Research Consulting Ltd., \\ Nottingham, UK
}

\section{Tom Addison}

Policy Manager, The Physiological Society

In October 2020 the then Science Minister, Amanda Solloway MP, announced a rootand-branch review of the Research Excellence Framework (REF) following the conclusion of REF 2021.

Among the reasons outlined by the Minister for the review were the need to "create 'more quality time' for research, build a culture that 'recognises all contributions', offer 'clear accountability for public funding without... complex bureaucracy' and motivate researchers "to do diverse, creative and risk-taking work" .

The review of REF 2021 is occurring in front of the backdrop of the Government's Innovation Strategy and R\&D People and Culture Strategy. The R\&D People \& Culture Strategy in particular has been designed to demonstrate the Government's commitment to co-create "a vision of the culture we want to see within the sector working together to make lasting change happen so that researchers and innovators with diverse backgrounds and ways of thinking can thrive and do their best work here". ${ }^{2}$

While the collaborative atmosphere is primarily focused on encouraging equality, diversity and inclusion (EDI) within the R\&D People and Culture Strategy, there is certainly an opportunity to link the mission-led focus of the Innovation Strategy and the Life Sciences Vision with the collaborative nature of interdisciplinary research.

\section{The Research Excellence Framework (REF) and its evaluation of interdisciplinary research}

The REF provides accountability for public investment in research and demonstrates this research's impact, benchmarks universities and the research they produce, and supports the allocation of about $£ 2$ billion of research funding.

The REF is a process of expert review, carried out by expert panels for each of the 34 subjectbased units of assessment (UOAs) ranging from Agriculture, Food and Veterinary Sciences to Theology and Religious Studies. Expert panels are made up of senior academics and research users.

For each submission, three distinct elements are assessed: the quality of outputs (e.g. publications, performances, and exhibitions), their impact beyond academia, and the environment that supports research.

Since the REF is broken down by subject matter, there has been a long-standing concern that the process disadvantages interdisciplinary research, with researchers uncertain as to which UOA to return their research under and a concern that this makes their research less likely to be selected by their institution.

Following the last REF process in 2014, a major review of REF was undertaken by Lord Stern, and the terms of reference included options for:

- A simpler, lighter-touch method of research assessment that more effectively uses data and metrics while retaining the benefits of peer review; and

- Ensuring that a future process identifies and supports excellent research across the UK, including dynamic changes in research quality and emerging areas of research excellence. ${ }^{3}$

The Stern Review also made specific reference to the important contribution that interdisciplinary research makes "to addressing complex, intrinsically difficult Grand Challenges of global importance".

\section{Stern also noted, however, that}

"Despite these perceived advantages the Call for Evidence revealed a sense that interdisciplinary work was disadvantaged by the [2014] REF through the disciplinary 'silos' embodied in the Unit of Assessment panel structures and that interdisciplinary work was often regarded less favourably than mono-disciplinary research. Such perceptions may have contributed to the relative underrepresentation of interdisciplinary outputs in Research Assessment Exercise (RAE) / REF compared with the known proportion of such work". 3
To address this, Stern recommended that future REF cycles should explicitly encourage the submission and identification of interdisciplinary research in the REF and that there was a varied use of the interdisciplinary identifier by institutions, and some uncertainty around its purpose. Stern also noted that "if there continues to be a discrepancy between the proportion of interdisciplinary research undertaken and that submitted to the REF, consideration might be given in future exercises to giving extra weighting to outputs that are strongly interdisciplinary". 3

There is, therefore, recognition within UKRI that interdisciplinary research is at the very least perceived to face additional barriers within the REF process and appetite to ensure that these barriers are overcome where possible.

\section{Why is this relevant to physiology?}

Physiology is by nature an interdisciplinary science - understanding how fundamental processes, such as the control of heart rate or the sense of vision, work and interact with other systems in the body in good health to then understand how to respond to ill health. Ensuring that interdisciplinary science is fully recognised as part of the next REF process will not only support the prioritisation of physiology, but other interdisciplinary disciplines too.

The process of formulating The Physiological Society's input into the next REF cycle began in January as we co-sponsored a roundtable with CaSE ${ }^{4}$. Participants noted the centrality of interdisciplinary research to solving challenges of the present and the future but that significant challenges remained across science in terms of a lack of visibility in career opportunities and access to funding for interdisciplinary research.

\section{Considering the future of REF for interdisciplinary research: Project overview}

Following on from the findings of the CaSE workshop, The Physiological Society convened a group of organisations with an interest in interdisciplinary research from across the STEM sector, chaired by Professor David Eisner, a former President of The Society and former panellist for REF in 2014 and RAE in 2008.

The Society also approached Research Consulting, a consultancy firm specialised in improving the effectiveness and impact of 
research and scholarly communication, to help deliver the project. This meant analysing efforts to improve the position of interdisciplinary research in previous iterations of the RAE/ REF process and reaching out to different stakeholders in the research community to assess the current landscape for interdisciplinary research. Further to this, Research Consulting has developed tangible recommendations in concert with the Steering Group to inform the consultation process for the next REF iterations.

\section{Key findings and recommendations}

In our report, The Future of Interdisciplinary Research Beyond REF 2021, we recommend that the next REF adopts a structure that explicitly identifies and rewards interdisciplinary research.

This includes a mechanism in any future assessment exercise to allow flexibility to researchers whose outputs straddle current discipline-based assessment structures to be returned to multiple units, recognising the breadth of the research teams in which they operate, and the outputs generated from this.

We also recommend that REF outputs contain an option for additional narrative to explain the interdisciplinary context of research outputs. While at first it may appear that this recommendation runs counter to the Government's current drive to reduce bureaucracy in R\&D, our findings demonstrate that the value of interdisciplinary collaboration is not always obvious and extends beyond current output metrics.
For The Physiological Society and other learned societies, we have recommended that they develop activities to support and facilitate the development of interdisciplinary collaborations with "near and far" disciplines and generate additional evidence on how interdisciplinary research shapes research careers. This collaboration could occur in both conference and journal planning and recognises the catalytic nature of interdisciplinary research to all the disciplines represented in a particular project.

The report also recommends further work to establish how greater understanding and characterisation of interdisciplinary research can be applied into wider practical use via a future research assessment cycle. In particular, the"cognitive distance" between collaborating disciplines is a major factor in how difficult it is to collaborate when researchers come from different disciplines, requiring time to build a common language that enables effective collaboration, access funding and publish the work. For example, collaborations between research in animal and human health may be easier to explain, develop and attract funding for, compared to social science and chemistry and yet all four areas will be crucial in combatting the effects of climate change.

Finally, there also remains the significant challenge of ongoing perceptions among researchers of negative impacts on career development for researchers involved in interdisciplinary research. Despite these pervasive attitudes across disciplines, there is a lack of evidence that provides current data or evidence on this.
Report launch event

To launch the report's findings, The Physiological Society organised a launch event in Parliament to discuss the fundings with the wider research community.

Unfortunately, owing to last-minute restrictions to public access to Parliament, we were unable to meet in person. However, an online launch was organised and can be found on The Society's policy webpage.

\section{References}

1. University Business (2020). REF review must motivate 'diverse, creative and risk-taking work' - Solloway. Available at: universitybusiness.co.uk/research/ref-reviewmust-motivate-diverse-creative-and-risk-taking-worksolloway/

2. Department of Business, Energy and Industrial Strategy (2021). R\&D People and Culture Strategy. Available at: assets.publishing.service.gov.uk/government/uploads/ system/uploads/attachment_data/file/1004685/r_dpeople-culture-strategy.pdf

3. Stern, Nicholas (2016). Building on success and learning from experience: an independent review of the Research Excellence Framework. Department for Business, Energy \& Industrial Strategy, London, UK. Available from: assets. publishing.service.gov.uk/government/uploads/system/ uploads/attachment_data/file/541338/ind-16-9-refstern-review.pdf

4. The Physiological Society (2021). Workshop on interdisciplinary research. Available at: physoc.org/policy/ research-landscape-and-funding/caseroundtable/

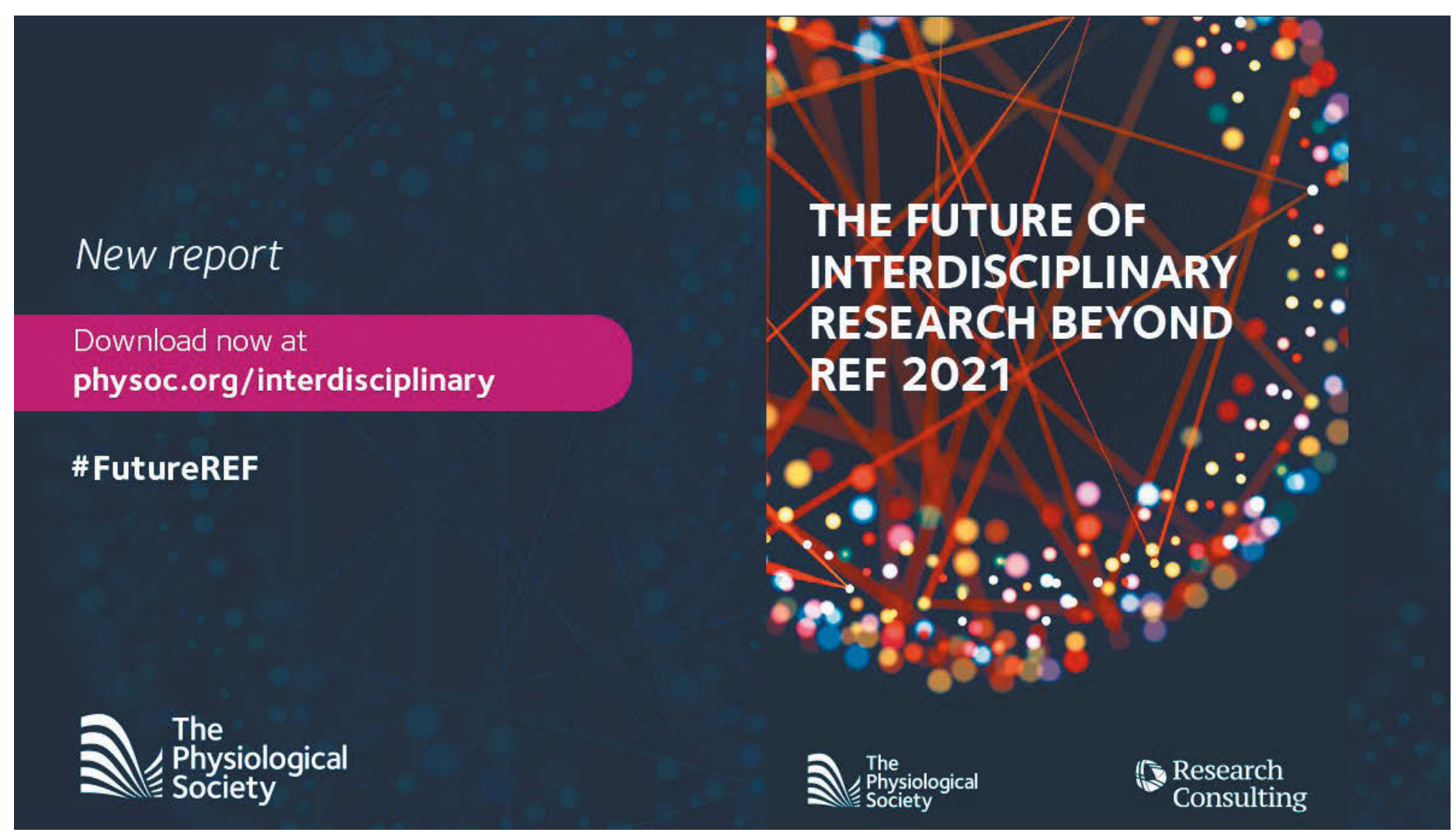




\section{The Doctor Who Fooled The World: Andrew Wakefield's war on vaccines by Brian Deer}

\author{
Dr Angus Brown \\ University of Nottingham, UK
}

The COVID pandemic has polarised public opinion regarding vaccination. Faced with the most serious global medical crisis for a century, it seem inexplicable that a significant proportion of the population are refusing vaccination, the only treatment proven to minimise the effects of the virus.

It is in the US that this issue is most visible, opinion divided primarily along political lines, with Republican voters more likely to express anti-vaccination sentiment than Democrat voters. The obscene situation where developed countries are destroying unwanted vaccines while developing countries suffer the ravages of the disease due to vaccine shortages may be considered the legacy of one man, Andrew Wakefield, whose fraudulent claims linking vaccination with autism in order to increase his academic profile, has led to one of the most serious threats to global health of the modern era.

The contrasting fates of charismatic arch frauds Lance Armstrong and Andrew Wakefield offer an insight into the public's attitude to lying. Both men's fame was founded on a series of escalating lies, which were vigorously defended, dissenters were confronted, their claims dismissed and they were ultimately threatened with legal action. Both men's lies were publicly exposed; they were sanctioned by their respective professional governing body, ending their careers. Armstrong's downfall was swift and complete. Stripped of all titles he was expunged from the record books, a punitive warning to potential cheats. Viewers of the three-week Tour de France, with up to five hours of daily coverage, are more likely to hear mention of Liberace than Lance. Wakefield met his match when new head of department Mark Pepys considered him a fraud and a fantasist, and made it his first order of business to rid the Royal Free Hospital in London of Wakefield's toxic mix of charisma and ruthless ambition. Wakefield relocated to Texas in 2004, Armstrong's home state, where the anti-vaccine movement embraced him as a seeker of the truth, and he currently enjoys enormous support as the world's most prominent anti-vaccine campaigner.
Brian Deer, a Sunday Times investigative journalist, was responsible for exposing Wakefield's fraud concerning claims that the MMR vaccine caused autism. This book describes his investigations, forensically unravelling the litany of fraud and lies perpetrated by Wakefield. Deer's prose style is not to my taste, but this should not detract from this extraordinary story. Unfortunately Deer also employs epithets for key characters and barely has a good word to say about anyone mentioned in the book, those attaining the lofty title of "Professor Sir" reserved for particular contempt. This is juvenile, Deer resorting to ridicule when he realises scientists and doctors are as venal and mendacious as his fellow journalists. An advantage of Deer's scientific ignorance is that he explains the medical facts in a very straightforward manner. However, the complex timeline, coupled with the interweaving roles of multiple characters, mandates a second reading of the book to establish a firm understanding of the chronology of events.

\section{Wakefield is portrayed as a frustrated} mid-ranking clinician with lofty ambitions of fame and fortune, working in a mediocre department in the early 1990s. Wakefield shrewdly realises a path to success lies in the Research Assessment Exercise, and focuses on creating a headline-grabbing story. He uses the future Nobel Prize winners Warren and Marshall, who showed against the prevailing accepted medical wisdom that peptic ulcers are caused by bacteria and could be easily cured with antibiotics, as his model. Wakefield lacks their medical insight and fabricates a tale in which children develop symptoms of autism within two weeks of receiving the MMR vaccine. It is important to note that initially Wakefield was not against vaccinations, but rather advocated immunisation against measles, mumps and rubella be given as individual vaccinations from which he would benefit financially, having patented a single dose measles vaccine. Wakefield vacillated on what he considered the agent of autism, settling initially on the partial live measles virus present in the MMR vaccine, then on thimerosal, a mercury-based compound contained in the MMR vaccine. He proposed that the MMR vaccine caused autism by penetrating the gut, with cognitive regression a secondary effect. His primary evidence was an electron microscopic image of the measles virus in the gut of a Crohn's disease sufferer.
No other laboratories were able to replicate this result when they used the sensitive PCR technique to detect the virus. The study that brought Wakefield the attention he craved was published in The Lancet in 1998. The dubious funding, clinical misconduct, data manipulation and patient coercion that underlay this paper are all described in great detail, so there can be no doubt as to the depth and extent of Wakefield's fraud. What is also evident is the role of fellow clinicians, scientific collaborators and ambitious hospital managers who acted as enablers, hitching their wagons to Wakefield as a fast track to career advancement, patient care and clinical ethics be damned. However, the publication of the paper attracted a little too much adverse attention for Wakefield's liking. The claims of the study were of such fundamental importance they demanded to be replicated and independently verified. Although Wakefield was given the opportunity to do this he stalled and then refused, precipitating his removal from the Royal Free in 2001. The pathway to publication of the study in The Lancet reveals a web of nepotism where conflicts of interest were ignored. Even when scrutiny of The Lancet paper becomes sufficiently intense to prompt an inquiry the self-serving committee members find no fault with the paper.

The paper was eventually retracted in 2010 and Wakefield was struck off in the same year. This should be where Wakefield's fate matches that of Armstrong, but the US has always embraced the charismatic anti-establishment loner to a greater degree than the UK. After his move to the US, Wakefield's stance varied depending upon circumstance, telling US TV that he believed that there was a link between the MMR vaccine and autism, and then telling the Guardian that "I do not make the claim that MMR is a cause of autism". The shifting tone of Wakefield's pronouncements makes it difficult to pin down his exact claims, and Deer suggests Wakefield himself was unable to articulate his theory precisely and varied his claims depending upon his audience, relying on his charisma to disarm sceptical interviewers.

Distrust of vaccines is not a new phenomenon. Indeed the comically reckless and criminally negligent manner in which Edward Jenner first demonstrated controlled vaccination in 1796 has tainted the practice ever since. This is largely due to the complexities involved in understanding 
how vaccines work, and the seemingly dangerous paradox of injecting an agent related to a disease-causing pathogen in order to prevent illness. The first public demonstrations against vaccination occurred in the mid $19^{\text {th }}$ century, when the British government ordered vaccination in their fight against smallpox. Despite the success of vaccination programmes, particularly smallpox, the public has never been fully convinced that vaccines are safe. At least part of this rests on the noble intention of parents in protecting their children. Many people fear hypodermic syringes, the greatest cause for vaccine hesitancy, and adverse reactions to vaccination are common. The difficulties in extrapolating population statistics, e.g. the vaccine is $70 \%$ effective, to the effect on an individual also confuses. These are legitimate concerns, and are an important part of the dialogue between the public and the medical profession.

The anti-vaccination movement has been infiltrated by those using it to further their own ends. The movement is based on ignorance and recalcitrance, fuelled by misinformation, political agendas, government distrust, financial gain, it is immune to logic and reason. There is enormous political capital to be gained in manipulating a large proportion of the population, a shared distrust of vaccinations the common bond used to steer opinion. It is in the US that Wakefield's fate spirals out of his control. He becomes dependent upon wealthy donors, some with autistic children, who represent a powerful lobby, whose personal tragedies drive a zealotry intent on exposing "the truth" that "they" are hiding, namely that all vaccines are dangerous. In order to receive financial support from these wealthy donors Wakefield must form a Faustian pact and adopt their extreme views on vaccination, declaring "If I had a baby, I would not vaccinate them", in 2017.

\section{Do the countless deaths resulting from} his advocacy of vaccine hesitancy prey on Wakefield? Apparently not, when he proclaims, "I do not feel responsible". How does he sleep at night? Rather comfortably you may imagine, in the multi-million dollar Florida mansion he shares with model Elle McPherson, but I'm not so sure. It is one thing to make peace with lies of your own invention, quite another to live a lie imposed upon you by the desperate, the deluded and the frankly dangerous.
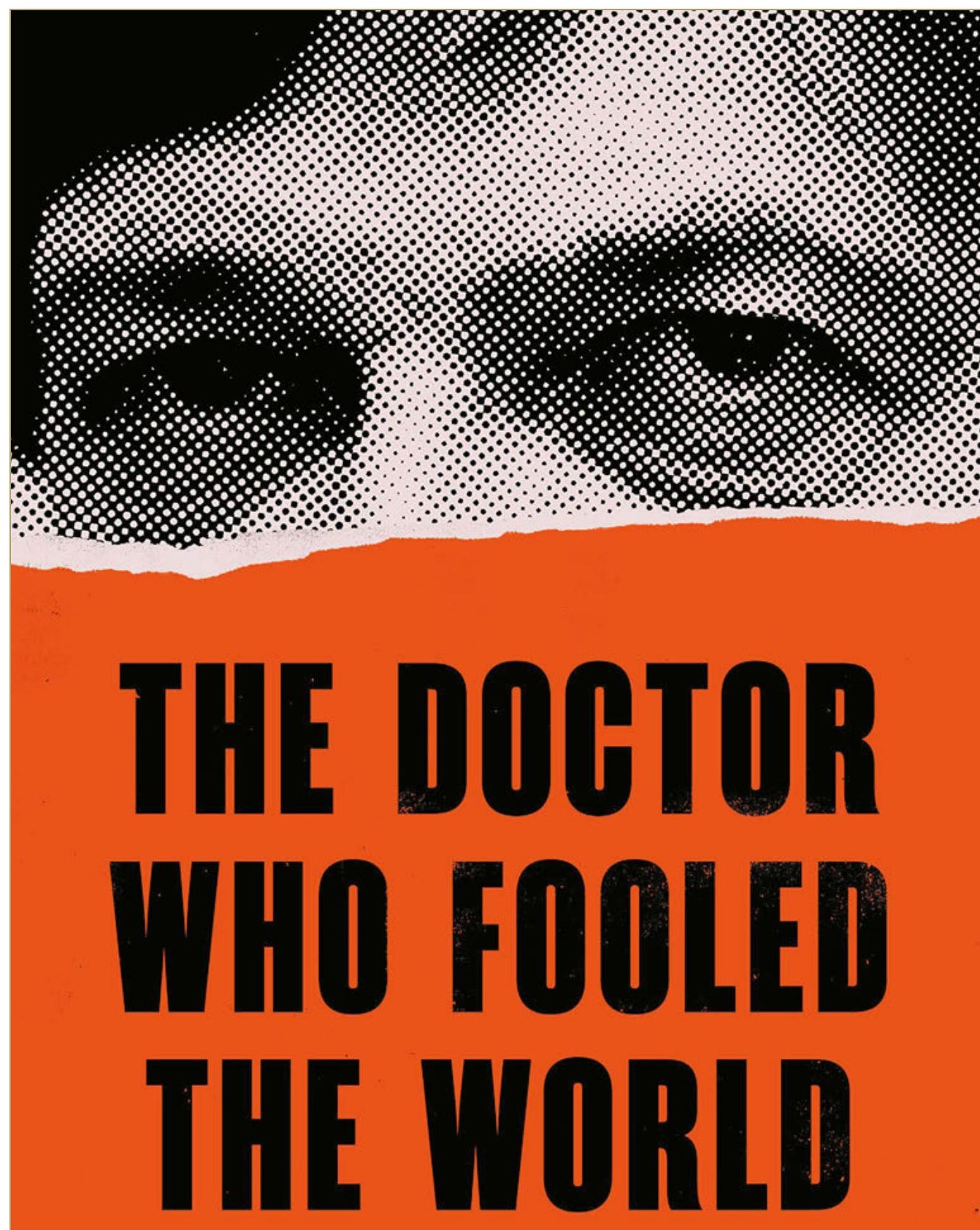

Andrew Wakefield's

war on vaccines

BRIAN DEER 


\section{Physiology and climate change: The Society's new booklet} showcasing the relevance of physiological research to climate change

When COP26 took place in Glasgow in early November, The Society launched a new booklet called Physiology and climate change. This booklet showcases the work of physiologists across the world in a global effort to understand and find solutions for the effects of climate change.
Below are a few examples of the physiological research stories elaborated on in the booklet, which can be downloaded on The Society's COP26 Hub:

www. physoc.org/climatechange.
Using medical technology to fight species extinctions

Physio-logging uses non-invasive sensing technology to continuously measure physiological function in different species, and will be vital in the fight to save species from extinction caused by climate change.
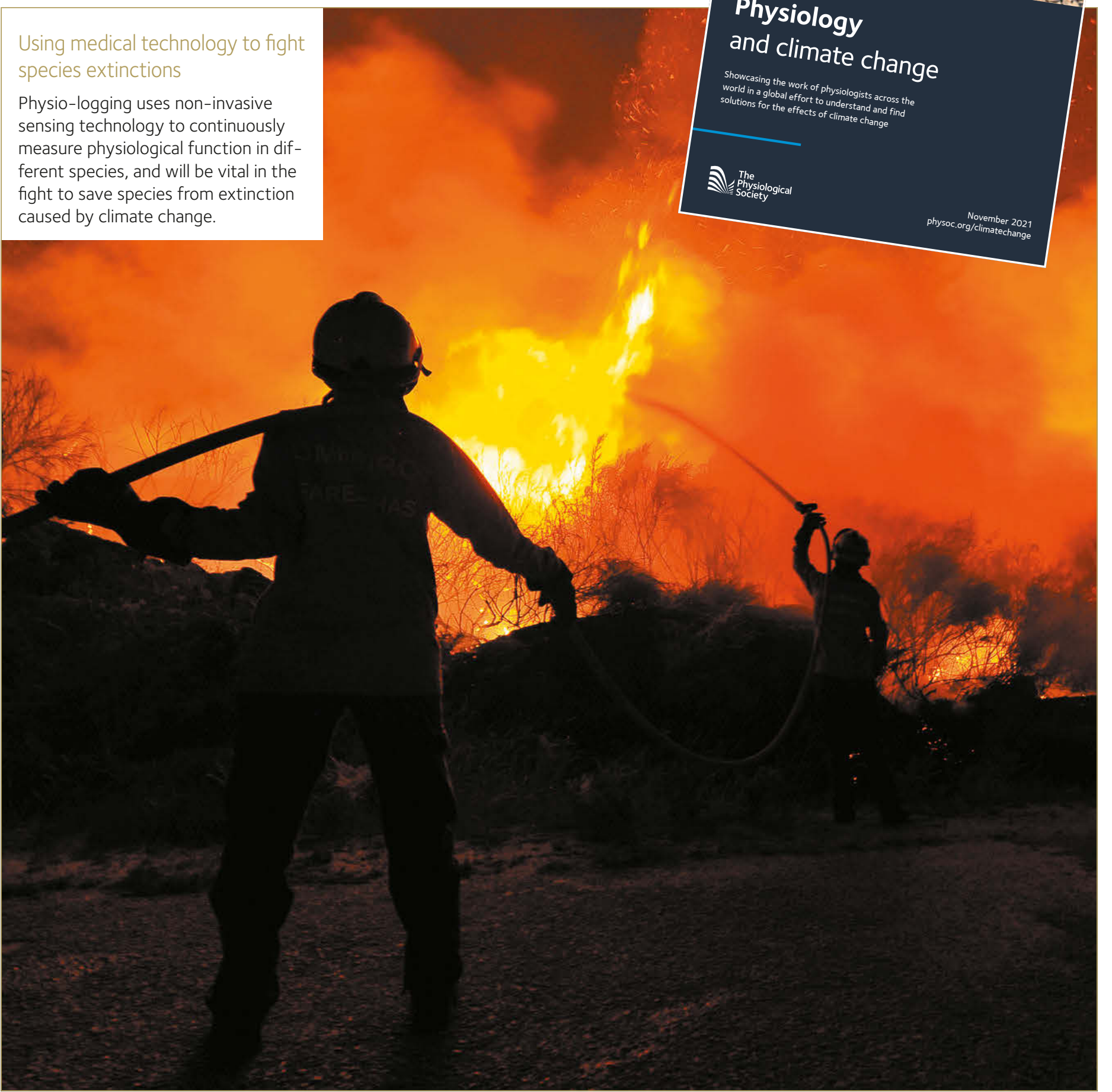
Living in a future with climate change challenges and opportunities for human thermal resilience As comfort seekers, we avoid being exposed to temperatures outside of our comfort zone. However, in the light of climate change and the need to drastically reduce our carbon footprint, we need to rethink many of our habits. Enhancing our own human resilience, by training our bodies' thermoregulatory system, presents an opportunity to reduce energy use, while at the same time improving our health.

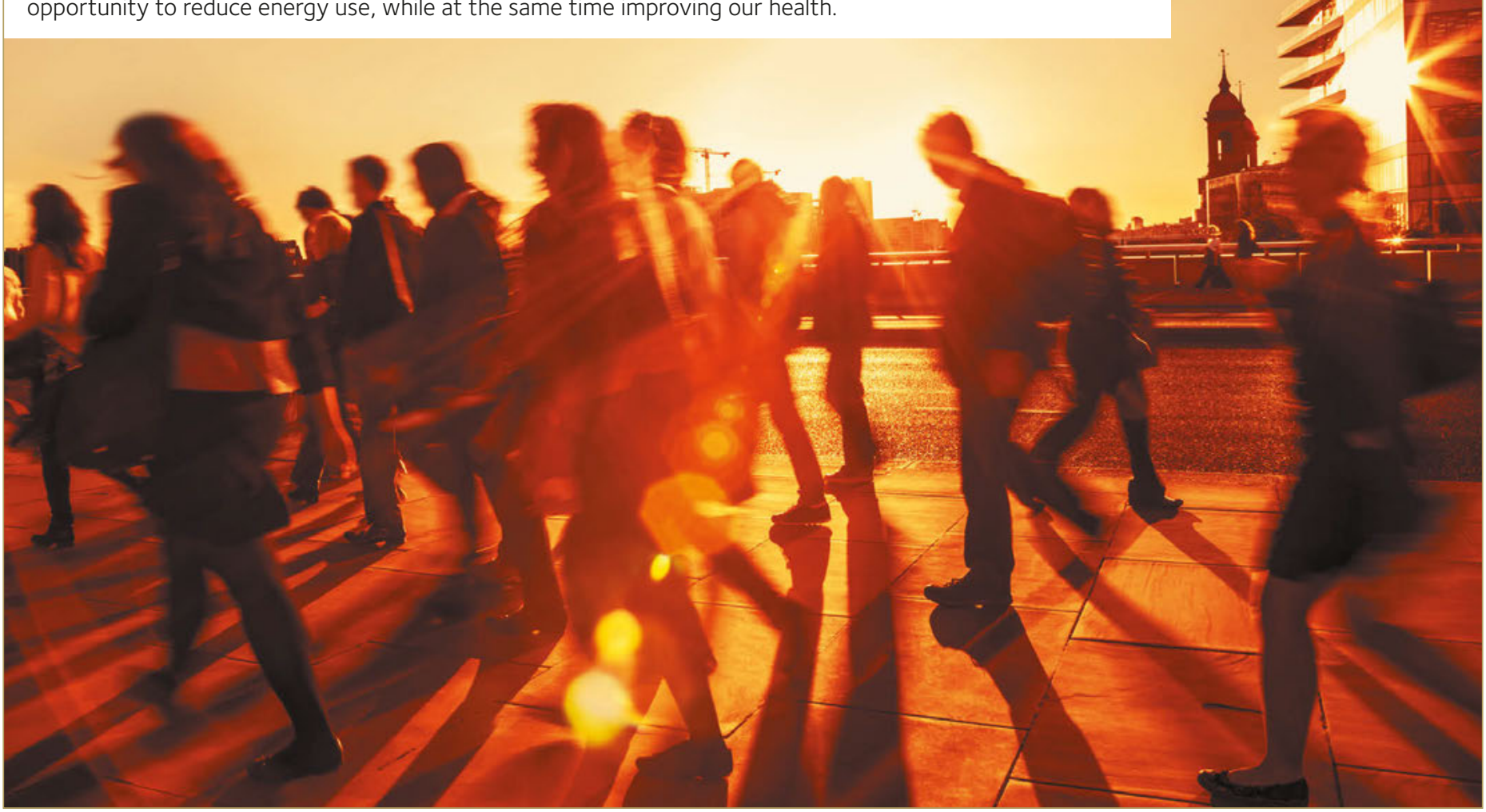

Protein nutrition, healthy ageing and climate change: how do we combine the three?

Our dietary protein choices can impact both our muscle physiology and the natural environment. Muscle physiology is framed in the context of maintaining muscle size and function as we age. The environment refers to the climate change effort that we, as a collective society, must embrace.

Diet clearly makes significant contributions to global warming and climate change. Regarding protein nutrition, the anabolic potential of a protein source is dictated by three key factors, namely the digestibility of the protein, the essential amino acid profile and the leucine content.

On the basis of current scientific knowledge, animalbased protein sources are more anabolic than plantbased protein sources, at least on a dose-matched basis. Future protein recommendations should take a holistic approach by considering muscle health, appetite and other nutrients of concern.

But climate change threatens our very survival and that of our ecosystems and consideration of this fact must drive food policy above all else. These recommendations will likely include a marked increase in plant-based foods, but without elimination of meat or dairy.

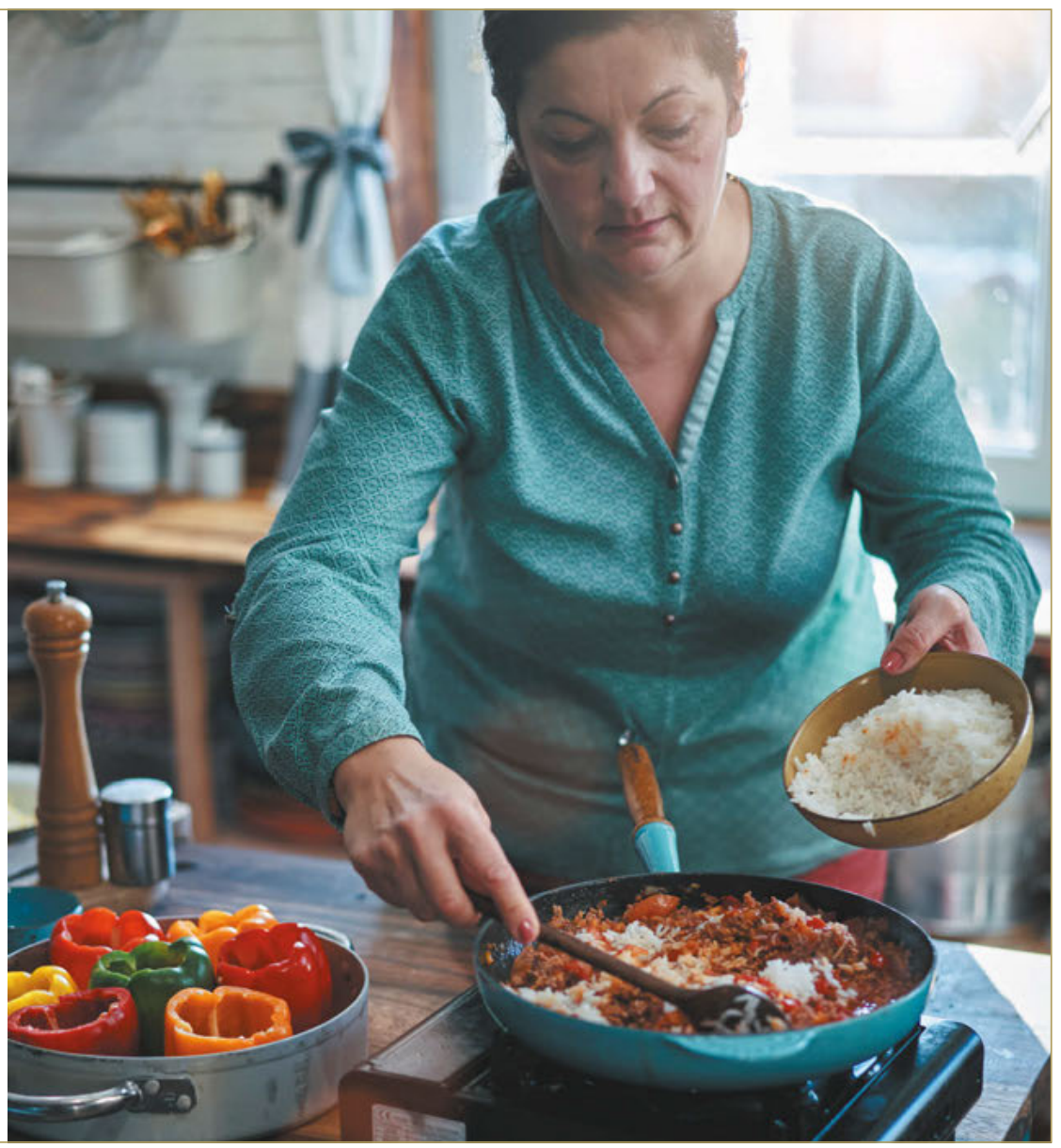




\section{EP Experimental Physiology}

\section{Oral administration of angiotensin-(1-7) decreases muscle damage and prevents the fibrosis in rats after eccentric exercise}

Nádia Lúcia Totou et al. May 2021

https://doi.org/10.1113/EP089308

https://physoc.onlinelibrary.wiley.com/doi/10.1113/EP089308

Physical activity leads to damage to our muscle fibres that can impair function. Changes in the muscle structure through development of fibrosis and infiltration of inflammatory cells are present following exposing rodents to short term physical exercise. In this study, the renin-angiotensin pathway has been utilised as it has been shown that an aspect of this signalling cascade is protective and has a potential to prevent muscle damage. Angiotensin (1-7) is a prominent mediator of vasodilation. Supplementing rodents with angiotensin $(1-7)$ reduces muscle inflammation demonstrated by reductions in inflammatory mediators TNFĐ and 1110 . This is accompanied by reductions in the number of inflammatory cells found in muscle post physical exercise in the angiotensin (1-7) treated group. Collagen accumulation in muscle post exercise was used to highlight increased fibrosis. However, in the angiotensin (1-7) treated cohort this was reduced. These data suggest that angiotensin (1-7) has the ability to protect muscle from exercise induced injury.

\section{Angiotensin-converting enzyme inhibitor prevents skeletal muscle fibrosis in diabetic mice}

Naoya Kakutani et al. may 2021

https://doi.org/10.1113/EP089375

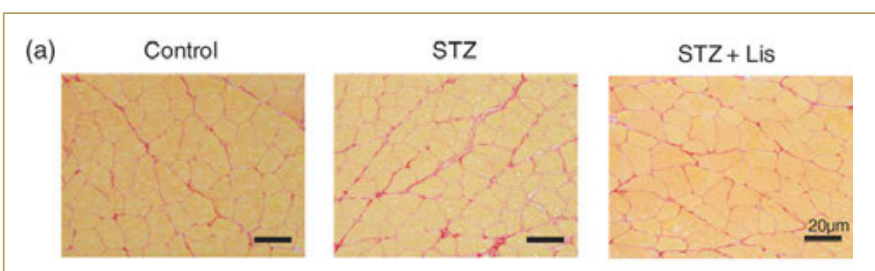

(b)

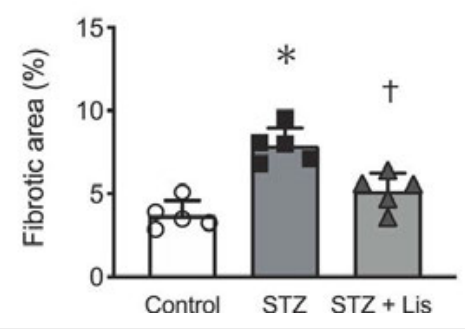

Figure 1. Effect of Lis administration on skeletal muscle fibrosis in diabetic mice. (a) Representative high-power photomicrographs of gastrocnemius cross-sections stained with Picrosirius Red from control, STZ and STZ + Lis groups of mice at 14 days post-STZ. Scale bars: $20 \mu \mathrm{m}$. (b) Summary data of skeletal muscle fibrosis $(n=5)$. Data are expressed as the mean $\pm S D$. ${ }^{*} P<0.05$ versus control; $+P<0.05$ versus $S T Z$. Abbreviations: Lis, lisinopril; STZ, streptozotocin
Excess production of extracellular matrix underlies the development of fibrosis, a process that can damage and impair muscle function. Previous studies highlight the involvement of the Renin Angiotensin system in the development of fibrosis in skeletal muscle. In this study a mouse model of type 1 diabetes is used to cause muscle atrophy and it is investigated whether an angiotensin converting enzyme inhibitor can prevent muscle fibrosis. Development of type 1 diabetes drives metabolic disturbances with enhanced blood glucose and reduced insulin levels. This is associated with muscle atrophy, reduction in muscle mass as well as an increase of collagen deposits. Treatment with an ACE inhibitor, Lisinopril reduced the accumulation of collagen, a prominent feature of extracellular matrix and fibrosis development. However, the hyperglycaemia induced muscle damage was not associated with alterations in angiotensin II or TNFĐ expression levels, which were unaltered by treatment with an ACE inhibitor. This study highlights that utilising the RAS system can be used to minimise muscle atrophy due to the development of fibrosis.

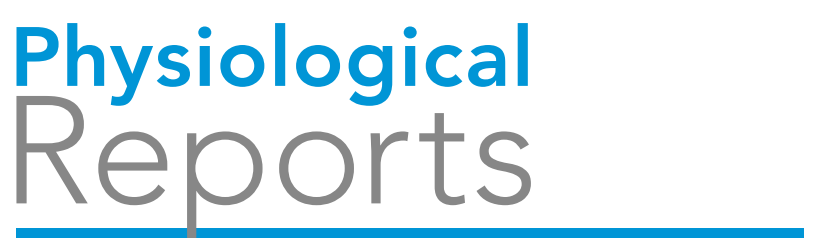

\begin{abstract}
Integrated respiratory chemoreflex-mediated regulation of cerebral blood flow in hypoxia: Implications for oxygen delivery and acute mountain sickness
\end{abstract}

Shigehiko Ogoh, et al. July 2021

https://doi.org/10.1113/EP089660

The brain is a highly metabolic tissue, dependent upon the effective delivery of oxygen and glucose, whilst relying upon efficient removal of waste metabolites such as carbon dioxide. During reductions in oxygen availability such as at altitude, the brain utilises chemoreflex pathways that sense alterations in the balance of oxygen and carbon dioxide to elicit a suitable response to overcome any imbalances. It has been highlighted this homeostatic system is not ubiquitous but supports specific brain structures, with increased blood perfusion noted in the posterior of the brain during hypoxia. This study recorded oxygen delivery and blood perfusion in the internal and external carotid artery during normoxia and hypoxia, inconjunction to determination of the contribution of the central and peripheral respiratory chemoreflex pathways. It was demonstrated that contrasting oxygen levels were found in differing arterial vessels during hypoxia and was represented by decreased oxygen in the internal carotid artery, whereas the external carotid artery remained unchanged. Through exploring the central and peripheral chemoreflex pathways, it was determined there was minimal input from the central respiratory chemoreflex pathway. Here it was determined that by modulating haemodynamic forces through alterations in blood perfusion could be an implicated risk factor in acute mountain sickness. 


\section{The Journal of Physiology}

\begin{abstract}
$1,25(\mathrm{OH})_{2}$ vitamin $D_{3}$ stimulates active phosphate transport but not paracellular phosphate absorption in mouse intestine
\end{abstract}

Hernando $N$ et al. (Nov 2020)

http://doi.org/10.1113/JP280345

Absorption of phosphate is thought to occur mainly via active transport coupled with $\mathrm{Na}^{+}$which is mediated by $\mathrm{Na}^{+} /$phosphate cotransporter NaPi-IIb/S/c34a2 and passively via a paracellular pathway which has not yet been clearly defined. Using intestinalspecific Slc34a2-deficient and wild-type mice, I.P. injections of $1,25(\mathrm{OH})_{2}$ vitamin $\mathrm{D}_{3}$ (vitamin $\mathrm{D}$ ) were administered once daily for two days followed by measurements of active transcellular transport as well as passive paracellular transport of phosphate in the jejunum and ileum using ligated loops and Ussing chambers. The results from the Ussing chamber experiments showed that in wild type mice, the ileum has the greatest phosphate active transport activity, but was not regulated by vitamin $D$, whereas in the jejunum vitamin $D$ treatment greatly increased active phosphate uptake. However, in the S/c34a2-deficient mice, comparatively low levels of active transport were not affected by vitamin D treatment. Paracellular permeabilities of phosphate were investigated by measuring the potential difference in response to the dilution of phosphate on either the apical and basolateral side of the epithelial membrane and the authors found no effect of genotype or treatment. To corroborate the effect of vitamin $D$ on active phosphate transport, in wild type mice, $\mathrm{NaPi}$-IIb protein expression was also found to be increased after treatment with vitamin D. In both genotypes, vitamin D treatment caused increased plasma FGF23 and decreased PTH levels which was associated with increased urine phosphate and decreased mRNA and protein levels of the transporters responsible for phosphate reuptake in the kidney ( $\mathrm{NaPi}$-lla and $\mathrm{NaPi}-\mathrm{Ilc}$ ). The results of this study demonstrate that $1,25(\mathrm{OH})_{2}$ vitamin $\mathrm{D}_{3}$ treatment specifically stimulates active intestinal uptake of phosphate, which depends on intestinal expression of $\mathrm{NaPi}-\mathrm{Ilb}$. Furthermore, in patients deficient in active uptake of phosphate, prolonged $1,25(\mathrm{OH})_{2}$ vitamin $\mathrm{D}_{3}$ treatment may lead to phosphate imbalance, due to high expression of FGF23 and its effect on the kidneys.

\section{Maternal but not fetoplacental health can be improved by metformin in a murine diet-induced model of maternal obesity and glucose intolerance}

Hufnagel A et al. (Sep 2021)
https://doi.org/10.1113/JP281902

Maternal obesity is a widespread problem associated with increased risk of short- and long-term complications affecting both mother and child, especially gestational diabetes mellitus (GDM). Metformin is a commonly used drug to improve glycemic control and reduce gestational weight gain in patients with GDM. However, while the beneficial effects of metformin on the mother are understood, there is a paucity of information regarding the fetal and placental effects. To investigate the effect of metformin on fetoplacental health, a diet-induced model of glucose intolerance and obesity was used. Female C57Bl6/J mice were fed either a control diet or a high sugar-high fat obesogenic diet. Obese mice (bodyweight > $35 \mathrm{~g}$ ) were separated into untreated or metformin-treated groups. Control-diet fed mice served as the control. Metformin treatment of pregnant dams resulted in a strong correlation of maternal serum, placental concentration, and fetal serum metformin. Transporters of metformin were also detected in the placenta and the fetal organs of pups from metformin treated dams. As expected, metformin treatment reduced fat mass and improved glucose tolerance and liver steatosis compared to untreated obese dams. Metformin improved uterine artery compliance (a measure of the ability of the artery to resist recoil toward its original dimensions) to levels similar to control dams. Metformin treatment was not able to rescue fetal weight or placental changes from the influence of maternal obesity and fetuses from obese dams were smaller compared to the control. Placental efficiency (fetal bodyweight to placental weight ratio) and labyrinthine area (nutrient exchange zone) were reduced in both treated and untreated obese dams compared to controls. These results show that while maternal health is improved by treatment with metformin, it did not improve fetal growth restriction or placental aging, despite the high uptake of metformin into fetal and placental circulation, highlighting the need for more investigation into the effects of metformin treatment on the fetus and the placenta.

\section{Dysbiosis of the gut microbiome impairs mouse skeletal muscle adaptation to exercise}

Valentino T et al. (Sep 2021)

https://doi.org/10.1113/JP281788

Recent evidence suggests that the gut microbiome is important in regulating skeletal muscle mass and function. This study set out to determine whether an intact gut microbiome is required for skeletal muscle adaptation in response to exercise. Female C57BI6/J mice were separated into progressive weighted wheel running (PoWeR) and controls, and within each group mouse were randomized to receive treatment with antibiotics or no treatment. The PoWeR exercise continued for 8 weeks and consisted of allowing mice to run freely on a wheel in their cage while increasing the resistance weekly by adding magnetic weights (maximum 6 added grams). As expected, antibiotic treatment reduced the microbiome diversity in both the PoWeR group and the control. Running distance between the treated and untreated groups was unchanged, and there was no difference with treatment or with time and increased resistance. PoWeR training resulted in heavier soleus muscle weight and larger cross-sectional area compared to the controls, which was likely due to an increase in type 1 muscle fibres. In both the soleus and plantaris, hypertrophy was blunted in the antibiotic treatment group. In the plantaris, antibiotic-induced dysbiosis resulted in a blunted shift of fast to slow muscle fibre types. Antibiotic treatment reduced the type $2 \mathrm{a}$ fibre and increased the type $2 \mathrm{~b} / \mathrm{x}$ fibre distribution compared to the untreated PoWeR training group. Importantly, antibiotic treatment did not result in systemic inflammation as serum inflammatory markers were not different among any of the groups. Antibiotic-induced dysbiosis resulted in impaired skeletal muscle adaptation, blunted muscle hypertrophy, and muscle fibre type shifts in mice undergoing similar training, which provides support for the necessity of an intact gut biome for skeletal muscle adaptation to exercise. 


\section{Diminishing returns}

\section{The rise of the rodent and the importance of larger animal species in biomedical research}

Professor Lucy $F$

Donaldson

University of Nottingham, UK Co-chair of The Society's In Vivo Task Force

\section{Professor Ramiro Alberio}

University of Nottingham, UK

$$
\text { Dr Jennifer Batson }
$$

Exonate Ltd, Cambridge, UK

\section{Dr Frances Henson}

University of Cambridge, UK

\section{Professor Roger Lemon}

University College London Institute of Neurology, UK

\section{Dr Anna Mitchell}

University of Oxford, UK

$$
\text { Dr } 70 \text { Murrell }
$$

University of Bristol, UK

\section{Dr Domingo Tortonese}

University of Bristol, UK

The Physiological Society was founded on 31 March 1876, largely in response to a Royal Commission and legislation on the use of animals in physiological research, which was driven by anti-vivisectionist protests and resulted in the Cruelty to Animals Act of 1876 (The Physiological Society, 2021). At that time, experimental physiology was a rapidly growing discipline following the appointments of new Chairs in Physiology at University College London, and the University of Cambridge. The regulation and legislation surrounding the use of animals in research has, since then, been a constant theme in the work of The Society.

Animals in research and The Physiological Society

In 2018, a Physiological Society meeting at the University of Exeter focused on Experimental Models in Physiology, in which our many participants presented and learned about different experimental models ranging from Antarctic fish to mathematical modelling in physiology (Menzies, 2018). Animal models, particularly but not exclusively mammalian models, have been fundamental to physiology for decades. This landscape is changing rapidly at the moment with a greater emphasis placed on the 3Rs than ever before (the principles of Reduction in animal numbers used in research, the Replacement of animals by other non-animal-based approaches, and the Refinement of existing approaches to minimise pain, distress and lasting harm to animals used in research) and greater importance of the use of species that are most amenable to genetic modification and rapid breeding to produce novel models, principally mice. Physiologists are now successfully using many different methods, models and animals to study function, as well as using non-animal-based methods in line with the 3Rs. Mammalian models remain necessarily important, however, due to the similarities in fundamental physiology between different animal species, and therefore the relevance to human physiology.

The use of animals in physiological and (bio)medical research

Although there has been legislation protecting animals in research since 1876, the Animals in Scientific Procedures Act (ASPA) 1986, revised and updated to conform with EU Directive 2010/63/EU in 2012, is the core legislation covering the use of animals in science in the UK today. ASPA regulates procedures carried out on protected animals (any living vertebrate, other than man, and any living cephalopod, including embryonic and foetal mammals, birds and reptiles in the last third of gestation or incubation period, larval forms of fish and amphibians that are capable of independent feeding, and cephalopods from the point of hatching). In the most recent UK statistics released by The Home Office (2019), 97\% of the 3.4 million procedures on animals involved only three categories of animals: rodents (mice and rats), birds and fish (Understanding Animal Research, 2021). By far the greatest number of procedures 
involved mice (2.51 million of the 3.4 million, 74\%). Procedures using large species (sheep, rabbits, guinea pigs) and species with special protections (dogs, cat, horses, and primates, which can only be authorised for use under specific circumstances and with oversight from the Home Office) comprised less than $3 \%$ of the total number recorded (Fig.1).

This balance in the use of different species was reflected in conversation at the Experimental Model meeting in 2018, where comment was made on the shift to the predominance of mice in biomedical research. This was felt to be a result of both the cost to funders for purchase and housing, as well as ease of genetic modification, making mice the preferred species for most researchers.

\section{Years of Animal Research in Great Britain}

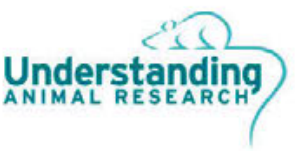

\section{Scientific testing on animals}

Organisations that carry out scientific, veterinary and medical research in Great Britain must record the number of procedures that are carried out on live animals each year to comply with the Animals (Scientific Procedures) Act 1986 . Animals can only be used in scientific research when there is no viable alternative available.
Types of animal research
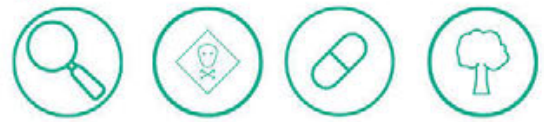

Fundamental Regulatory Translational Environmental

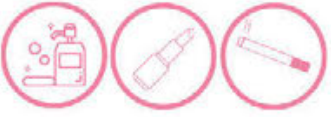

Animals are not used to test cosmetic, household or tobacco products

Procedures and their purpose

Experimental procedures Breeding and creation of genetically altered animals

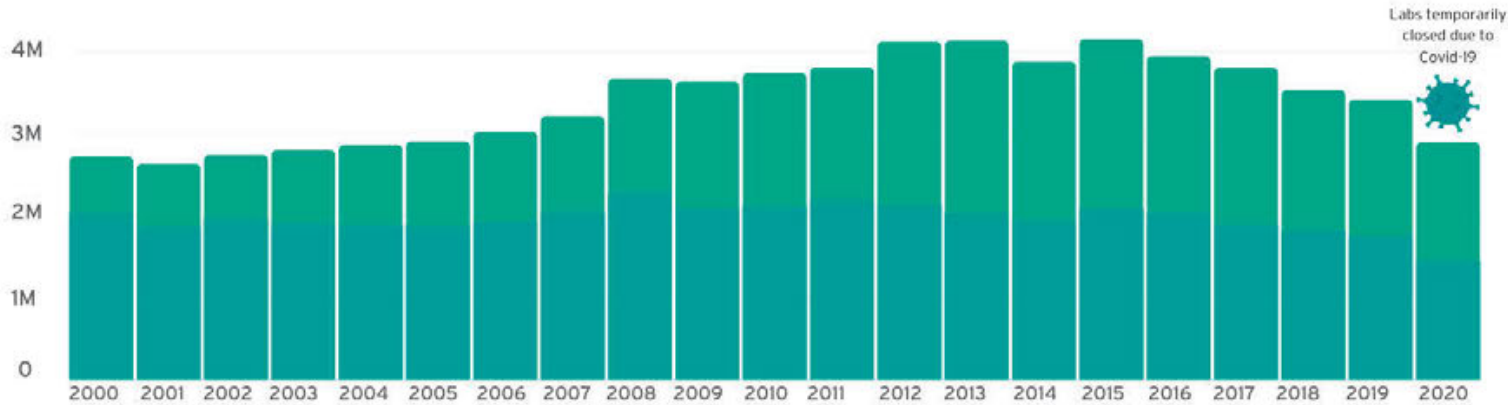

Procedures by animal species

Most commonly used animals

Mice Rats Fish Birds

Only used when no other species is suitable

Horses Dogs Monkeys Cats
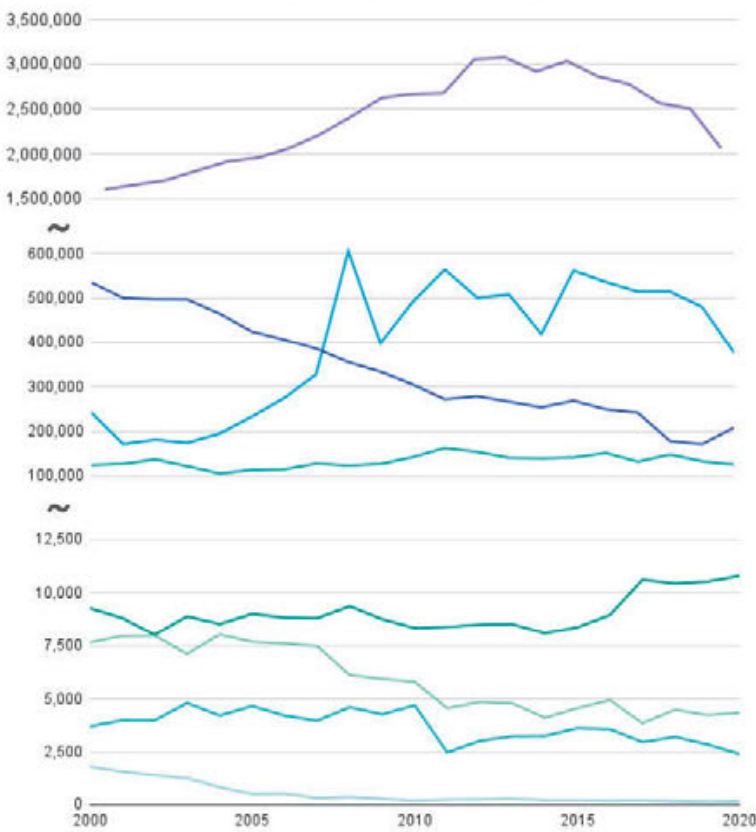

Procedures by severity

From 2014, procedures have been categorised by their retrospective severity. Procedures can be as mild as an injection or as severe as an organ transplant.

Sub-threshold Mild Moderate $\square$ Severe $\square$ Non-recovery Procedure examples

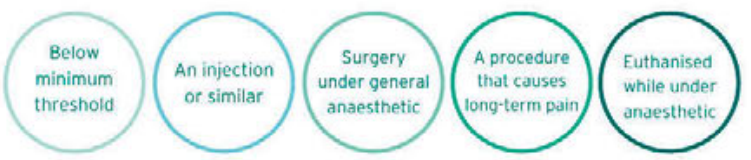

$4 \mathrm{M}$

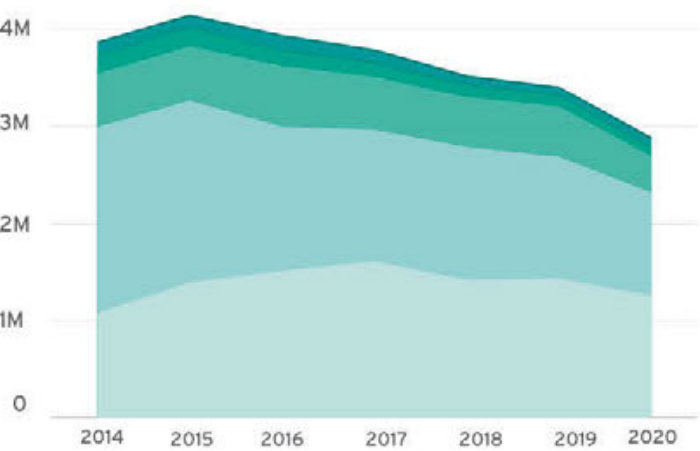

This data has been sourced from the UK Government Home Office annual report 'Statistics of scientific procedures on living animals, Great Britain' for the years $2000-2020$.

Figure 1. Procedures by animal species. To comply with the Animals (Scientific Procedures) Act 1986, organisations in Great Britain who carry out scientific, veterinary and medical research must record the number of procedures carried out on live animals. These data are from the UK Government Home Office annual report for the years 2000-2020. [๔ 2021 Understanding Animal Research]. 
But surely, if we use animals in research with the aim of achieving progress in both understanding and in translation of findings to humans and animals, we should always endeavour to use the most appropriate species and experimental model and try to resist pressure to reduce cost as a priority, or to always rely on the outcomes of a genetic manipulation as the strongest evidence for a physiological role.

There are notable examples of significant differences in mammalian physiology that make some animals unsuitable for some areas of study. The normal mouse heart rate ranges from 500 to 700 beats per minute (bpm) in contrast to the human rate of $60-100 \mathrm{bpm}$, with cardiac action potentials in the mouse being $10 \%$ of the length of the human, and lacking the calcium plateau that is present in the human. This means that mouse heart and cardiac myocytes are unsuitable for the study of cardiac rhythm or arrythmias. As the cardiac action potential in the rabbit is similar to the human, the rabbit heart is more frequently used in the study of cardiac ion channels, and for example, the effect of drugs on these channels as part of safety testing (Ellerman et al., 2021; Fig.2). This is one example of where a larger animal species is necessary to provide findings directly translatable to humans. There still are strong justifiable needs for the use of larger animals such as pigs, rabbits, sheep, dogs, cats and non-human primates across wider areas of physiological research.

\section{Animal research for animal health and welfare}

The need to do research for animals, on animals, for the purposes of improved animal welfare and increased understanding is often overlooked, although this is covered by ASPA. This is not limited to pet and companion animal species of course, but also extends to species used in both agriculture and sport. Endocrine physiology and reproductive seasonality has huge impact on both agricultural breeding and farm animal welfare, and on, maybe surprisingly to PN readers, such issues as jet lag in racehorses.

Both sheep and horses are seasonal breeders displaying strong circannual cycles in their physiology - that is they come into breeding season once per year. Sheep and horses reproduce at opposite times of the year

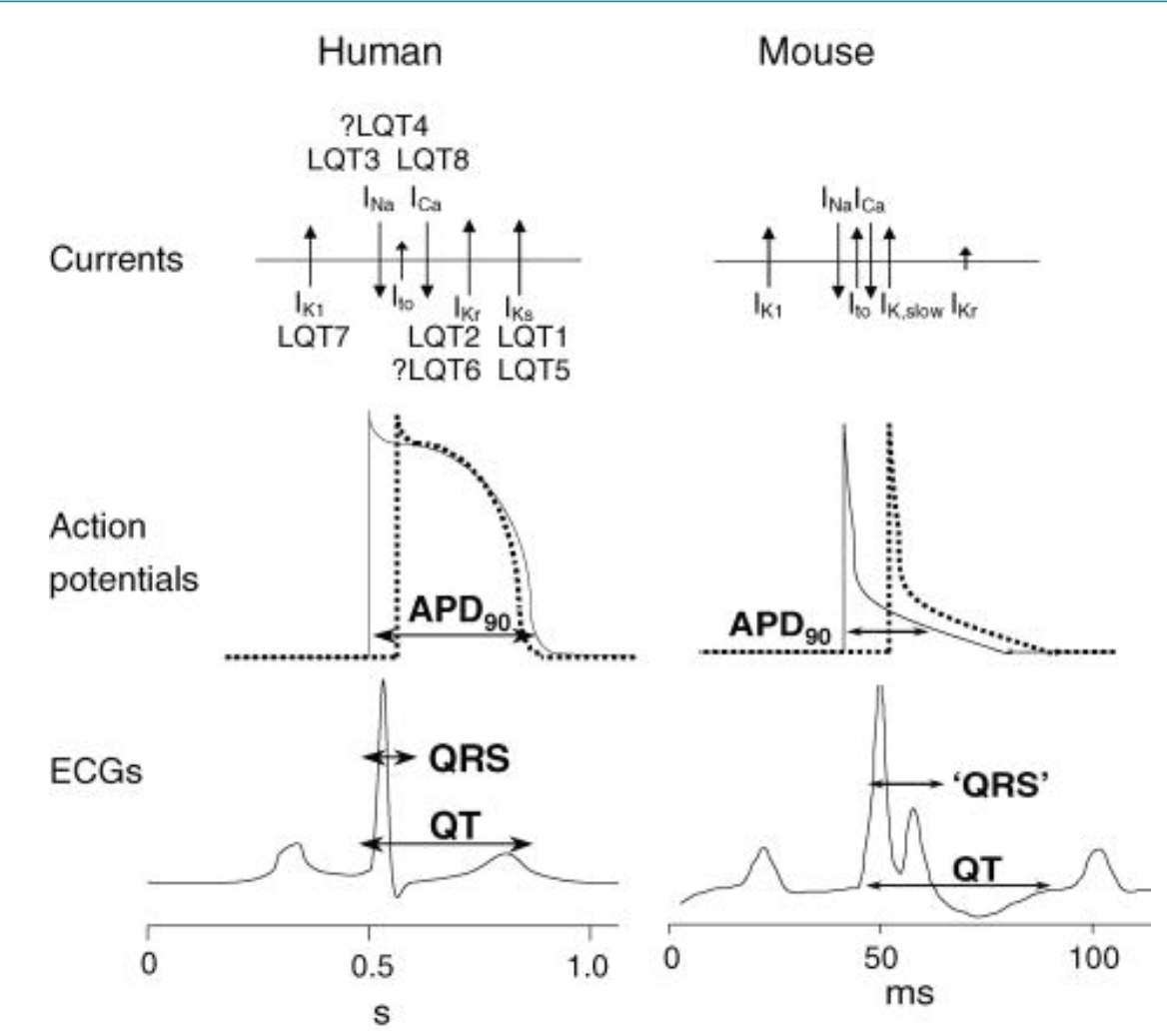

Figure 2. Cardiac ionic currents, action potentials and ECGs in humans versus mice. Major depolarising and repolarising currents are shown for the human and mouse heart. The size of the arrow for each current is roughly proportional to its magnitude, and arrows for outward currents point upward. Long QT loci (LQT1-LQT8) are listed near the current responsible for the phenotype. For each heartbeat, action potentials of the first cells to depolarise are depicted as continuous lines and action potentials of the last cells to depolarise are depicted as dotted lines. APD90 is the time until $90 \%$ repolarisation of the action potential. The ECG of the mouse is the signal average of five consecutive beats, and the ECG of the human is a simulation. Note that the apparent QRS duration (QRS) in the mouse corresponds to both depolarisation and early repolarisation. [ $\odot 2007$ The Journal of Physiology. Salama and London, 2009. doi.org/10.1113/jphysiol.2006.118745].

and so investigations on the mechanisms regulating the seasonal physiology in both species can unravel the similarities and differences in their physiology that underlie the successful adaptation to the same changes in the environment. Understanding the control of fertility in sheep and horses can have positive effects on both the animals and on farming, for example, farmers can better understand how to induce sheep fertility at a different time of the year, to delay lambing until the worst of the late winter/early spring weather is over. This can improve the welfare of both sheep and lambs particularly in areas where sheep are not housed indoors during lambing.

Some investigations are possible in these large animals that would certainly not be feasible in rodents let alone zebrafish or fruit flies. Circannual cycles can be readily studied in animals that display endogenous rhythms of hormonal output that are synchronised by external environmental cues. Withdrawal of serial blood samples for the measurements of hypothalamic, pituitary and/or gonadal hormones (Gómez-Brunet et al., 2008) causes less detrimental effect on larger animal well-being than in rodents due to their greater blood volume and therefore the much smaller impact of removing a series of samples from an individual animal and is very difficult in zebrafish due to tiny blood volumes. The feasibility of performing neurosurgery in sheep with a large brain without complications (Lincoln and Tortonese, 1995) or conducting athletic performance tests in horses (Tortonese et al., 2011; Tortonese and Short, 2012) is similar to that in humans, and is much greater in these species than in rodents. These sorts of studies can be used to test hypotheses directly in the species in which the information is to be applied and can produce highly translational and repeatable information.

This argument for the use of larger animals in research also extends to investigation of disease mechanisms and treatments in animals as well as humans, in addition to being important for physiological understanding, enhanced animal welfare and sustainable agricultural production.

Osteoarthritis is probably the most common joint disorder affecting humans in the world. It can affect many species other than humans, including dogs, chickens and guinea pigs. Larger animals are thus particularly relevant to osteoarthritis research. While mice and rats can provide information on mechanistic events in articular joints, there are fundamental differences in locomotion, weight bearing, joint structure and physiology between rodents and humans that often make rodents unsuitable for the full evaluation of new therapies. For example, mice have open growth plates (Mangiavini et al., 2017), unlike larger animals and humans, that may contribute stem/progenitor cells to the joint region, thereby distorting the intrinsic healing 
response. Mice usually represent a very inbred population, whereas sheep, for example, are an outbred population, more closely resembling the genetic diversity of humans (Brekke et al., 2018).

Naturally occurring osteoarthritis (OA) is very common in dogs and causes severe pain and disability. However, very little is known about underlying pain mechanisms in dogs suffering from $\mathrm{OA}$, for example, whether the mechanisms of the disease in dogs are similar or different to those in humans. Since so little is understood about this, the development of treatments for OA in dogs is limited. Much of the current osteoarthritis research is conducted using induced models in rats, mice and rabbits, but these may not relate well to spontaneous $\mathrm{OA}$ in dogs and indeed humans. Study of mechanisms of OA pain in dogs would not only be of tremendous benefit to the welfare of dogs suffering from this condition, it could also establish whether spontaneous $\mathrm{OA}$ in dogs is a valid translational model of OA in humans. This could result in the use of dogs as intermediaries between studies in man and laboratory rodents and would be particularly useful when testing new analgesics or disease-modifying treatments. This could both help overcome the wellknown limitations of using induced models of $\mathrm{OA}$ in laboratory rodents, increase the development of potential treatments for the dogs themselves (Chakrabarti et al., 2020).

Even larger animals, particularly sheep but also goats and horses, are also used in translational orthopaedic and orthopaedic pain research. Sheep provide opportunities to study individual behaviours in their natural environment rather than in the laboratory, and to contribute sufficient experimental tissue to permit multiple investigations in a single animal, so using fewer animals in the study compared with mice, and consistent with the aims of the 3 Rs. Large animal joints are of a similar size, anatomy and physiology to the joint in human, as is the weight borne on the joints. Larger animals are thus important in the development of tissue engineering solutions to treat joint defects, for example, the implantation of biomaterials into cartilage defects and the administration of the quantities of therapeutic cells that could be used clinically. A recent systematic review of such studies in large animals supported the use of these models as effective translational models, particularly for such joint regeneration studies (Veronesi et al., 2020).

\section{Where size really makes a difference}

One example of where size can really matter is in the selection of appropriate models for ophthalmology, especially for drug discovery but also for study of physiological responses to retinal damage. Rodent models of eye disease are used and drugs - such as the highly effective wet age-related macular degeneration (WAMD) treatment

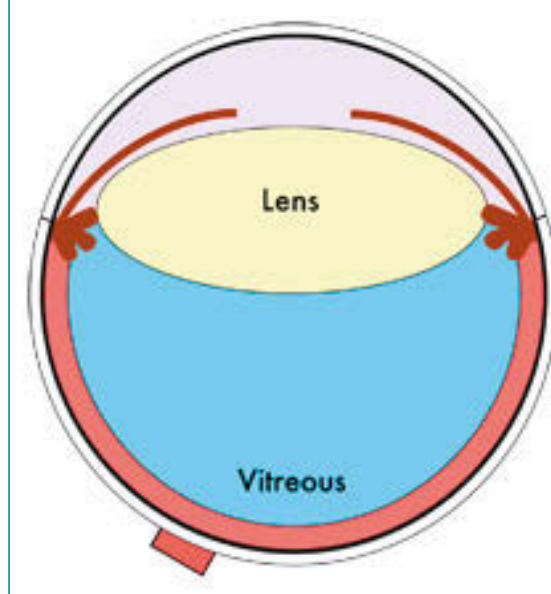

Human

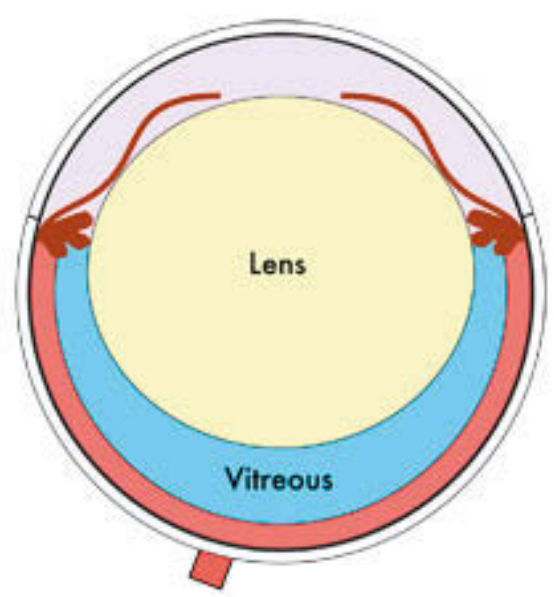

Mouse

Figure 3. Mouse eye diagram. Cross-sectional schematic of the human and mouse eye shows the relative smaller vitreous volume in the mouse eye due to its larger lens. [๑ 2011 JoVE. Skeie et al., 2011. doi.org/10.3791/2795].

Lucentis - have been tested in these models and successfully translated into the clinic, these models do not however completely recapitulate the causative processes of human eye conditions that result in blindness, such as WAMD and diabetic macular oedema (DME). Rodent eyes are obviously much smaller than human eyes, they have thinner cornea and sclera and much lower aqueous and vitreous volumes, plus a large lens occupying a relatively large amount of the intraocular space (Fig.3). Lower vitreous volume hinders the ability to sample vitreous humour to check for example for drug location and/ or concentration. Despite these limitations, the use of rodent models of retinal disease in showing new drug efficacy is predictive of translation into humans. Study of animals with larger eyes that more closely mimic human ocular physiology is however essential to ensure that sufficient drug reaches the appropriate target, for example the retina, before progressing to clinical trials, which is necessary for pharmacokinetic study.

In line with the 3 Rs, replacement models, such as pig eyes ex vivo, can be used to screen for drug penetration through the wall of the eye, for example if developing eye drops for the treatment of retinal disease. Results from such ex vivo models closely correlate with drug penetration into eyes in vivo and are being used to screen novel drugs for appropriate penetration through the eye, before experiments in vivo. Pharmacokinetic studies are therefore usually done after such ex vivo screening in larger eyes, such as rabbit, in vivo. Rabbit eyes, like rodents, do exhibit significant differences to human eyes, for example rabbits have Harderian glands (found in animals with a nictitating membrane), no macula and differences in retinal architecture, and these differences in structure present some problems for translation. Current best, and required, practice is therefore to confirm the efficacy seen in rodent models and the pharmacokinetic data in rabbits, in non-human primates, prior to phase 1 clinical trial. The non-human primate (NHP) eye has the closest anatomy and retinal vascular system to the human eye and is the only large eye model with a macula, which is the region of the eye affected in WAMD and DME. Models of retinal damage in non-human primates have high predictive translational value. Non-human primate studies obviously require very careful justification, and in-depth, ethical consideration by both NC3Rs and the Animals in Science committee, and the use of highly specialised facilities with highly trained personnel. As a result, such studies are reserved only for final drug molecule efficacy testing prior to clinical trials in ophthalmology.

\section{Genetic modification - not only knockout mice}

It has been argued that, because mice can be easily genetically modified, these are the most useful experimental species for this reason alone. There are many researchers for whom the gold standard for demonstration of the importance of a specific gene product in a physiological process is the effect of the complete absence, "knock-out" of that product. The problems of compensation, embryonic lethality and redundancy have been overcome in many cases by the advances in technology allowing selective inducible, tissue and cell-specific knockouts to become more available. There is still a problem of the time and cost to produce the necessary lines when two, three or more genetic alterations are required in a single animal, but this change in approach has led to some very elegant and informative, albeit expensive and involved, experiments, and the application of CRISPR/ Cas9 gene-editing technology will continue to revolutionise these approaches. 
It has been possible to apply genetic modification techniques to other, larger species since the 1980s, for example the production of genetically modified goats resulting in the production of therapeutic proteins in milk (Menchaca et al., 2016). CeLab (Centre for Large Animal Biotechnology) at the University of Nottingham is a unique UK resource dedicated to research in large animal biotechnology. CeLab conducts research on enhancing the productivity and welfare of farm animals but also has an emphasis on developing models of human development and disease.

Pigs have been widely used as models of development and disease due to the anatomical, physiological and molecular similarities with humans but also have potential for the study of disease mechanisms (Yao et al., 2016). Traditionally, pigs have been a preferred model over rodents for cardiovascular diseases, and cystic fibrosis, and also for some neurodegenerative disorders such as Alzheimer's disease, and Parkinson's disease. In recent years there has been renewed interest in using pigs in research due to the development of novel gene-editing technologies such as CRISPR/Cas9 (Alberio and Wolf, 2021), that have greatly enhanced the efficacy of genetic modification using gene targeting. In addition to these technical advances, there is also a better appreciation of the developmental similarities between pigs and humans and the significant advantage of studying pig embryos for understanding human development and organogenesis. Research in pigs also has the added advantage that they represent a species of choice when thinking of using animal organs for transplantation, and recent reports have demonstrated the prospect of creating humanised pig organs (Sykes \& Sachs 2019). Indeed, human organs in pig interspecies chimeras are closer than ever before, and potentially offer a new source of organs for xenotransplantation. Thus, pigs continue to represent a sustainable and ethically acceptable model organism of considerable significance in biomedical research.

The most in-depth debate and consideration of the use of larger animals and the ethics surrounding this usually centres on the use of the species with special protections - cats, dogs, horses and NHPs. In the most recent Home Office figures (2019), procedures on protected species constituted $0.5 \%$, NHPs representing $0.08 \%$ of the total. NHP research is probably the most strictly regulated in the UK. Home Office licences that authorise NHP research are only granted after extensive scrutiny, and rigorous application of the $3 R s$ is crucial. Researchers must adapt their experimental approaches to ensure that results can be statistically reliable and reproducible with the minimum number of animals used. Strong pressure exists to reduce primate numbers: current projects usually involve $~ 2-4$ NHPs. Using highly refined research methods, with ongoing developments pioneered in specialist UK NHP centres, even such low numbers can produce important and meaningful results. In addition, global initiatives are being developed (Mitchell et al., 2021) that are facilitating the collective sharing of retrospective NHP neuroscience data to address research questions that require larger sample sizes. However, establishing international collaborations in NHP research are difficult as acceptable common international standards for NHP welfare, ethics and regulation are currently absent.

Approximately 300 NHPs, mostly macaques and marmosets, are purpose-bred in the UK for basic and translational research in two main areas: neuroscience and infectious diseases. Notably, the use of the great apes (chimpanzees, orangutans and gorillas) in research has been banned in the UK since 1986. The genetic, anatomical, physiological, and behavioural similarities of NHPs to humans makes them the best available animal model for such neuroscience research Major differences between NHPs and other animals, especially rodent brain organisation, mean that the more advanced and cognitive

\section{References}

Alberio R and Wolf E (2021). 25th anniversary of cloning by somatic-cell nuclear transfer: Nuclear transfer and the development of genetically modified/gene edited livestock. Reproduction 162(1), F59-F68. https:// doi.org/10.1530/REP-21-0078

Brekke TD et al., (2018). Inbred or outbred? Genetic diversity in laboratory rodent colonies. G3 8(2), 679 686. https://doi.org/10.1534/g3.117.300495

Chakrabarti A et al., (2020). Peripheral mechanisms of arthritic pain: A proposal to leverage large animals for in

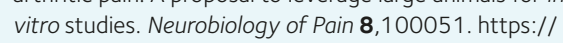
doi.org/10.1016/j.ynpai.2020.100051

Ellerman et al., (2021). Role of the rabbit whole-heart model for electrophysiologic safety pharmacology of non-cardiovascular drugs. Europace 23(6), 828-836. https://doi.org/10.1093/europace/euaa288

Gómez-Brunet A et al., (2008). Endogenous circannual cycles of ovarian activity and changes in prolactin and melatonin secretion in wild and domestic female sheep maintained under a long day photoperiod. Biology of Reproduction 78, 552-562. https://doi.org/10.1095/ biolreprod.107.064394

Lincoln GA and Tortonese DJ (1995). Does melatonin act on dopaminergic pathways in the mediobasal hypothalamus to mediate effects of photoperiod on prolactin secretion in the ram? Neuroendocrinology 62 425-433. https://doi.org/10.1159/000127032

Mangiavini L et al., (2017). Analysis of mouse growth plate development. Current Protocols in Mouse Biology 6, 67-130. https://doi. org/10.1002/9780470942390.mo150094

Menchaca A et al., (2016). New insights and current tools for genetically engineered (GE) sheep and goats. Theriogenology $\mathbf{8 6}(1)$, 160-9. https://doi. org/10.1016/j.theriogenology.2016.04.028 functions and behaviours can only be studied in NHP models. Primates are also crucial for validation of non-invasive methods used in human neuroscience. NHP research is having a major impact on understanding normal brain function and treatment of human brain disorders, such as Parkinson's disease, stroke and motor neurone disease, and neuropsychiatric disorders such as anxiety syndromes and obsessive-compulsive disorder.

We, like many of the attendees at The Society's Experimental Models meeting in 2019, feel there is still a justifiable need for the use of larger animals in research - not for all experimental work obviously, but where the most appropriate model is needed to generate the required reliable and meaningful results. In this world, the use of large animals in research is, when justified to meet specific aims, a necessity, if we wish to carry on generating the appropriate invaluable knowledge in physiology and medicine needed to address the problems we face in respect to both human and animal health and well-being, the use of large animals in research is, when justified and necessity.

Menzies R (2018). Experimental Models meeting: giving your research a fresh perspective. Physiology News 112: 20. Available at: physoc.org/magazine-articles/ experimental-models-meeting-giving-your-researcha-fresh-perspective/

Mitchell AS et al., (2021). International primate neuroscience research regulation, public engagement and transparency opportunities. Neuroimage 229, 117700 https://doi.org/10.1016/j.neuroimage.2020.117700

The Physiological Society (2021). Society timeline. Available at: physoc.org/about-us/history-archives/ society-timeline/

Sykes M, Sachs DH (2019). Transplanting organs from pigs to humans. Science Immunology 4(41), eaau6298. https://doi.org/10.1126/sciimmunol.aau6298

Tortonese DJ et al., (2011). Experimental jetlag disrupts circadian clock genes but improves performance in racehorses after light-dependent rapid resetting of neuroendocrine systems and the rest-activity cycle. Journal of Neuroendocrinology 23(12), 1263-1272. https://doi.org/10.1111/j.1365-2826.2011.02222.x

Tortonese DJ, Short RV. (2012). Biological rhythms, jetlag and performance in Thoroughbred racehorses. Equine Veterinary Journal 44(4), 377-378. https://doi. org/10.1111/j.2042-3306.2012.00589.x

Understanding Animal Research (2021). Numbers of animals. Available at: understandinganimalresearch.org. uk/animals/numbers-animals/

Veronesi F et al., (2020). Meniscectomy-induced osteoarthritis in the sheep model for the investigation of therapeutic strategies: a systematic review. International Orthopaedics 44, 779-793. https://doi. org/10.1007/s00264-020-04493-1

Yao J et al., (2016). Genome editing revolutionize the creation of genetically modified pigs for modeling human diseases. Human Genetics 135, 1093-105. https://doi.org/10.1007/s00439-016-1710- 6 


\section{The highs of endocannabinoid physiology}

\section{Currently licenced cannabinoids and targeting of the endocannabinoid system}

\section{Dr Aoife $M$ Thornton \\ Institute of Neuroscience, Trinity \\ College Dublin, Ireland}

\section{Dr Michelle Roche}

National University of Ireland Galway, Ireland

The marijuana plant, Cannabis sativa, has been used for medicinal, recreational, and religious purposes for millennia. The Irish-born physician Sir William O'Shaughnessy is credited with introducing cannabis-based medicine to the western world in the 1800s after noting significant medicinal effects of cannabis for conditions such as epilepsy and pain while working in India. Reports from the 1840s suggest that Queen Victoria used cannabis for the relief of menstrual pain and morning sickness. However, the medicinal use of cannabis declined in the 1900s due to the social and political concerns, emergence of legalisation prohibiting the recreational use of cannabis and the development of more selective therapeutics.

Interest in the medicinal effects of cannabis re-emerged when the primary psychoactive component of the cannabis plant, $\Delta^{9}-$ tetrahydrocannabinol (THC) was isolated in the early 1960s by Professor Raphael Mechoulam, now regarded as the godfather of modern-day cannabinoid research. Shortly afterwards, the non-psychoactive phytocannabinoid cannabidiol (CBD) was isolated. However, it was a further 30 years before the receptors that bind THC were identified in the early 1990s, namely cannabinoid (CB)1 receptor and CB2 receptor. While both receptors are located throughout the body, CB1 receptors are highly expressed in the central nervous system activation of which by $\mathrm{THC}$ is responsible for the psychoactive effects associated with cannabis. In comparison, CB2 receptors are highly expressed on cells and tissues of the immune system - activation of which elicit potent immunomodulatory effects.

Shortly after the discovery of the CB receptors, the endogenous ligands that bind to these receptors were identified and named the endocannabinoids - the best characterised of which are anandamide and 2-arachidonoylglycerol (2-AG). The endocannabinoids are synthesised on demand from membrane phospholipids by a range of enzymes, in response to activity dependent depolarisation and the subsequent increase in intracellular calcium levels (Fig.1). Following release, the endocannabinoids bind to the Gi/ o-coupled CB receptors, which are negatively coupled to adenylyl cyclase and positively coupled to mitogen-activated protein kinase, resulting in downstream changes in gene expression and cellular activity. In addition, endocannabinoids act as retrograde inhibitory neurotransmitters in the central nervous system, where binding to presynaptic CB1 receptors results in the inhibition of $\mathrm{N}$ - and $\mathrm{P} / \mathrm{Q}$-type voltage-gated calcium channels and the induction of inwardly rectifying potassium currents with the resultant inhibition of neurotransmitter release (Fig.1). In addition to CB1 and CB2 receptors, endocannabinoids also have an affinity for, and activity at, several non-cannabinoid receptors including transient receptor potential vanilloid 1 , the 


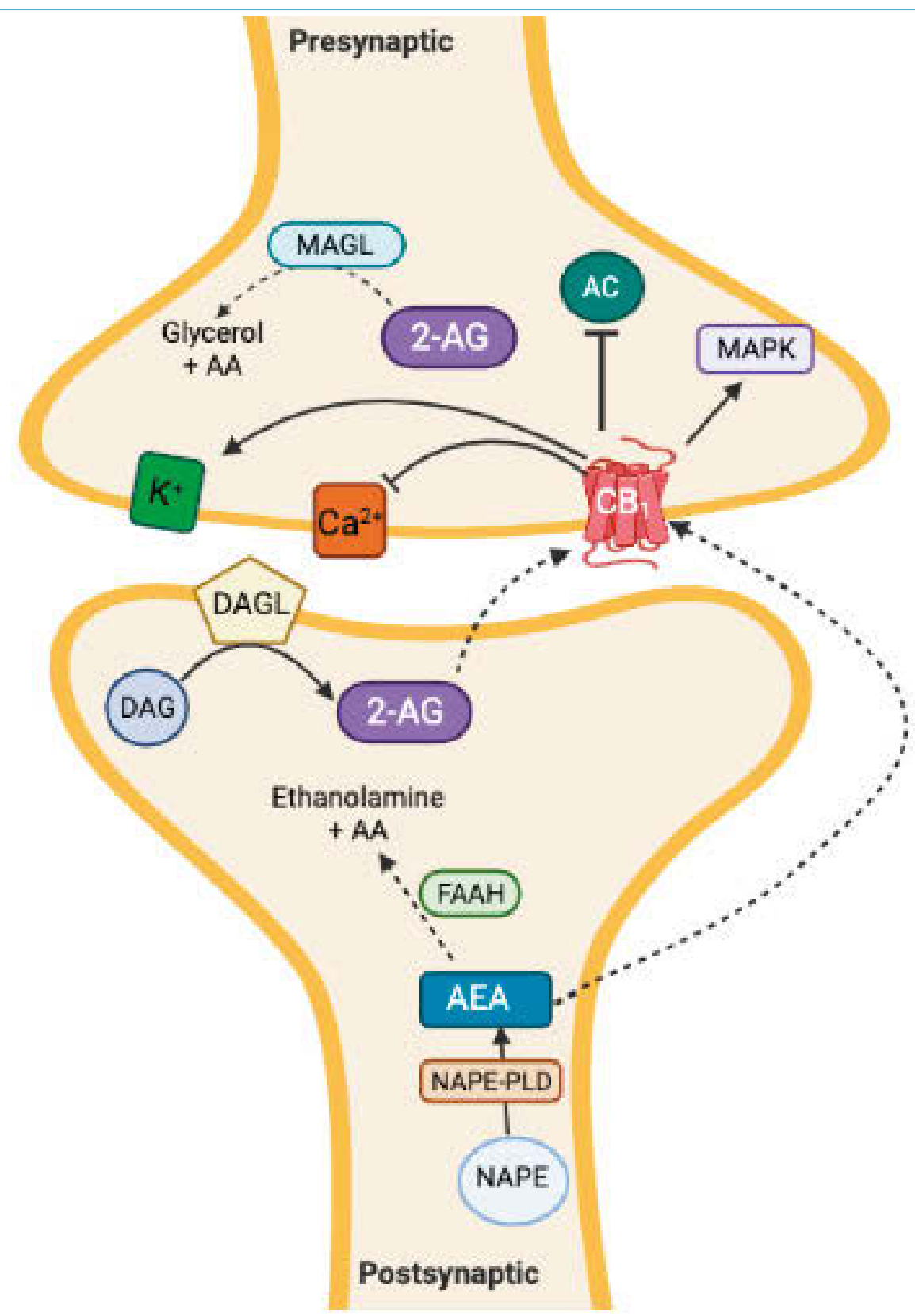

Figure 1. Diagram depicting the key components of the endocannabinoid in neurons. 2-AG: 2-arachidonyl glycerol; AA: arachidonic acid; AEA: anandamide; AC: adenyl cyclase; CB1: cannabinoid receptor 1; DAG: diacylglycerol; DAGL: diacylglycerol lipase; FAAH: fatty acid amide hydrolase; MAGL: monoacylglycerol lipase; MAPK: mitogenactivated protein kinase; NAPE-PLD: N-arachidonoyl phosphatidylethanolaminephospholipase D. (Created by the authors using BioRender). nuclear family of peroxisome proliferatoractivated receptors and a number of orphan G-protein coupled receptors, GPR55, GPR18 and GPR119. Catabolism of endocannabinoid mainly occurs via the enzymes fatty acid amide hydrolase (FAAH) for anandamide, and monoacylglycerol lipase (MAGL) for 2-AG.

The endocannabinoid system is responsible for mediating and modulating a wide array of physiological functions throughout the body, including emotion, pain, immune function, reproduction, cardiovascular activity, and gastrointestinal function (Fig.2). As such, it is not surprising that there has been an explosion of research over the past 20 years examining the effects of cannabis, phytocannabinoids (most notably THC and CBD), and endocannabinoid system modulators on various medical conditions including cancer, chronic pain, and obesity.

\section{Currently licenced cannabis-based} medicines, synthetic cannabinoids and clinical trials

Political, public and patient support has resulted in regulatory changes in several countries including the UK, US and several European countries, permitting the use of cannabis for specific medical conditions such as multiple sclerosis, retractable epilepsy and chronic pain. While these changes have benefited many patients, the content of phytocannabinoids in the cannabis plant can greatly differ between batches and strains. Furthermore, the cannabis plant also contains a large number of terpenes, flavonoids and other compounds, which, themselves, may be pharmacologically active. In comparison, cannabis-based medicines are registered medicinal cannabis extracts, with well-defined and standardised THC and/or CBD contents. Such medicines have been licenced for the treatment of spasticity associated with multiple sclerosis, epileptic seizures associated with Lennox-Gastaut syndrome or Dravet syndrome and chemotherapy-induced nausea and vomiting (see Table 1).

\begin{tabular}{|c|c|c|}
\hline Name & Active Ingredient & Indications \\
\hline Epidiolex ${ }^{\circledR}$ & CBD & $\begin{array}{l}\text { Treatment of seizures in } \\
\text { - Lennox-Gastaut syndrome } \\
\text { - Dravet syndrome } \\
\text { - Tuberous sclerosis complex }\end{array}$ \\
\hline Sativex ${ }^{\circledast}$ (Nabiximols) & CBD:THC (1:1 ratio) & - Spasticity in multiple sclerosis \\
\hline Cesamet $^{\circledR}$ and Camenes ${ }^{\circledR}$ (Nabilone) & Synthetic THC & - Nausea and vomiting associated with chemotherapy \\
\hline Marinol ${ }^{\circledR}$ and Syndros ${ }^{\circledR}$ (Dronabinol) & Synthetic THC & $\begin{array}{l}\text { - Weight loss in AIDS patients } \\
\text { - Nausea and vomiting associated with chemotherapy }\end{array}$ \\
\hline CannEpil ${ }^{\circledR}$ & CBD:THC (20:1 ratio) & - Severe, refractory epilepsy \\
\hline
\end{tabular}

Table 1. Currently licenced cannabis-based medicines in the EU and UK 


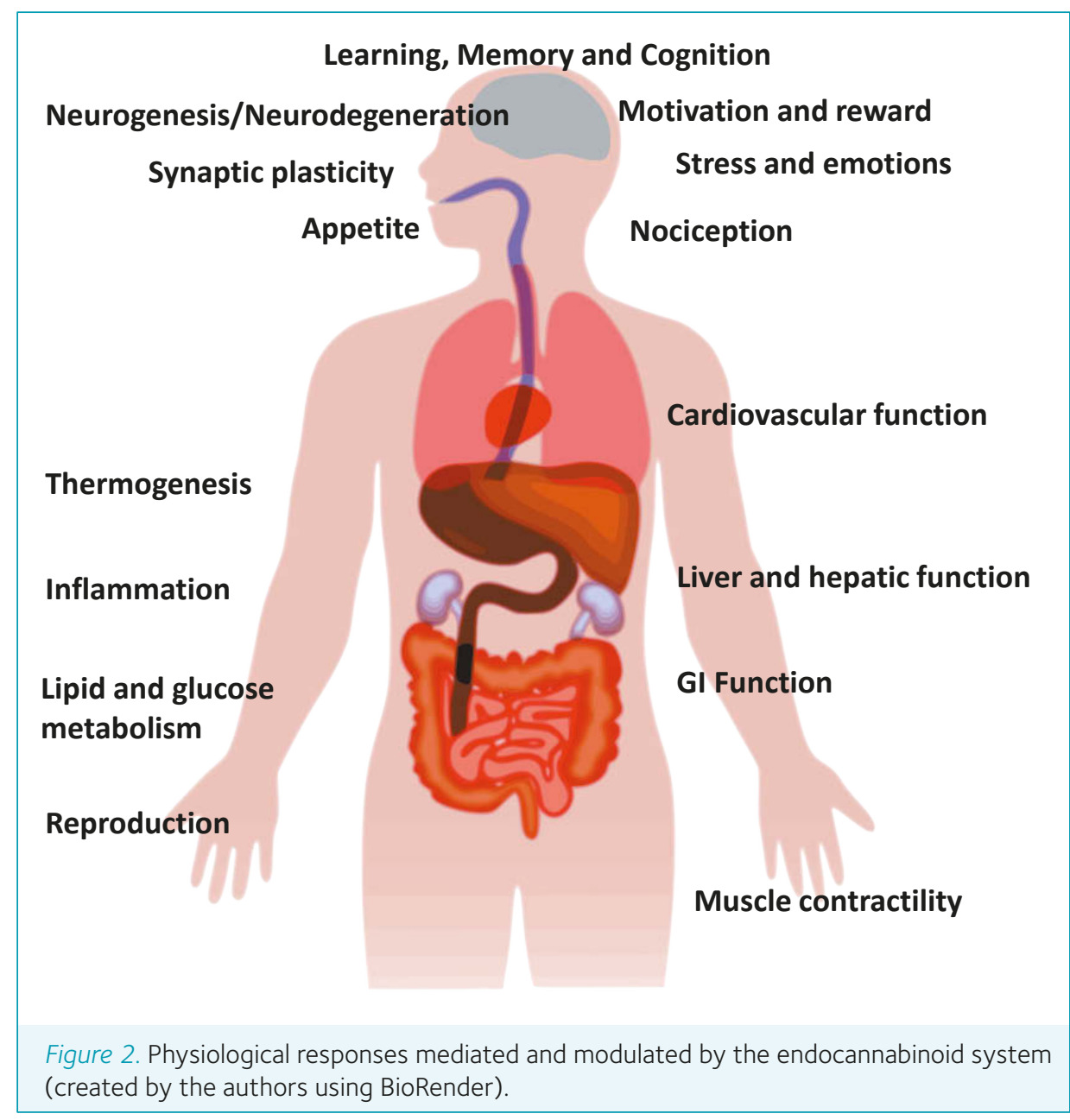

In addition to cannabis-based medicines, endocannabinoid system modulators have also shown therapeutic promise and a large number of clinical trials are currently underway into the effects in various medical conditions (Table 2). The CB1 antagonist/inverse agonist Rimonabant ${ }^{\circledR}$ was briefly licenced for the treatment of obesity in 2006 . Although a very developed psychiatric side effects, most notably depression, resulting in withdrawal of its licence. However, research on the anti-obesity effects of CB1 antagonists continues with current research focused on neutral and peripherally restricted CB1 antagonists, which are devoid of psychiatric side effects. Inhibiting the catabolic enzyme effective treatment, a number of patients
FAAH specifically increases AEA and related $\mathrm{N}$-acylethanolamine levels in areas involved in specific physiological responses. FAAH inhibitors have demonstrated therapeutic efficacy in several preclinical models, without inducing psychoactive effects associated with direct $\mathrm{CB} 1$ receptor activation. Furthermore clinical trials have shown that FAAH inhibitors are well tolerated and effective in the treatment of cannabis withdrawal and dependence, and pain in osteoarthritis. However, as with all pharmacological agents, selectivity is important and in 2016, a clinical trial of a FAAH inhibitor was terminated following the death of a male volunteer and the brain injury of four others. Subsequent investigations found that these adverse effects were not due to FAAH inhibition but rather due to off-target effects of this specific compound. Such effects have not been observed with subsequent selective FAAH inhibitors, and as such these compounds have the potential to provide novel therapeutic strategies for a number of disorders, with several clinical trials underway examining efficacy in treatment of post-traumatic stress disorder, Tourette syndrome and schizophrenia.

\section{Therapeutic potential of cannabinoids and endocannabinoid modulators}

It is not possible to provide a complete overview of all the physiological effects of the endocannabinoid system or pathophysiological conditions that may benefit from cannabis-based medicines or endocannabinoid system modulators (see recent review for overview (Lowe et al., 2021)). As such, we will provide a brief overview of some key recent research endeavours in the field relating to neuroscience and neurological conditions.

\begin{tabular}{|ll}
\hline Cannabinoid & Clinical Disorder \\
Cannabis & Sickle cell anaemia; Anxiety; Chronic pain \\
CBD:THC (1:1) & $\begin{array}{l}\text { Huntington's disease; Spasticity in MS; Attention deficit hyperactive disorder; Neuropathic } \\
\text { Different ratios including 1:1, 5:1, 20:1, 50:1 } \\
\text { pain; Autism spectrum disorder; Seizures in Dravet syndrome; Chemotherapy-induced } \\
\text { peripheral neuropathy; Tourette syndrome; Amyotrophic Lateral Sclerosis/Motor Neuron } \\
\text { Disease; Drug-resistant epilepsy; Fibromyalgia }\end{array}$ \\
THC & $\begin{array}{l}\text { Obsessive compulsive disorder; Neuropathic pain; Osteoarthritis; Fear extinction; Irritable } \\
\text { bowel syndrome; Anorexia nervosa; Oesophageal pain; Spasticity; Insomnia; Agitation in } \\
\text { Alzheimer's disease; Parkinson's disease; Tourette Syndrome }\end{array}$ \\
CBD & $\begin{array}{l}\text { Osteoarthritis; Post surgery pain; Chemotherapy-induced peripheral neuropathy; } \\
\text { Schizophrenia; Agitation in Alzheimer's disease }\end{array}$ \\
CBDV & Autism spectrum disorder; Prader-Willi syndrome \\
FAAH inhibitor & $\begin{array}{l}\text { Post-traumatic stress disorder; Cannabis dependence; Tourette syndrome; Osteoarthritis; } \\
\text { Schizophrenia }\end{array}$ \\
MAGL inhibitor & Tourette syndrome; Motor tic disorder; Pain; Dyspepsia \\
\hline
\end{tabular}

Table 2. Currently registered clinical trials with cannabis, cannabis-based medicines or endocannabinoid modulators (source ClinicalTrials.gov; September 2021) 


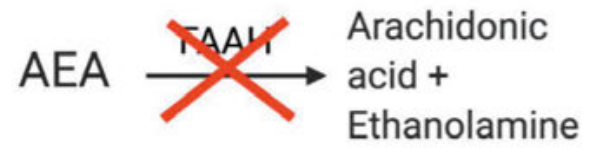

FAAH inhibition

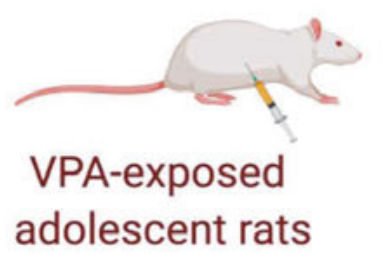

MGL inhibition

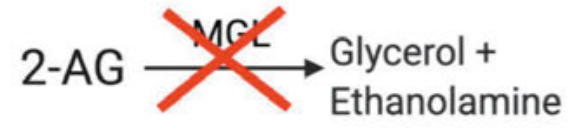

\section{오}

\section{$\Leftrightarrow$ thermal nociception}

anxiety-like behaviour

If stress coping behaviour

ษ social play ${ }^{12}$

$\Leftrightarrow$ social motivation ${ }^{27}$

$\Leftrightarrow$ repetitive-like behaviour ${ }^{27}$

$\Leftrightarrow$ thermal nociception

个 anxiety-like behaviour

个 stress coping behaviour (first 5 min)

? social motivation

? repetitive-like behaviour

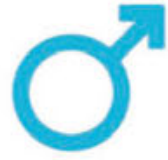

$\Leftrightarrow$ thermal nociception ${ }^{27}$

If anxiety-like behaviour ${ }^{12,15,20}$

个 stress coping behaviour ${ }^{20}$

厄 social play ${ }^{15}$

个 social motivation ${ }^{15,20,27}$

If repetitive-like behaviour ${ }^{15,20}$

? thermal nociception

? anxiety-like behaviour

? stress coping behaviour

个 social motivation ${ }^{42}$

If repetitive-like behaviour ${ }^{42}$

Figure 3. Schematic depicting the effects of FAAH and MGL inhibition on anxiety-like behaviour in VPA-exposed female and male rats. Bold highlights the data depicted in the current study. References provided for data cited in Thornton et al., 2021.

"Political, public and patient support has resulted in regulatory changes in several countries including the UK, US and several European countries, permitting the use of cannabis for specific medical conditions."

\section{Acute and chronic pain}

The analgesic effects of cannabis were some of the first recorded medicinal effects, and as such it is unsurprising that cannabis, cannabis-based medicines, and modulators of the endocannabinoid system have received considerable interest as treatments for pain (i.e. analgesics). This has been further fuelled by recent endeavours to identify non-opioid alternatives for pain management and the licencing of medical marijuana for the treatment of certain pain conditions in several countries including the UK and several EU countries. Components of the endocannabinoid system are located at all levels of the pain pathway from peripheral nociceptors, dorsal horn spinal cord neurons, and in specific brain regions involved in ascending and descending pain modulation. Cannabinoids and enhancing endocannabinoid tone have been shown to reduce nociceptive transmission at all of these levels. Furthermore, increasing evidence also indicates a key role for the endocannabinoid system in glial cells in modulating nociception. The high comorbidity of mood disorders and chronic pain is widely recognised, with up to $70 \%$ of chronic pain patients experiencing comorbid anxiety and/or depression, and increasing preclinical evidence from our group and others indicates that cannabinoids and endocannabinoid modulators may provide a novel therapeutic target for patients that may exhibit co-morbid depression and chronic pain (Fitzgibbon et al., 2015).
To distil the wealth of data, both clinical and preclinical, in various models and conditions, both the European Pain Federation (EFIC) and the International Association for the Study of Pain (IASP) established task forces on the use of cannabis, cannabinoids and cannabis-based medicines for pain management. Systematic reviews and meta-analysis indicate considerable support for cannabinoidinduced analgesia, in particular for treatment of neuropathic pain (Hauser et al., 2018; Soliman et al., 2021). EFIC recommend that "therapy with cannabis-based medicines should only be considered by experienced clinicians as part of a multidisciplinary treatment and preferably as adjunctive medication if guideline-recommended firstand second-line therapies have not provided sufficient efficacy or tolerability". However, it was acknowledged that translating the wealth of preclinical findings to the clinic remains challenging and currently "IASP does not currently endorse general use of cannabis and cannabinoids for pain relief but rather recognizes the pressing need for further studies to fill the research gap".

Neuroinflammatory and neurodegenerative disorders

Uncontrolled systemic and central immune responses have been proposed to underlie the pathophysiology and exacerbation of a host of neurological and psychiatric conditions. A wealth of evidence over the past two decades has demonstrated 
potent immunomodulatory effects of cannabis, cannabis-based medicines and endocannabinoid modulators, with effects dependent on the compound investigated, time of administration and condition under investigation. Glial activation and neuroinflammation is associated with increased expression of CB2 receptors. As such several research groups have examined the therapeutic potential of CB2 receptor agonists or enhancing endogenous endocannabinoid tone in various preclinical models, noting significant beneficial effects both on neuroinflammation and neuroprotection (Henry et al., 2016; Kelly et al., 2020). A number of clinical trials are ongoing examining the effects of cannabinoids in neurodegenerative disorders including Huntington's disease, Alzheimer's disease and Parkinson's disease (Table 2).

\section{Autism spectrum disorder symptoms}

Anecdotal evidence reporting autism spectrum disorder (ASD) symptom improvement following the intake of cannabis or medical marijuana has resulted in the establishment of numerous advocate groups. While the precise mechanism mediating the potential beneficial effects of cannabis or medical marijuana remain to be uncovered, alterations in CB2 receptor expression and circulating levels of the endocannabinoids have been reported in ASD individuals (Aran et al., 2019). The endocannabinoid system is well recognised to play a key role in mediating and modulating social responding, repetitive behaviour and emotion, alterations that represent core behavioural changes in ASD individuals. Data from our lab and others have demonstrated alterations in endocannabinoid system and beneficial effects of cannabinoids or enhancing endocannabinoid tone on core ASD behavioural alterations in environmental and genetic models of ASD (Fig. 3) (Zamberletti et al., 2017; Thornton et al., 2021). A number of recent clinical trials have demonstrated beneficial effects of phytocannabinoids for the treatment of specific ASD symptoms such as selfinjurious behaviour, hyperactivity, sleep problems and anxiety (Fusar-Poli et al., 2020; Silva et al., 2021), although there is wide recognition that randomised, double blind, placebo-controlled clinical trials are necessary to clarify and further support findings. Currently, there are four clinical trials registered examining the efficacy and safety of CBD, CBDV and CBD:THC (1:1 ratio) in $A S D$

\section{Future directions}

The endocannabinoid system is present in every cell of the body and thus modulates a wide array of physiological responses. New technological and methodological advances in the measurement of endocannabinoids, site- and circuit- specific genetic and pharmacological modulation

\section{References}

Aran A et al. (2019). Lower circulating endocannabinoid levels in children with autism spectrum disorder. Molecular Autism 10,2. https://dx.doi. org/10.1186/s13229-019-0256-6

Cannabis IPTFo, Cannabinoid A (2021). International Association for the Study of Pain Presidential Task Force on Cannabis and Cannabinoid Analgesia position statement. Pain 162,S1-S2. https://dx.doi. org/10.1097/j.pain.0000000000002265

Finn DP et al. (2021). Cannabinoids, the endocannabinoid system, and pain: a review of preclinical studies. Pain 162,S5-S25. https://dx.doi org/10.1097/j.pain.0000000000002268

Fitzgibbon M et al. (2015). High times for painful blues: the endocannabinoid system in paindepression comorbidity. International Journa of Neuropsychopharmacology 19,pyv095. https:// dx.doi.org/10.1093/ijnp/pyv095

Fusar-Poli L et al. (2020). Cannabinoids for people with ASD: A systematic review of published and ongoing studies. Brain Sciences 10(9), 572. https://dx.doi. org/10.3390/brainsci10090572

Henry RJ et al. (2016) For whom the endocannabinoid tolls: Modulation of innate immune function and implications for psychiatric disorders. Progress in Neuropsychopharmacology and Biological Psychiatry 64,167-180. https://dx.doi org/10.1016/j.pnpbp.2015.03.006

Karhson DS et al. (2018). Plasma anandamide concentrations are lower in children with autism spectrum disorder. Molecular Autism 9,18 https:// dx.doi.org/10.1186/s13229-018-0203-y

Kelly R et al. (2020). Microglial Phenotypes and Their Relationship to the Cannabinoid System: Therapeutic Implications for Parkinson's Disease. Molecules 25 https://dx.doi.org/10.3390/

and the development of more clinically relevant preclinical models, will enable a greater understanding of the role of the endocannabinoid system and its effects on physiological processes. The need for rigorous, balanced, and well-controlled clinical trials is imperative to determine if the wealth of preclinical data can be translated to the clinic and ultimately provide new therapeutics. Accordingly, at the time of writing this article there are over 450 registered clinical trials examining the efficacy and safety of cannabis, cannabis-based medicines or endocannabinoid modulators for various medical conditions. Harnessing the potential of the endocannabinoid system without inducing psychoactive or global immunosuppressive effects will be key to the success of these products. As such CBD, which has no affinity for the cannabinoid receptors, peripherally restricted $\mathrm{CB} 1$ receptors, and FAAH or MAGL inhibitors, which increase endocannabinoid tone, may be particularly beneficial. Future studies that take into account the stratification of patients, the inclusion rather than exclusion of patients with co-morbidities, and examination of effects of sex and age, will further enhance our understanding of the system and its potential as a therapeutic target. molecules 25030453

Kerr DM et al. (2016). Pharmacological inhibition of fatty acid amide hydrolase attenuates social behavioural deficits in male rats prenatally exposed to valproic acid. Pharmacological Research 113,228-235. https:// dx.doi.org/10.1016/j.phrs.2016.08.033

Lowe $\mathrm{H}$ et al. (2021). The endocannabinoid system: a potential target for the treatment of various diseases. International Journal of Molecular Sciences 22(17). https://dx.doi. org/10.3390/ijms22179472

Silva EAdSJ et al. (2021) Cannabis and cannabinoid use in autism spectrum disorder: a systematic review. Trends in Psychiatry and Psychotherapy https:// dx.doi.org/10.47626/2237-6089-2020-0149

Soliman N et al. (2021). Systematic review and metaanalysis of cannabis-based medicines, cannabinoids and endocannabinoid system modulators tested for antinociceptive effects in animal models of injuryrelated or pathological persistent pain. Pain https:// dx.doi.org/10.1097/j.pain.0000000000002269

Thornton AM et al. (2021). Increasing endocannabinoid tone alters anxiety-like and stress coping behaviour in female rats prenatally exposed to valproic acid. Molecules 26(12). https://dx.doi.org/10.3390/ molecules 26123720

Wang J (2019). Glial endocannabinoid system in pain modulation. International Journal of Neuroscience $\mathbf{1 2 9}$ 94-100. https://dx.doi.org/10.1080/00207454.20 18.1503178

Zamberletti E et al. (2017). The endocannabinoid system and autism spectrum disorders: insights from animal models. International Journal of Molecular Sciences 18 https://dx.doi.org/10.3390/ ijms18091916 


\title{
The role of exercise physiology in 2021
}

\author{
Applying seminal concepts to contemporary issues
}

\section{Dr Paul Ansdell}

Northumbria University, UK Early Career Theme Lead - Human, Environmental, and Exercise Physiology

The past 18 months have been unique for a multitude of reasons, and as I prepared for my PhD viva voce in Spring 2020 I found myself studying cardiopulmonary physiology during the COVID-19 pandemic. As an exercise physiologist by training, I began to consider how the stress imposed by exercise could provide information about this disease's acute mechanisms; which systems are involved/limited? How do they recover? We now know that long COVID, the persistent symptoms following acute infection, is an issue. So now questions exist such as what underpins these prolonged symptoms? If we know the mechanisms, can we improve recovery? Can exercise testing help answer these questions?

Fast forward 18 months to the Tokyo Olympic and Paralympic Games, and I watched the athletes compete, admiring the pinnacle of endurance physiology during events from 400 metres to the marathon and triathlon. I watched these athletes work to exhaustion, stressing physiological systems that they had strategically trained for the entirety of the previous Olympic cycle and beyond, in awe. Whilst the limiting factors to endurance performance are debated within the exercise science community, one key factor is thought to be the maximal rate of oxidative phosphorylation, the resynthesis of ATP with oxygen. Here, with elite athletes, performance is the other end of the spectrum to COVID-19 patients; however, the principles of exercise limitation and the methods used to assess them are, broadly speaking, the same. The Human, Environmental and Exercise Theme at The Physiological Society spans a broad range of topics within the Physiological Society, and in this Theme Lead Article, I aim to demonstrate its importance across the spectrum of health and disease, by highlighting recent research in the theme.
The role of oxygen in health and disease

A major part of my viva preparation involved revising oxygen transport and utilisation during exercise in the form of a paper by Professor Peter Wagner: "Determinants of Maximal Oxygen Transport and Utilisation" (Wagner, 1996). This paper reviews the journey of oxygen from the airways to the mitochondria and discusses how changes in this cascade can influence the maximal oxygen uptake $\left(\dot{\mathrm{V}}_{2 \max }\right)$ during exercise. Wagner categorised the oxygen cascade into convective factors, such as ventilation, cardiac output, and red blood cell flow, that permit oxygen transport to the working musculature; and diffusive factors that depend on factors such as capillarity and mitochondria density, which mediate the journey of oxygen across membranes in the lungs and skeletal muscle. He argued that there was no single limiting factor to $\dot{\mathrm{VO}}_{2 \max }$, that convective and diffusive factors work as part of an integrated system, and that any one component has the potential to alter $\dot{\mathrm{VO}}_{2 \max }$ (Wagner, 2000). Fig.1 demonstrates the structures involved in this system and their individual functions. 
Wagner (1996) also introduced a visual construct of this integrated system showing how both convective and diffusive processes can be modelled to predict $\dot{\mathrm{V}}_{2 \text { max }}$. Fig. 2 demonstrates this, whereby the straight line beginning at the origin represents the diffusive capacity of muscle, underpinned by Fick's law of diffusion, and the curved negatively sloped line represents oxygen transport through the microcirculation, underpinned by the Fick principle of mass conservation and physiological variables such as blood flow, arterial oxygen saturation, and haemoglobin mass. The point on the $y$-axis where these two lines intersect determines an individual's maximum oxygen uptake. As can be seen, the intersect depends on oxygen delivery (cardiac output $x$ arterial oxygen content) and diffusion of oxygen. In turn, arterial oxygen content depends on haemoglobin and arterial $\mathrm{O}_{2}$ saturation. Arterial $\mathrm{O}_{2}$ saturation reflects pulmonary gas exchange. Thus, the intersection point depends on lung function, cardiovascular function, the blood, and muscle diffusional transport in an integrated manner.

This conceptual model is universal in humans and has been used previously to describe how clinical conditions such as chronic obstructive pulmonary disease (COPD) impairs functional capacity, or how increasing altitude can reduce exercise capacity. In the following sections, I will highlight recent physiological research in the theme of Human, Environmental and Exercise Physiology on contemporary issues and topics, such as the Tokyo 2020 Olympic marathon and long COVID, relating back to the Wagner model to provide a conceptual physiological explanation of the findings.

\section{Marathon running and the Tokyo Olympics}

Through exercise training, one might improve the ability of the central systems to transport oxygen to the muscle (e.g. cardiac output), raising the curved line. Similarly, exercise training might improve an individual's capillary density within skeletal muscle, permitting an increased diffusive capacity, and increasing the slope of the straight line. In both circumstances, the net result is an increased $Y$ value for the intersection of the two lines: an increased $\mathrm{V}_{2 \max }$. As one would expect, elite marathon runners demonstrate the optimal physiology, and integrated oxygen transport system, for endurance exercise. Whereby both oxygen transport and utilisation are far superior to the average healthy human, permitting a greater $\mathrm{V}_{2 \max }$. Indeed, a recent study by Jones et al., (2021) investigated the physiological profiles of the 16 world-class athletes involved in the Nike "Breaking 2" project, which eventually led to the performance of a marathon in 1 hour 59 minutes and 40 seconds by Eliud Kipchoge.

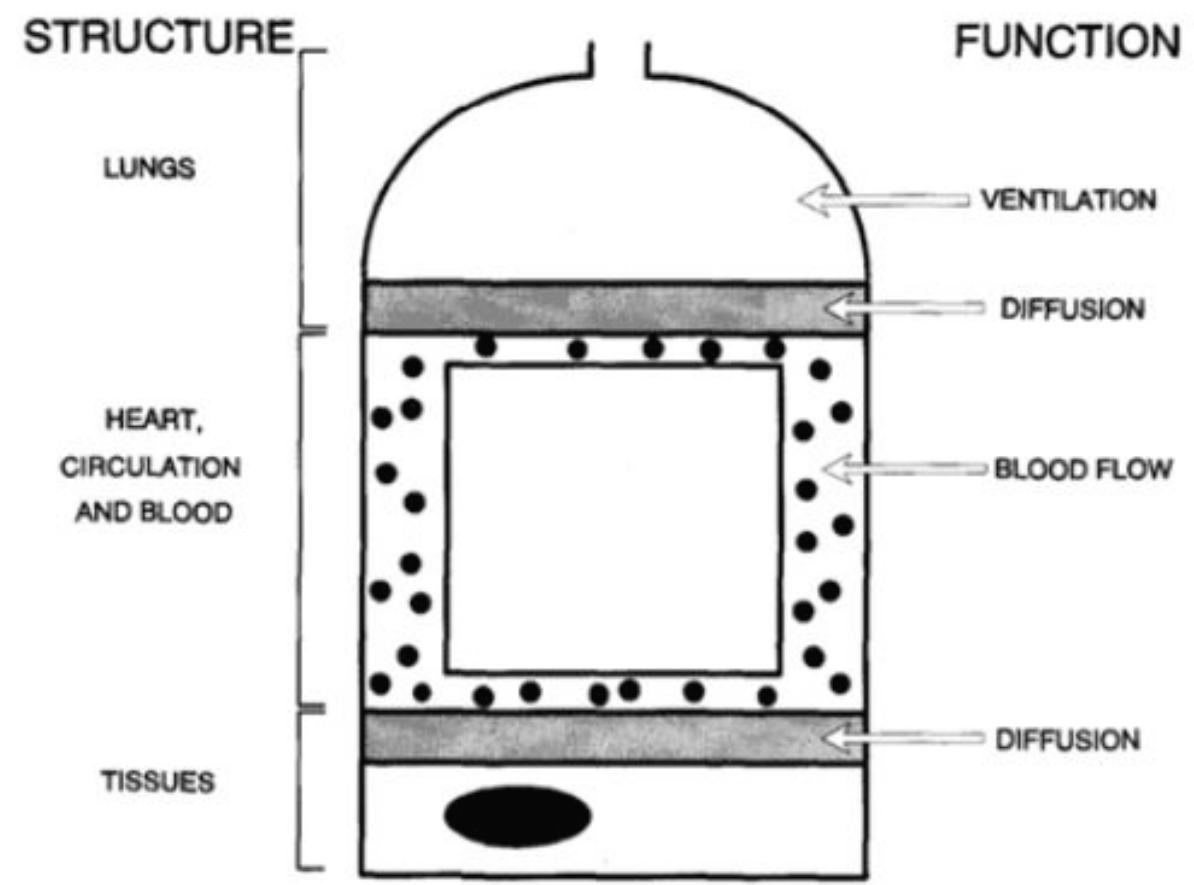

Figure 1. From Wagner (1996, Figure 2, p. 27). Simplified model of the $\mathrm{O}_{2}$ transport pathway, showing the principal structures and their associated functions. $\mathrm{O}_{2}$ transport requires the integrated interaction of the four principal functional components indicated, mixing convective and diffusive processes. Non-uniform distribution of ventilation, blood flow, and metabolic rate within the lungs or muscle tissues are neglected but will reduce transport if present.

\section{CONVECTION AND DIFFUSION IN $\mathrm{O}_{2}$ TRANSPORT}

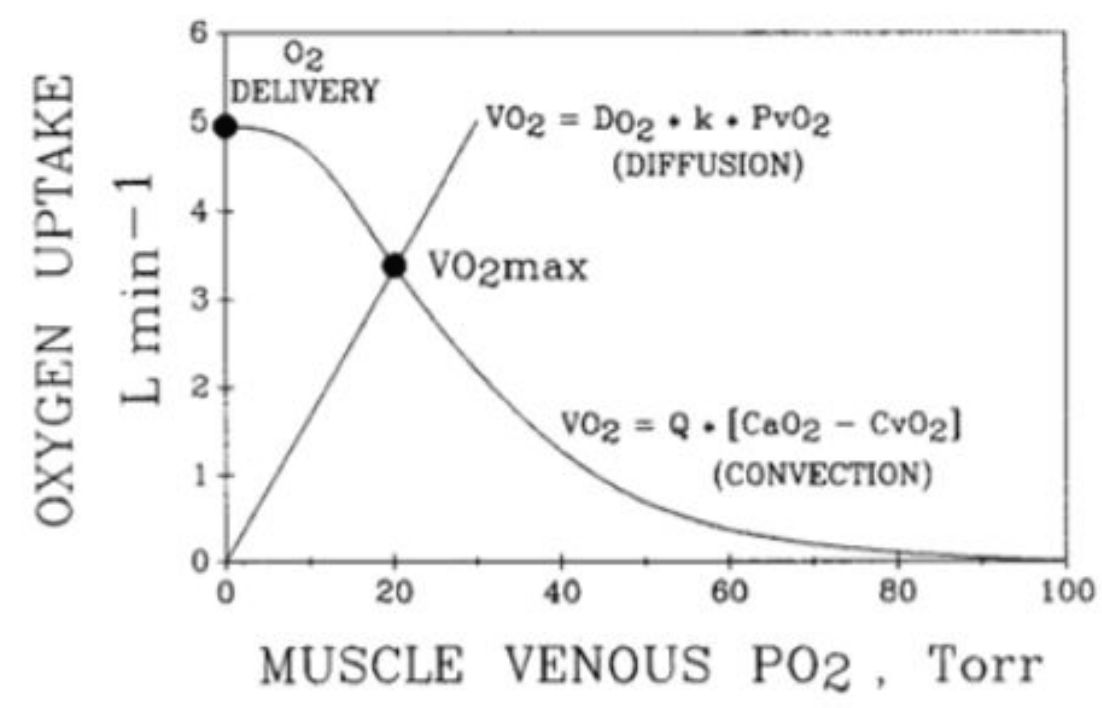

Figure 2. From Wagner (1996, Figure 6, p. 43). The conceptual model for the interaction between diffusive and convective capacities in determining $\dot{\mathrm{V}}_{2 \max }$. The curved, negatively sloped line represents transport of oxygen to working muscle, and the straight line represents the diffusive capacity of muscle. The $y$-axis value for the intersection of the two lines represents $\mathrm{V}_{2 \max }$. 
Jones et al., demonstrated a mean $\dot{\mathrm{VO}}_{2}$ peak of $71.0 \pm 5.7 \mathrm{~mL} / \mathrm{kg} / \mathrm{min}$, amongst some other impressive physiological variables, reinforcing the notion that the physiology of elite marathoners is very well suited to running 26.2 miles as fast as humanly possible. Fortunately for spectators, marathon running is determined by more than $\mathrm{VO}_{2 \max }$, however. The paper by Jones et al., helps to highlight the physiology required for such a remarkable feat.

The Women's Olympic marathon in 2021 took place on 7 August, starting at 6 a.m. local time, and while not unique to Sapporo, the environmental conditions during the race were not favourable for optimal performance. At the start of the race the temperature was $25^{\circ} \mathrm{C}$ and $82 \%$ relative humidity, with temperatures peaking at nearly $30^{\circ} \mathrm{C}$ by the end of the race. The acute effects of exercising in "humid heat" are well studied and relate to the negative consequences of dehydration and hyperthermia. Under such conditions, the physiological determinants of exercise performance can be affected. For example, $\dot{\mathrm{V}}_{2 \max }$ is reduced by up to 18\% in extreme temperatures (Arngímsson et al., 2004). This decline is primarily underpinned by a decrease in cardiac output due to decreased blood volume and the consequential negative effects on stroke volume. Additionally, the competition for blood flow between the skin for cooling and the exercising musculature further diverts oxygen from the working muscles in a hot, humid environment. When this is considered in the framework of the Wagner model, a decrease in cardiac output would manifest as a downward and leftward shift in the curved line that represent convection of oxygen to the working muscle. This therefore reduces the $y$-axis value of where the two lines intersect, and for the exercising athlete, a reduction in $\dot{\mathrm{V}}_{2 \max }$ (Fig.3). While reduced muscle blood flow has negative consequences for $\mathrm{O}_{2}$ delivery, it increases red blood cell time in transit through the muscle microcirculation. This provides more opportunity for extraction of oxygen into muscles, a slight buffer to the reduced delivery of oxygen, that could otherwise cause even more severe impairments. These alterations in the oxygen transport system mean it is perhaps no coincidence that the winner of the Women's Tokyo Olympic marathon finished in a time of 2 hours 27 minutes and 20 seconds - nearly $10 \%$ slower than the current world record of 2 hours 14 minutes and 4 seconds.

\section{Long COVID}

The estimates of long COVID prevalence vary, with the most recent UK Office for National Statistics report stating that $1.9 \%$ of the total population (1,200,000 individuals) are currently experiencing prolonged symptoms in the 4 weeks following acute infection (ONS, 2021). The most reported symptoms in the ONS report were fatigue (55\%), shortness of breath (39\%), and difficulty concentrating (30\%); indeed, $65 \%$ of individuals reported that their activities of daily living had been adversely affected. Long COVID is therefore a novel problem, that requires the attention of the physiological community in tandem with clinical sciences.

A recent series of studies have highlighted the role that exercise physiology can play in determining the causes of prolonged symptoms, investigating the responses to cardiopulmonary exercise testing (CPET) in long COVID patients. Firstly, Baratto et al., (2021) demonstrated that at discharge from hospital, COVID-19 patients' $\mathrm{VO}_{2 \max }$ was reduced by 30\% compared with age-, sex-, and BMImatched healthy controls. Although a moderate reduction in respiratory function, assessed via forced vital capacity (the total amount of air that can be expelled from the lungs), was observed, the authors suggested that the primary cause of $\dot{\mathrm{VO}}_{2 \max }$ impairment was due to reduced arterio-venous oxygen difference. This variable represents the ability of working muscles to extract oxygen from the blood.

Following this, Rinaldo et al., (2021)

investigated 75 COVID-19 patients with a range of disease severity three months following hospital discharge. The authors split the sample into those demonstrating impaired exercise capacity $\left(\mathrm{V}_{2 \max }<85 \%\right.$ predicted) and those with preserved exercise capacity $\left(\mathrm{V}_{2 \max }>\right.$ $85 \%$ predicted). In both groups, aspects of respiratory function (forced vital capacity

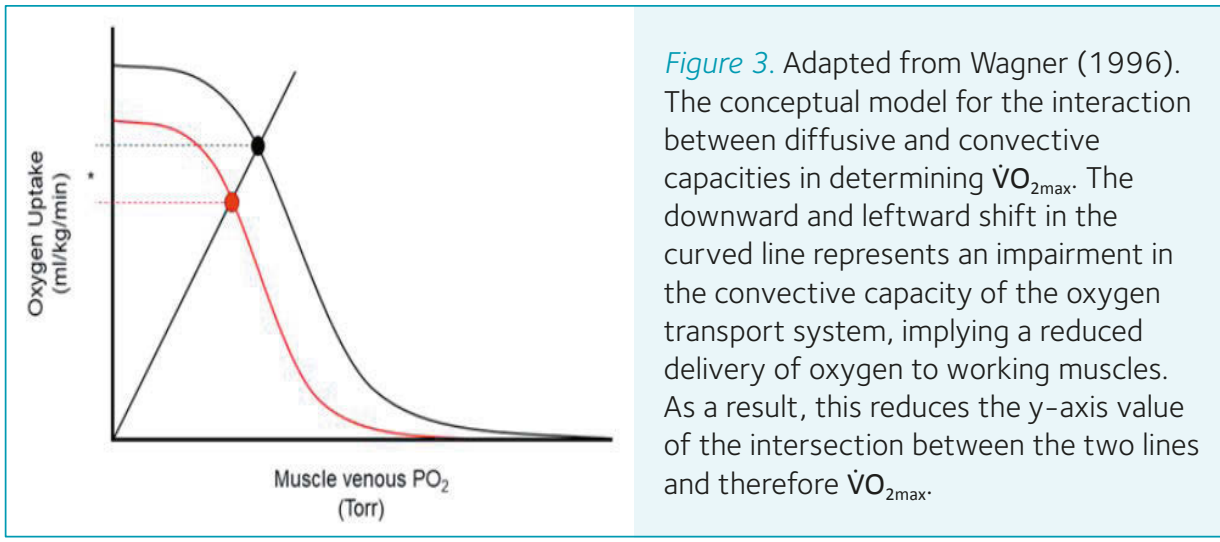

and forced expiratory volume in 1 second) were normal, as were indices of ventilatory efficiency and gas exchange, implying that the pathophysiology associated with exercise impairment was not pulmonary in origin. The primary difference between the two groups was the ventilatory threshold ( $48 \pm 9 \% \dot{\mathrm{VO}}_{2 \max } \mathrm{Vs} .62$ $\left.\pm 13 \% \mathrm{~V}_{2}{ }_{2 \max }\right)$, the point during an incremental test where non-oxidative energy systems begin to contribute more substantially to the resynthesis of ATP. The authors attributed this to an impairment in oxygen extraction within skeletal muscle, either directly caused by viral load or the associated muscle deconditioning.

Finally, Singh et al., (2021) studied COVID-19 patients 11 months after acute infection, and importantly, only one of the 10 patients had been admitted to hospital. These patients were compared with age and sex-matched controls, and once again demonstrated no impairment in the function of central physiological systems, when cardiac and respiratory function was assessed. Consistent with the studies of Baratto et al., (2021) and Rinaldo et al., (2021), the patient group demonstrated an impairment in $\dot{\mathrm{V}}_{2 \max }(70 \pm 11 \%$ predicted $)$. In this cohort, cardiac function and delivery of oxygen was preserved, whereas peak oxygen extraction in the COVID group was only $62 \%$ of that in the control group. The authors argued that the impairments caused by long COVID should not simply be attributed to deconditioning, as function of central physiological systems (e.g. cardiac output, a hallmark of conditioning status) was preserved.

The consistent message between the three studies is that COVID-19 likely induces dysfunction within the microcirculation involved with the diffusion of oxygen, and/

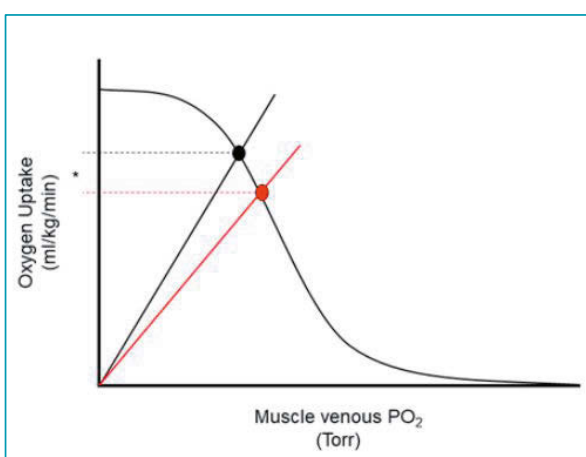

Figure 4. Adapted from Wagner (1996). The conceptual model for the interaction between diffusive and convective capacities in determining $\dot{\mathrm{V}}_{2 \text { max }}$. The reduced slope of the red straight line indicates an impairment in the diffusive capacity of muscle that is likely induced by long COVID. As a result of this impairment, the $y$ value for the intersection of the two lines is reduced, representing a reduction in $\dot{\mathrm{V}}_{2}$ 
or the mitochondria within skeletal muscle itself. Collectively this dysfunction manifests as an impaired ability to extract oxygen from the blood - a key component in the determination of $\dot{\mathrm{V}}_{2 \max }$. When considered under the framework of the Wagner model, this would appear as a reduced slope in the straight line representing diffusive capacity, consequently reducing the $y$-axis value for the intersection of the two lines, implying a reduction in $\mathrm{VO}_{2 \max }($ Fig.4). Given the importance of cardiovascular fitness in predicting functional capacity, quality of life, and mortality in clinical populations, interventions addressing these impairments in long COVID patients must be at the forefront of physiological and medical research.

An example of using the integrated oxygen transport system approach can be found in recent research that demonstrated the mechanisms that underpin adaptation to single-limb exercise training in COPD patients (Broxterman et al., 2021). Specifically, Broxterman et al., showed that muscle diffusive capacity (as measured by the arteriovenous oxygen difference) improved by $\sim 38 \%$. In contrast, convective capacity (as measured by thermodilution-assessed leg blood flow) did not change in COPD patients, constraining overall adaptation. This approach helped the authors to understand the specific pathophysiology associated with the disease, rather than simply attributing impairments to deconditioning.

\section{The role of exercise physiology in understanding contemporary issues}

The aim of this article was to use the Wagner model of $\dot{\mathrm{V}}_{2 \max }$ determination to contextualise recent events and issues within the theme of Human, Environmental and Exercise Physiology. The integrative oxygen transport system that Wagner describes is universal in mammalian physiology, and by using the framework from his seminal 1996 review paper, we can begin to understand how changes to aspects of the system can affect key factors (e.g. $\dot{\mathrm{V}}_{2 \max }$ ) across the spectrum of health and disease. Using the world-class marathon runners profiled by Jones et al., (2021), we can see how years of strategic training optimises an athlete's physiology for transporting oxygen from the air to the mitochondria to fuel a feat that only one human being has managed to ever perform: a sub 2-hour marathon. The Tokyo Olympics gave us an example of how environmental factors can influence delivery of oxygen to the exercising muscle, worsening performance. Then finally, the recent studies highlighting impairments in the skeletal muscles of long COVID patients demonstrate how we can quantify the integrated oxygen transport system, identify mechanisms that could underpin clinical conditions, and begin to work out the best way of treating this growing patient population. Investigating the integrative oxygen transport system in different contexts allows us to quantify and separate convective and diffusive factors, study their interactions, and potentially identify therapeutic targets that might otherwise have been missed.

As the early-career theme lead for Human, Environmental, and Exercise Physiology, my goal is to promote our discipline, highlight the work being done, and demonstrate how our theme can integrate with others to advance our understanding of how the human body responds to all types of stressors. The other Theme Leads and I aim to promote Human, Environmental and Exercise Physiology through conferences, workshops, and other initiatives within The Physiological Society. For more information please visit our Theme Page (physoc.org/themes) or see upcoming events (physoc.org/events).

\section{References}

Arngrímsson SÁ et al., (2004). Hyperthermia and maximal oxygen uptake in men and women. European Journal of Applied Physiology, 92(4), 524-532. http://doi.org/10.1007/s00421-004-1053-1

Broxterman R et al., (2021). Exercise training in chronic obstructive pulmonary disease: muscle 02 transport plasticity. European Respiratory Journal. In Press. http://doi.org/10.1183/13993003.041462020

Baratto C et al., (2021). Impact of COVID-19 on exercise pathophysiology: a combined cardiopulmonary and echocardiographic exercise study. Journal of Applied Physiology 130(5), 1470-1478. http://doi. org/10.1152/japplphysiol.00710.2020

Jones AM et al., (2021). Physiological demands of running at 2-hour marathon race pace. Journal of Applied Physiology, 130(2), 369-379. http://doi. org/10.1152/japplphysiol.00647.2020

Office for National Statistics (2021). Prevalence of ongoing symptoms following coronavirus (COVID-19) infection in the UK: 4 Novemberr 2021. https:// www.ons.gov.uk/peoplepopulationandcommunity/ healthandsocialcare/conditionsanddiseases/bulletins/ prevalenceofongoingsymptomsfollowingcoronaviruscovid19infectionintheuk/4november2021

Rinaldo RF et al., (2021). Deconditioning as main mechanism of impaired exercise response in COVID-19 survivors. European Respiratory Journal. In Press. http://doi.org/10.1183/13993003.008702021

Singh I et al., (2021). Persistent exertional intolerance after COVID-19: Insights From invasive cardiopulmonary exercise testing. Chest. In Press. http://doi. org/10.1016/j.chest.2021.08.010

Wagner PD (1996). Determinants of maximal oxygen transport and utilization. Annual Review of Physiology, 58(1), 21-50. http://doi.org/10.1146/annurev. ph.58.030196.000321

Wagner PD (2000). New ideas on limitations to VO2max. Exercise and Sport Sciences Reviews, 28(1), 10-14.
"A recent series of studies have highlighted the role that exercise physiology can play in determining the causes of prolonged symptoms, investigating the responses to cardiopulmonary exercise testing (CPET) in long COVID patients." 


\section{Sir Gordon Morgan Holmes}

\section{On the confluence of physiology, medicine, history, industrial design and art in war}

\section{Dr Sean Roe}

Queen's University Belfast, UK

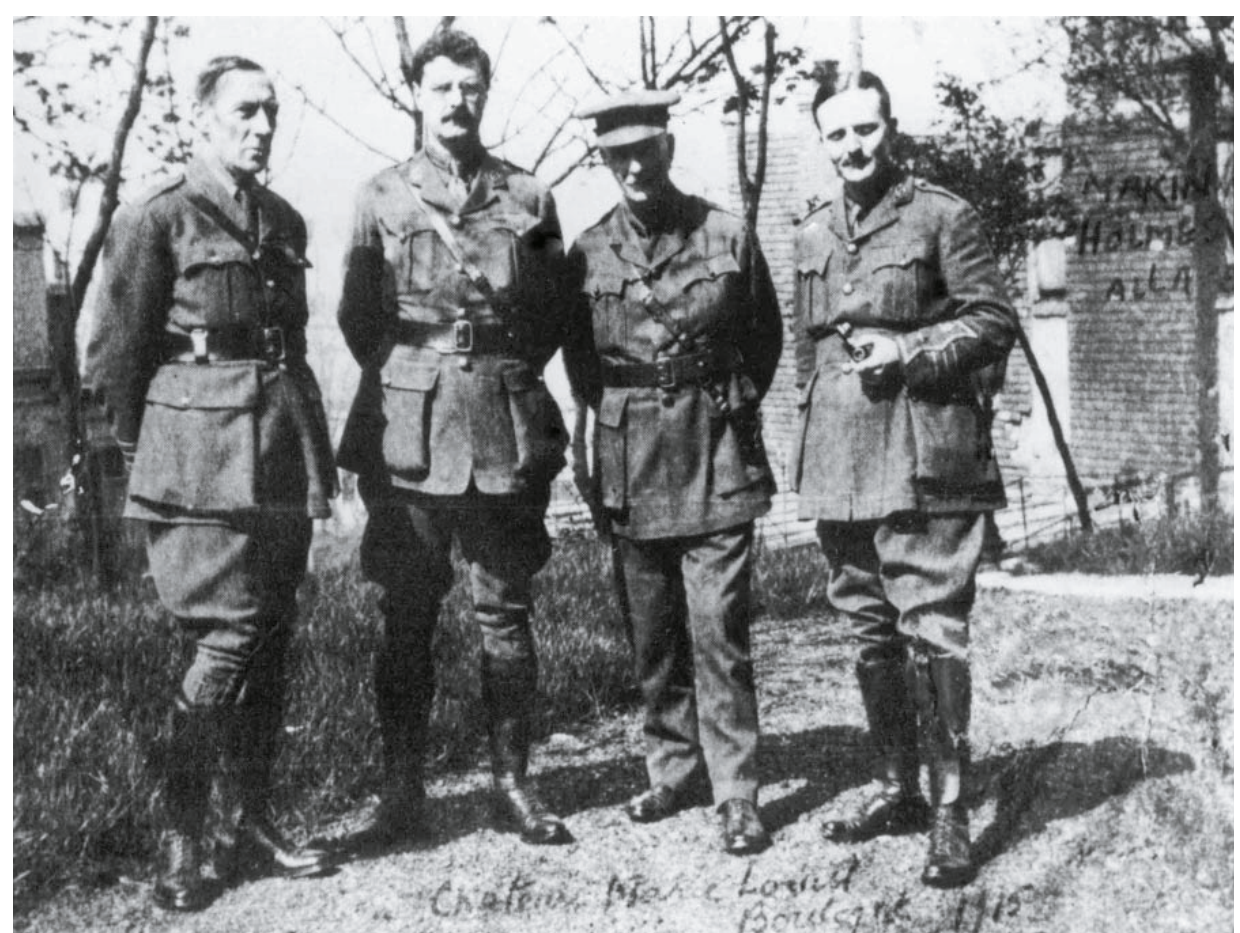

Figure 1. Gordon Morgan Holmes (second from left) in his British Expeditionary Force (BEF) uniform on the Western Front in 1915 (Credit: Raven Press).

To the Dublin native working in Queen's University Belfast, the small townland of Castlebellingham on the border is a convenient stop to get fuel and perhaps a sandwich when driving to visit family. To the student of Medical Physiology and the history enthusiast, it is the childhood home of a remarkable man. Gordon Morgan Holmes, born in Dublin in 1876, travelled far beyond his birthplace and authored a remarkable body of work borne of his experiences in Ireland, England, Germany, and, most notably, the Western Front of the First World War (Fig.1). It is to him that we owe much of our modern understanding of the functional anatomy of the visual cortex and the cerebellum. Many of the techniques still used to examine cerebellar and visual function were originated by him, under fire in casualty clearing stations, where, after long days on the line, he retired to make copious notes late into the night (Fishman, 1997). Here, in France, between 1915 when he arrived, and 1918 at the cessation of hostilities, existed a confluence of factors and personalities that lent themselves uniquely to the advancement of the science of neurology.

\section{Cometh the man}

Born in February 1876, Holmes, after local schooling, studied Medicine in Trinity College Dublin, after which, seized by a desire to travel, he enlisted as a ship surgeon travelling to New 


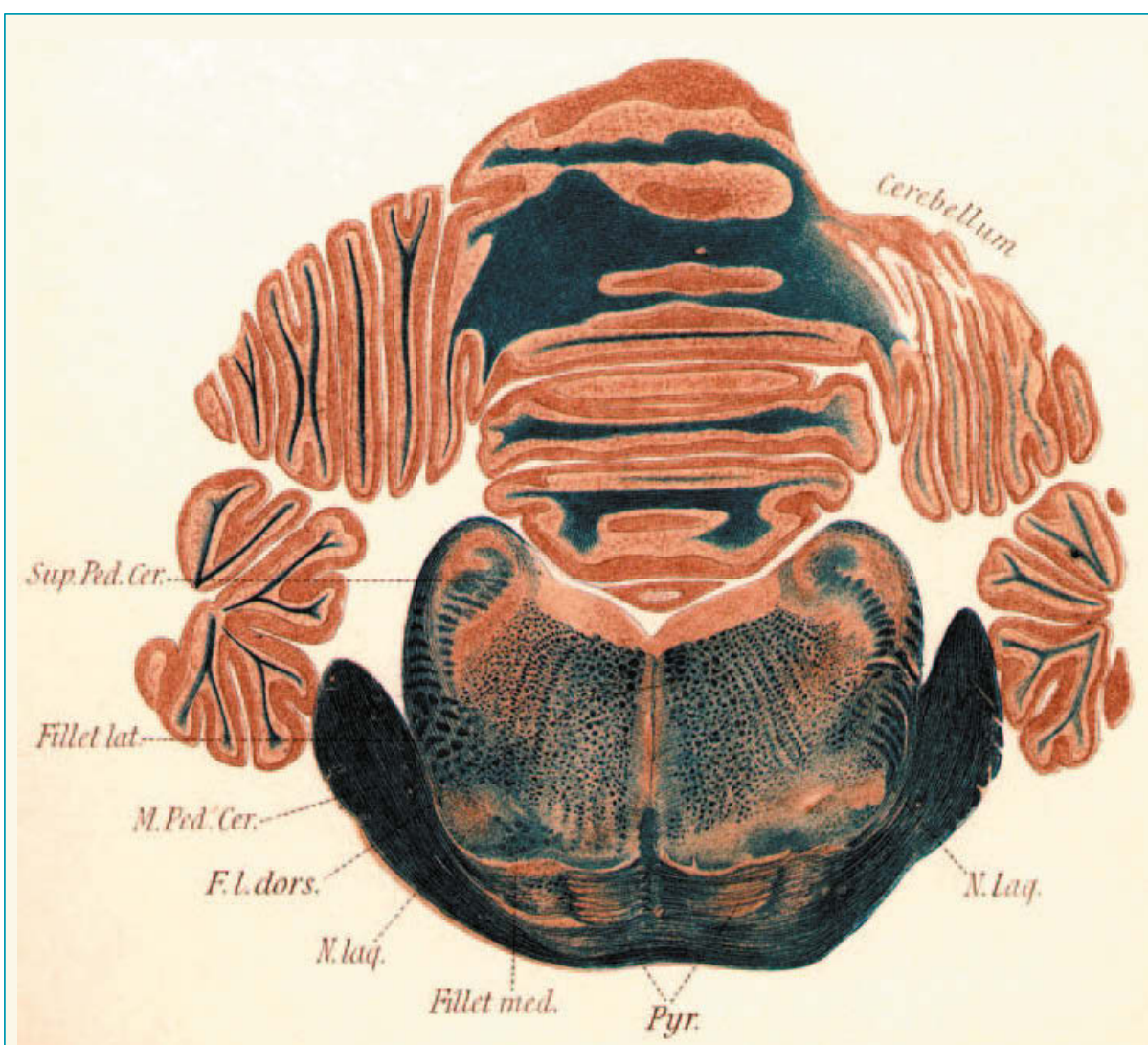

Figure 2. Holmes' 1901 rendition of the brainstem and cerebellum of Golz's "Dog without a forebrain" in The Journal of Physiology. of the clinical signs of cerebellar dysfunction resulting from their observations of 40 patients with cerebellar tumours (Fine et al., 2011).

\section{Cometh the hour}

At the outbreak of the First World War in August 1914, Holmes applied for a commission in the Royal Army Medical Corps (RAMC) but was initially rejected due to his myopia. Unabashed, he volunteered with Percy Sergeant, another Surgeon from Queen Square for duty in a Red Cross Hospital just behind the front line. Their success here led to the RAMC reconsidering their decision and he was appointed as consultant neurologist to the British Armies in France. Harvey Cushing describes his tireless work with patients after the Battle of Ypres and Passchendaele thus; "There are 900 acutely ill soldiers, convoys of 300 wounded might arrive in a day, and there were only 10 doctors" (Lepore, 1994). After long days caring for them, Holmes would go back at night to write up his notes and examine them in more detail, sometimes going as far as to conduct bedside visual field tests (Fishman, 1997).

Thus set the stage for a remarkable body of work on the physiology, anatomy and pathophysiology of the cerebellum and visual cortex. A confluence of events and talents led directly and indirectly to some of the most important scientific and clinical advances of the $20^{\text {th }}$ century.

Firstly, the Brodie helmet used by the British on the Western front was designed to be easily and cheaply produced from a single stamping of metal (Shadrake and Pugh, 2014), and provided good protection from airburst shells but not from shrapnel rounds that burst closer to ground level. In this case, occipital lobe and cerebellar damage resulted because "British helmets danced on top of
Edinger, and learned staining techniques and histopathology with Carl Wiegert (Fine et al., 2011).

His education with the "Herr Professor" Edinger was challenging; sections of the spinal cord painstakingly drawn (over 2 days) were unceremoniously torn up when they did not reach the exalted standards required (McDonald, 2007). Soon after this, however, Edinger warmed to Holmes, so much so that he gave him the brain of Goltz's famous preparation "dog without a forebrain" for detailed histologic study. The beautiful, almost artistic drawings resulting from this can be seen in Holmes early work for The Journal of Physiology (Fig.2). This exacting early training in neuroanatomy, physiology and histology would serve Holmes well in his later life, where these skills combined to inform some of his most important discoveries.

On returning to Ireland from Germany, he applied for a post as registrar at the National Hospital, Queen Square, London, and in 1903 received his $M D$ and gained membership of the Royal College of Physicians in London in 1908 (Breathnach, 1975). In Queen Square, under the mentorship of John Hughlings Jackson the skills of "unresting contemplation of the facts of observation, scrupulously and untiringly acquired" were inculcated (McDonald, 2007). Thus was Holmes uniquely schooled in the German tradition by Edinger and the British by Jackson. Notable research produced around the time included a description of familial cerebellar degeneration in 1908, and, with Thomas Grainger Stewart, a characterisation

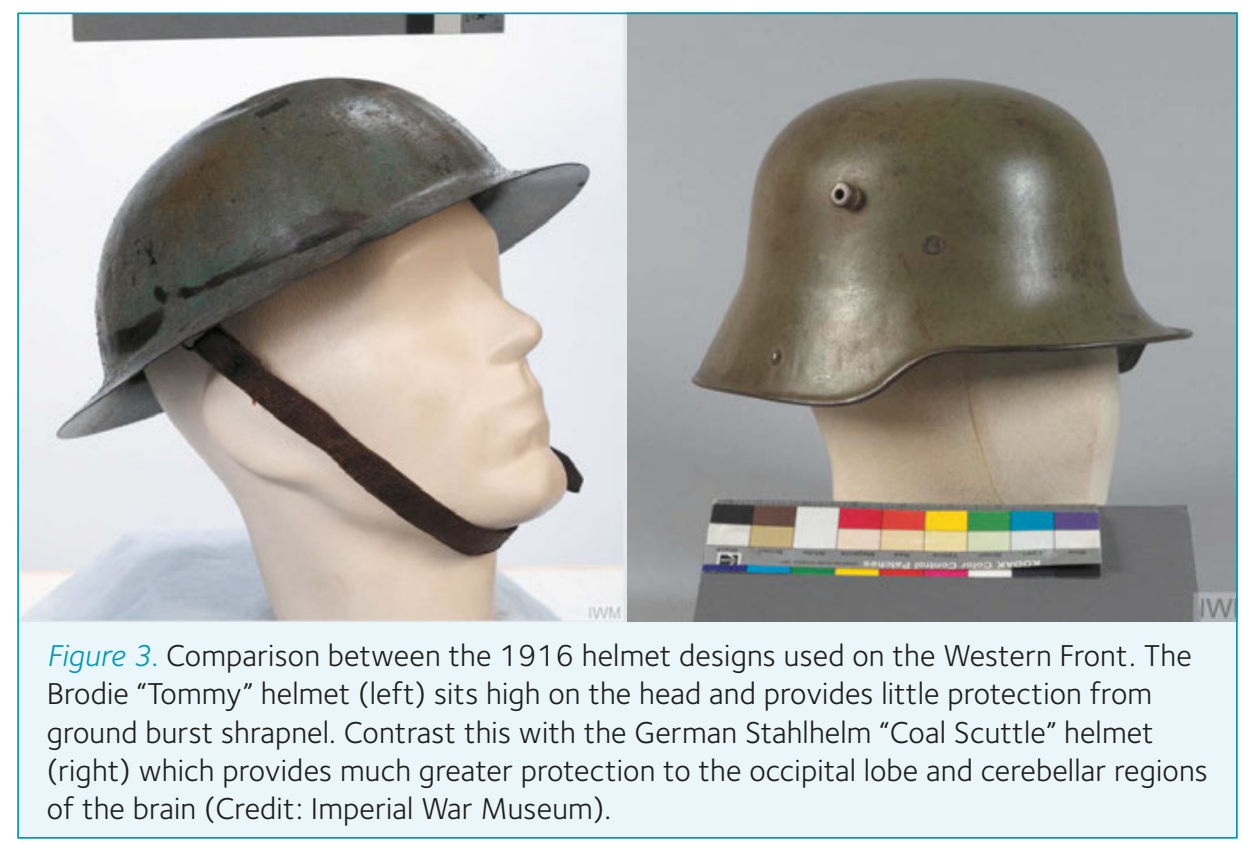



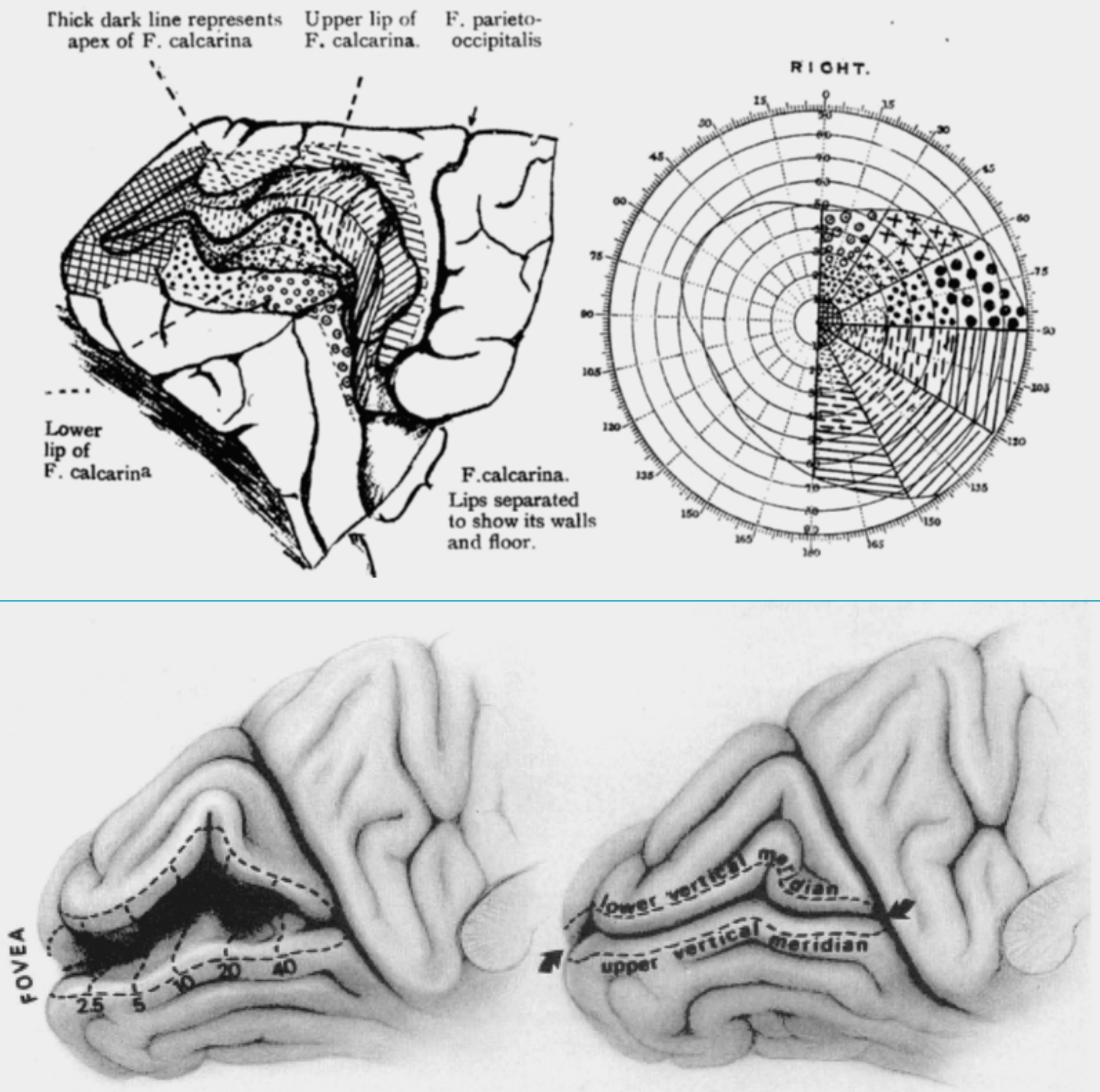

Lett Visual Cortex

Right Visual Field
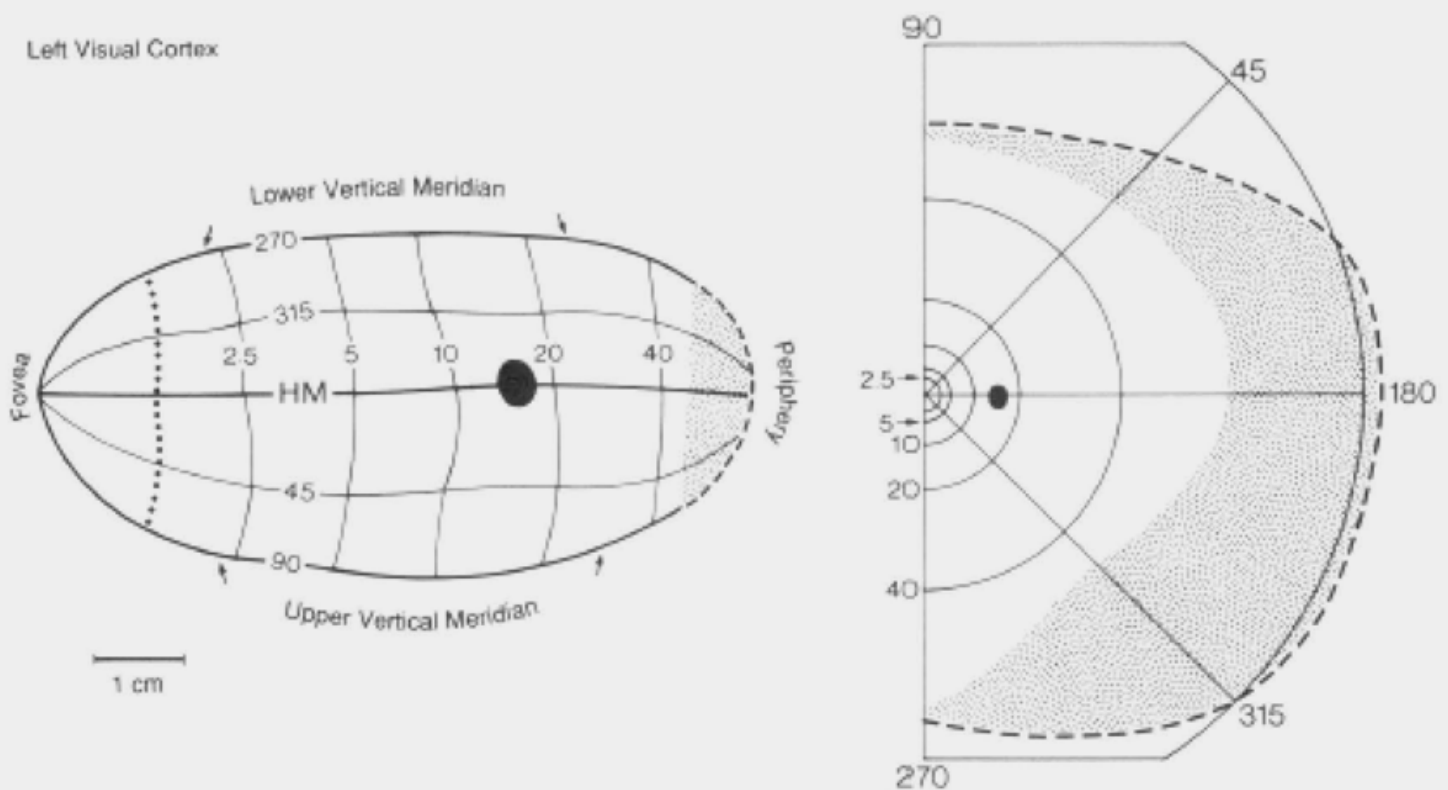

Figure 4. Comparison between Holmes' 1918 classic map of the "cortical retina" and rendition of human visual fields (top panels: Holmes, 1918) and that in Horton and Hoyt's adaptation of Holmes' Map using Magnetic Resonance Imagery (MRI) techniques (bottom panels: Horton and Hoyt, 1991). While remarkably similar, Holmes underestimated the proportion of the striate cortex serving the central visual field. He ascribed only $25 \%$ of the surface area to the central 15 degrees of visual field. In later maps, 15 degrees occupies about $70 \%$ of striate cortex surface area. 
their heads, unlike those of the Germans" (Fig.3, Fishman, 1997).

Secondly, the introduction of new, more powerful rifles in the late 1800s imparted enough velocity to allow a projectile to enter the skull and cause limited and discrete damage, but not so much velocity as to produce the cavitation and extensive shockwave damage that modern weapons do. As Holmes himself described in his 1917 article on cerebellar lesions, "The opportunity of making uncomplicated clinical observations is rare in civil life, since acute lesions of the cerebellum, comparable with those produced by physiologists, are uncommon; tumours and abscesses which develop in it are very liable to compress or influence the functions of other parts too...... In warfare, on the other hand, wounds limited to the cerebellum and injuries of it of different extent and localization, can be frequently observed" (Holmes, 1917).

Thirdly, Holmes had rigorous training in anatomy, physiology and clinical observation. This uniquely disposed him to the characterisation and mapping of visual field loss due to discrete lesions of the occipital lobe. His extensive pre-war experience in measuring functional loss (movement dysmetria, decomposition and loss of recoil) due to cerebellar tumours (Stewart and Holmes, 1904) was also invaluable when studying the large cerebellar lesions consequent to shrapnel and bullet wounds. Holmes' initial maps of visual field localisation (Holmes, 1918) survived almost unaltered until Horton and Hoyt's (1991) revision of this map using magnetic resonance imaging
(Fig.4). His description of the clinical signs of cerebellar damage (ataxia, dysmetria, movement decomposition, tremor, hypotonia, nystagmus) provided comprehensive tools by which clinicians could characterise and quantify loss of cerebellar function (Holmes, 1917), tools still very much in use today.

\section{Intersections and perspectives}

To the Irish medical educator, Holmes's contribution to the body of knowledge on neuroscience is a source of great pride. From a UK perspective, there is gratitude for his insistence on front line duty and tireless service to the injured "Tommy" on the Western front. Expanding to a European point of view, Holmes can be seen as a great inheritor of both the German and British neuroscience traditions who used his panEuropean background to push the boundaries of the field. Further afield, as editor of Brain from 1922 to 1937 , he influenced the science worldwide.

Wilder Penfield (who studied under notables such as Ramon y Cajal and CS Sherrington amongst others, opined that Holmes was "one of the finest teachers he had known; beneath the exterior of a martinet, there was an Irish heart of gold" (Breathnach, 1975). His legacy has relevance for modern educational interdisciplinarity, combining, as it did, excellence in visual art, anatomy, physiology, pathology and clinical skills. His life and work makes the case for the nonsiloed, interdisciplinary thinking beloved of future educational planners.

injuries due to gunshot injuries. Brain 40(4), 461-535 https://doi.org/10.1093/brain/40.4.461

Holmes G (1918). Disturbances of vision by cerebral lesions. British Journal of Ophthalmology 2(7), 353-384 https://doi.org/10.1136/bjo.2.7.353

Horton JC, Hoyt WF (1991). The representation of the visual field in human striate cortex: a revision of the classic Holmes map. Archives of Ophthalmology 109(6), 816-824. https://doi.org/10.1001/archopht.1991.01080060080030

Lepore FE (1994). Harvey Cushing, Gordon Holmes, and the neurological lessons of World War I. Archives of Neurology 51(7), 711-722. https://doi.org/10.1001/ archneur.1994.00540190095022

McDonald I (2007). Gordon Holmes lecture: Gordon Holmes and the neurological heritage. Brain 130(1), 288-298. https://doi.org/10.1093/brain/awl335

Shadrake D, Evans-Pughe C (2014). Putting a lid on it [First World War Equipment Design]. Engineering \& Technology 9(6), 44-47. https://doi.org/10.1049/ et. 2014.0603

Holmes GM (1901). The nervous system of the dog without a forebrain. The Journal of Physiology 27(12), 1-25. https://doi.org/10.1113/jphysiol.1901. sp000855

Stewart TG, Holmes G (1904). Symptomology of cerebellar tumours. Brain 27, 522-592. https://doi. org/10.1093/brain/27.4.522

Holmes G (1917) The symptoms of acute cerebellar
"A confluence of events and talents led directly and indirectly to some of the most important scientific and clinical advances of the 20th century."

org/10.1093/brain/27.4.522 


\section{Mark your diary for our exciting 2022 events}

\section{Next year promises a range of online and in-person events showcasing first-class physiology across our Themes}

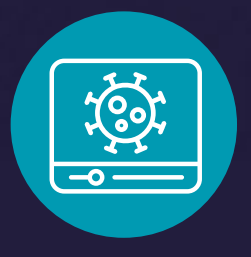

\section{Long COVID: Mechanisms, Risk Factors, and Recovery}

February 2022 I Online

Persistent symptoms following SARS-CoV-2 infection, otherwise known as long COVID, have affected patients all around the world. It is a heterogeneous disease with multimorbidities and affecting many physiological systems. In bringing physiologists and clinicians together, we can better understand the underlying mechanisms and identify potential therapies. Join colleagues to discuss the mechanisms, risk factors and recovery from long COVID with an interdisciplinary panel of international speakers.

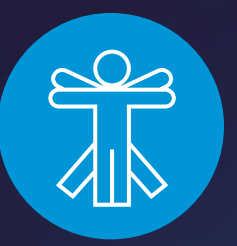

\section{The Biomedical Basis of Elite Performance 2022}

\section{2-13 April 2022 | University of Nottingham, UK}

Join internationally recognised speakers as they explore physiological responses to exercise, in the context of human adaptation and performance, and the central role that biomedical science is playing in directing understanding in this area. Sessions will cover cardiovascular, neuronal, and neuromuscular physiology, along with molecular and cellular metabolism, and the application of transformative methods in human physiology.

Submit your abstracts from 16 December 2021-31 January 2022

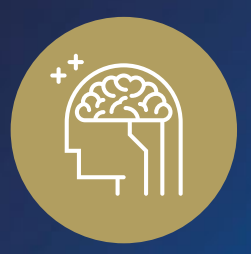

\section{Processing and Modulation of Sensory Signals: From the Periphery to the Cortex}

\section{0-21 June 2022 | Royal College of Physicians, London, UK}

Hear from world-leading experts studying sensory signals in different modalities and at different levels, from peripheral transduction to cortical integration. Foster collaborations, cross-pollinate ideas and network with friends and colleagues face-to-face.

Submit your abstracts from 1-31 March 2022 


\section{Europhysiology 2022}

16-18 September 2022 | Tivoli Congress Center, Copenhagen, Denmark

Our Annual Conference in 2022 will be taking place as part of Europhysiology. The scientific programme promises three days of the best and most exciting in current physiological research, including inspirational plenary and keynote lectures, symposia, oral communications and posters.

Submit your abstracts from 1-25 May 2022

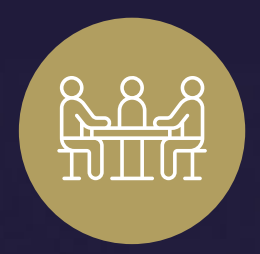

\section{Variability, Physiological Variability and Individual Responses: A Practical Research Workshop}

\section{September 2022}

Variability is ubiquitous in physiological research, but we often choose to ignore it, hide it or remove it. This workshop will feature contributions from a small number of discipline experts, allowing a greater amount of time for the presenters to expand on key-points. They will also give step-by-step guidance and provide practical worked examples of approaches to the assessment of variability covering a variety of experimental designs (and their strengths and weaknesses) and statistical methods.

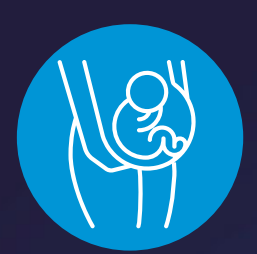

\section{Environmental Impacts on Pregnancy and Offspring Outcomes: Lessons Learned and Avenues for Intervention}

\section{September 2022 | Coin Street Conference Centre, London, UK}

This symposium will bring together researchers studying different model systems to help improve our understanding of pregnancy and life course physiology. Invited talks and discussions will cover the latest research into the impact of environmental influences on maternal physiological support of offspring development and strategies mitigating the negative impacts of adverse environmental conditions on the lifelong health of the mother and child.

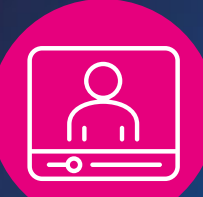

\section{Future Physiology 2022}

December 2022

Future Physiology is our annual conference for early career researchers by early career researchers with a focus on professional development. It is tailor-made to offer our early career researchers the experience, renewed enthusiasm, and networking opportunities to help them take the next steps in their career.

Submit your abstracts from 1-30 September 2022 
Meeting notes

Looking ahead to The

Society's exciting 2022

conference programme:

The outgoing Conference

Committee Chair passes the baton

\section{By Professor Sue Deuchars, University of Leeds, UK. Outgoing Chair of Conference Committee}

I am very sad to be coming to the end of my tenure as Chair of The Society's Conferences Committee since it has been an incredibly enriching and positive experience.

The work of the committee would not be possible without the efforts and support of the amazing staff at The Society, particularly within the events team but also across the whole of the Society team.

Without their hard work, there would be no events or indeed any activities. It has been such a pleasure to work alongside such a dedicated and insightful group of physiologists on the committee itself and with all the Theme Leads who give so much of their time to ensure that the conferences are relevant to our scientific community, thought-provoking and packed full of physiology. We have covered so much, from extreme physiology, through elite performance to COVID-19, considering exciting new technologies and breaking, new concepts.

Their enthusiasm and teamwork are behind all of our activities. The last 18 months have certainly been eventful and as we make plans to return to in-person conferences for this year and beyond, I am pleased to introduce $\mathrm{Dr}$ Catherine Hall (University of Sussex, UK) as The Society's incoming Chair of Conferences Committee.
Dr Hall says, "I'm so excited to be starting this role. Professor Deuchars has shown what a fantastic range of conferences and meetings it's possible to stage even during such challenging times of a global pandemic, and I think it'll be so interesting and important to take forward the positive things we've learnt about staging events online, while also getting back some of the really vital experiences that only come from meeting people in person."

The Society's Conferences Committee has been discussing what the framework for Society conferences and meetings looks like as we can meet face to face again. There have certainly been huge positive outcomes in offering meetings, webinars and symposia online. They bring together a more international audience and can also be convenient and time efficient.

The Annual Conference attracted people from 45 countries. Smaller, more focused conferences, such as Future Physiology had an audience from 36 different countries.

It's important that we include online and hybrid meetings in our conference calendar going forward to add balance to the inperson programme. We would welcome your comments through the events team at The Society so do please get in touch at events@physoc.org.

Looking at the programme we have coming up, it's diverse and demonstrates the breadth of physiology.

Building on the success of the conference that was held jointly in 2020 with the Intensive Care Society (COVID-19: Lessons Learned from the Frontline), we are planning a conference looking at long COVID. Long COVID: Mechanisms, Risk Factors, and Recovery will be online only and bring together physiologists and clinicians to explore the long-term effects of COVID and its physiology and pathophysiology. This is planned for February 2022.

\section{Biomedical Basis of Elite Performance}

will be from 12-13 April in Nottingham. This is once again organised by Paul Greenhaff (University of Nottingham, UK) and colleagues, as it was in 2012 and 2016. This two-day meeting will look at key topics in elite performance.
Processing and Modulation of Sensory Signals: From the Periphery to the Cortex will be from 20-21 June in London at the Royal College of Physicians. This meeting, organised by Jamie Johnston (University of Leeds, UK), Jennifer Linden (University College London, UK) and Sue Deuchars (University of Leeds, UK) is designed to help foster new connections and cross-pollinate ideas between researchers studying sensory systems in different modalities and at different levels from peripheral transduction to cortical integration.

Europhysiology 2022 will be from 16-18 September in Copenhagen at the Tivoli Convention Center. There will also be pre-symposia on 15 September from Special Interest Groups. This is an important conference enabling you to connect with physiologists working in Europe. It will also host a number of Society Prize Lectures, including the Annual Review Prize Lecture to be delivered by Gero Miesenboeck.

Future Physiology will be in December 2022. This will remain free for Undergraduates, Masters, Affiliates and Postgraduate members.

There will also be in-person-only one-day meetings called Environmental Impacts on Pregnancy and Offspring Outcomes: Lessons Learned and Avenues for Intervention and Variability, Physiological Variability and Individual Responses: A Practical Research Workshop. Both of these are in September of next year.

We will also be organising some online meetings and webinars, so if you have an idea for a half- or one-day meeting, or a short webinar, and want to reach a large international audience, please email events@ physoc.org.

We are in another new phase where Society conferences and meetings can offer members the face-to-face serendipitous coffee chats that we have so missed these past 18 months, but also preserve the new and exciting technologies, and online experiences, that have allowed us to connect with wider international audiences. We look forward to meeting with you all soon - either over that coffee or through the wonders of online networking! 
Meeting notes

\section{Our first online Annual Conference Physiology 2021: Members give testimonials from the event}

\section{By Professor Sue Deuchars, Chair of Conference Committee, The Physiological Society}

Each year, our Annual Conference brings together the physiology community for a fantastic programme of the latest research and professional development activities. Physiology 2021 was no exception, although it did have one unique feature compared with previous years - it was held entirely online! Due to the ongoing COVID-19 pandemic, this decision was made early in the year and whilst it was disappointing not to be able to meet face to face, we welcomed a much more international community of physiologists with close to 600 attendees from 45 different countries.

Over the five days, the audience was inspired by seven Prize Lectures, and the lecturers themselves who gave an exclusive insight into their career paths to date in two "Meet the Speaker" panel discussions. Seventy-two symposia speakers showcased their work, ranging in subject from Cardiac Sodium Channel: From Function to Dysfunction to Physiological Resilience Across the Lifecourse: In Utero and Beyond. With 83 oral communications and 95 poster communications, there was plenty of opportunity to hear from researchers at all levels and across Themes. The high-quality science on show, despite the pandemic, made clear the resilience and motivation of our community.

Alongside our scientific programme, we had several professional development sessions.

Two of these sessions allowed attendees to reflect on the past year and what it means for the future, with a workshop looking at what is next in teaching and a townhall-style discussion exploring what life could look like for a researcher long-term following the COVID-19 pandemic.

There were also well-attended sessions with our Editors-in-Chief of The Journal of Physiology and Experimental Physiology and a panel of knowledge exchange experts. Finally, attendees heard more about The Society's competition, "Aspiring Black Physiologists", which has been developed as part of The Society's wider D\&I commitment and were invited to give their feedback into this work.

As always, Physiology 2021 could not have happened without our members and the wider physiology community, and so we extend our gratitude to all those involved and those who joined us over the week. Here two attendees reflect on their highlights.

\section{Dr Yevheniia Kravenska}

University of Padova, Italy

I have been a member of The Physiological Society for many years, I regularly participate in their Annual Conferences, and I can only say good things about the events and the wonderful team.
Speakers at one of the symposia of our online conference Physiology 2021

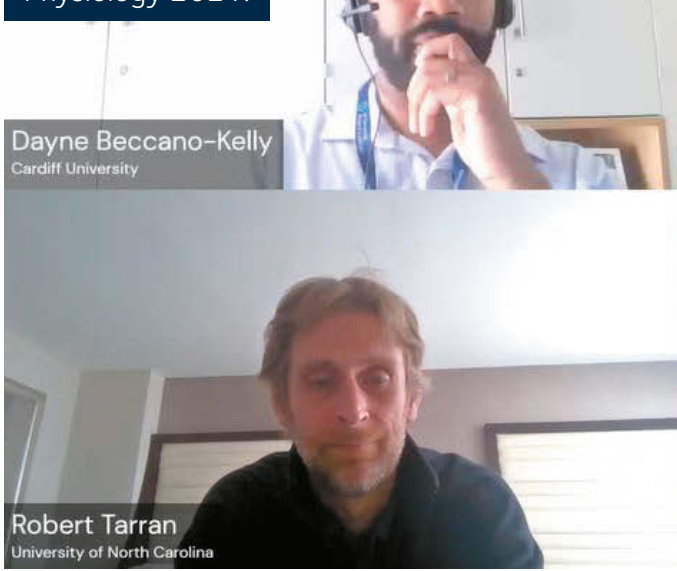

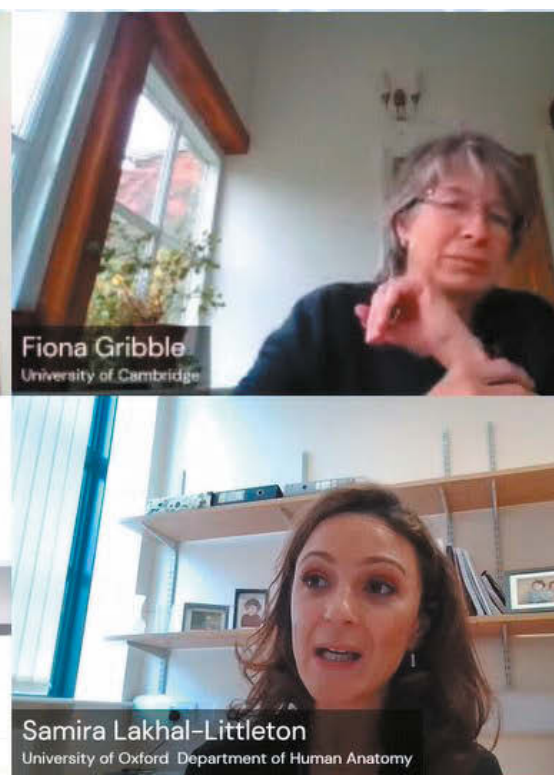

This year, for the first time, the world faced the need to hold global online conferences, and The Society has adapted remarkably well.

First, I was grateful for the detailed preconference webinar on preparing online posters. The platform turned out to be user-friendly and colourful. Online support, as always, was at its best; the team was friendly, kind and competent.

Regarding the conference itself, I would like to immediately note the rich and thorough programme, with sessions ranging from the introduction of new technologies to Prize Lectures.

I really enjoyed the impressive Paton Prize Lecture by Professor Semir Zeki, which, in addition to covering very interesting scientific material, contained thought-provoking quotes of famous people.

I was also sincerely amused by the quiz, in which I took part almost by accident: I had no idea how witty seemingly simple questions might be (especially about the vortex).

The work of a cheerful and close-knit team, as well as the humour with which the Society approached the organisation of the quiz, boosted my spirits for many days.

I was also pleased with my presentation time, by the significant interest of the audience, as well as by their sincere and pleasant feedback, which I subsequently shared with my co-authors.

I also would like to note the affordable price of participation in Physiology 2021, in comparison with other similar conferences. The financial aspect can play a key role for participants from poorer regions, who get a chance to demonstrate their results and make useful contacts for further cooperation.

Summing up, I want to thank The Physiological Society for another excellent Conference that will be remembered for a long time. Your hard work for many years, your kindness and the intention to do your best make our world a little better.

\section{Sophy Creed}

University of Exeter, UK

Last month, I, along with 600 other scientists from across the world attended The Physiological Society's Annual Conference, Physiology 2021, which was delivered virtually. 


\section{and \\ Physiology 2021}

Almost 600 attendees

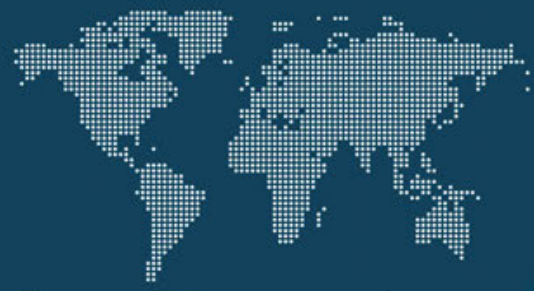

from 45 countries
$91 \%$

rated the quality of the symposia as 'Good'

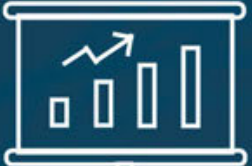
or 'Excellent'

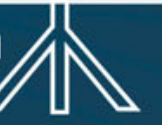

$\mathbf{8 8} \%$ rated conference as 'Good' or 'Excellent' and $99 \%$ would reccomend

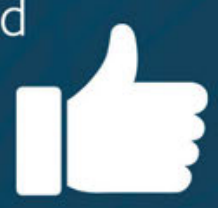

$89 \%$ said the online format worked well

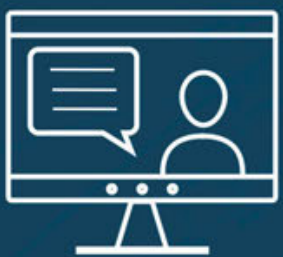

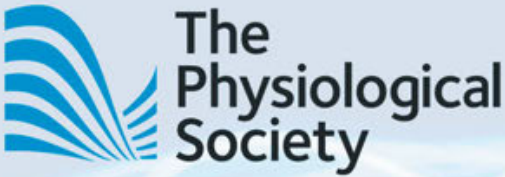

Why did people attend?

The

Physiological

Society
To hear the latest

research (79\%)

Professional development (42\%)

It was online and
accessible (36\%)

\#Physiology2021

There was a wealth of interactive and collaborative sessions in a variety of formats including 95 ePosters, 83 oral communications, 72 symposia speakers and 7 Prize Lectures. I was extremely privileged to have the chance to present my undergraduate research as an ePoster on the first day of the conference and become one of the recipients of the prestigious Rob Clarke Award.

\section{This award recognises excellence in} undergraduate physiology research, given in memory of Dr Rob Clarke (1956 - 2004) who made important contributions to physiology as a researcher and teacher, and who was a passionate advocate for nurturing the next generation of physiologists. As one of only eleven recipients for 2021, I am very proud to have my work recognised, and I must take this moment to say congratulations to Keady Flynn from Trinity College Dublin, Ireland who received both an abstract and the presentation award at Physiology 2021.

I presented my research entitled "Exploring the use of breath-holding for measuring the trajectories of cerebral blood flow and regulation in the developing brain" twice over the course of an hour to four leading physiologists from the UK, and this was despite being hospitalised the week before and being left with transient aphasia due to my brain injury. I want to take this opportunity to extend my thanks and gratitude to them for being very understanding, with a special nod to Eleanor Newton, Professional Development Officer with The Society who guided me through the whole process and made sure I was fully supported throughout.

I was able to attend several sessions over the course of the week, including a "Meet the Editors" professional development session with Professors Kim Barrett and Michael Tipton that allowed for an insight into how research is gathered and how publications are produced, which was very helpful for an early career researcher such as myself. Research presentations and ePosters were categorised into specialism themes including but not limited to cardiac and vascular physiology, epithelia and membrane transport, neuroscience, and human environmental and exercise physiology. This allowed the attendee to pick and choose what to attend based on personal preference or interests. The whole platform was really user friendly, especially for someone like me who has acquired dyslexia, and I found I was able to navigate around with ease, this included when it came to my own presentation, which was created on KubifyLearning Toolbox for ePosters.

During the conference, I attended an ePoster presentation by Curtis Wadey from the University of Exeter, who discussed the role of cardiopulmonary exercise testing (CPET) in predicting mortality and morbidity in people with congenital heart disease and I was then able to have a good chat with him afterwards about his work. Another presentation by Annie Constable demonstrated her work in childhood bone health as part of the Physical Activity and Nutrition in Children (PANIC) study, and at the end there was opportunity to observe a live Q\&A about the research, which I found very informative. I was also thrilled to watch the Annual Review Prize Lecture by Professor Atwell on the regulation of blood-flow at the capillary level in health and disease; it was really relevant to my own research interests and will inform my work to come.

This type of networking and research sharing through ePosters, virtual presentations and open discussion has been really accessible, and in turn raised my confidence for attending conferences in the future, as it was quite a daunting prospect as a first timer to such an event! Attending and presenting at Physiology 2021 has led to me learning a whole host of new digital skills and given me the valuable chance to participate at an international scientific forum. I would like to thank The Physiological Society for the opportunity to attend the conference, as well as my supervisor and my lab The Cerebrovascular Research Unit at the University of Exeter, for supporting me throughout my dissertation. 


\section{Membership}

\section{Physiology News Editorial Board welcome two new members}

This past summer, Physiology News recruited two new Editorial Board members, and welcomed back Christopher Torrens and Lalarukh Haris Shaikh for their second terms. Read about our whole team at physoc.org/ editorialboard.

\section{Dr Wendy Hempstock}

University of Shizuoka, Japan

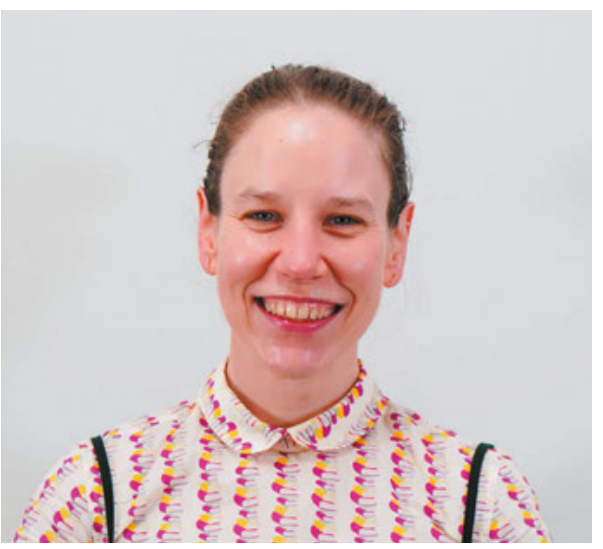

I joined The Physiological Society after starting my PhD studies in the Laboratory of Physiology at the University of Shizuoka in Japan. I completed my degree this year
(2021) and am now working as an assistant professor in the School of Nursing at the University of Shizuoka. My research is in the intestine, and my PhD focused on the role of tight junction proteins in the transport of water and sodium in the large intestine of mice. Currently I am working to establish my own lab and find my place in the world of physiology, which luckily has brought me to the Editorial Board of Physiology News. Since I joined The Society, I have enjoyed learning about the history and other areas of physiology outside my own through reading Physiology News and I am excited to be able to take part in the creation of future issues. I am also interested in physiology education, and I hope to get some tips for teaching my nursing students (many of whom do not seem so keen as I am about physiology).

\section{Dr Alexander Carswell}

University of East Anglia, Norwich, UK

After completing my undergraduate degree in sports biomedicine at the University of Dundee, UK, I studied exercise physiology as a postgraduate and have since undertaken several years of postdoctoral

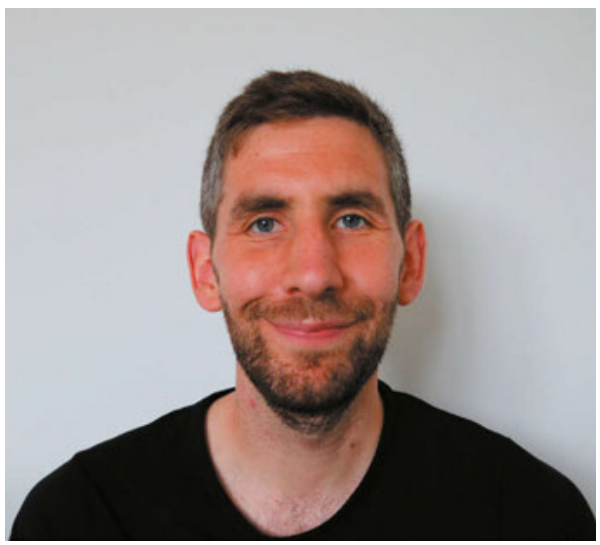

research. I have had the privilege of being a member of the Extremes Research

Group at Bangor University, UK Endurance Research Group at the University of Kent, UK and Norwich Medical School at the University of East Anglia, Norwich, UK. I have worked on multidisciplinary, UK Ministry of Defence research projects since 2014, with our findings used to support policy. I am motivated to better understand the physiological mechanisms underlying human health and physical performance, with an interest in the impact of exercise, nutrition, and environmental extremes. I became a member of The Physiological Society during the first year of my PhD and joined the Editorial Board of Physiology News in 2021.

The Biomedical Basis of Elite Performance 2022

University of Nottingham, UK

12 - 13 April 2022

physoc.org/BBEP 


\section{The Society honours its newly elected Fellow Members}

Each year, The Society elects new Fellow Members, recognising the experience, commitment, and contributions of these distinguished physiologists. Learn about a few of this year's cohort in interviews conducted by Physiology News. Apply by 1 May 2022 for a chance to be part of next year's group: physoc.org/join/fellow/.

\section{Dr Etain Tansey}

Queen's University Belfast, UK

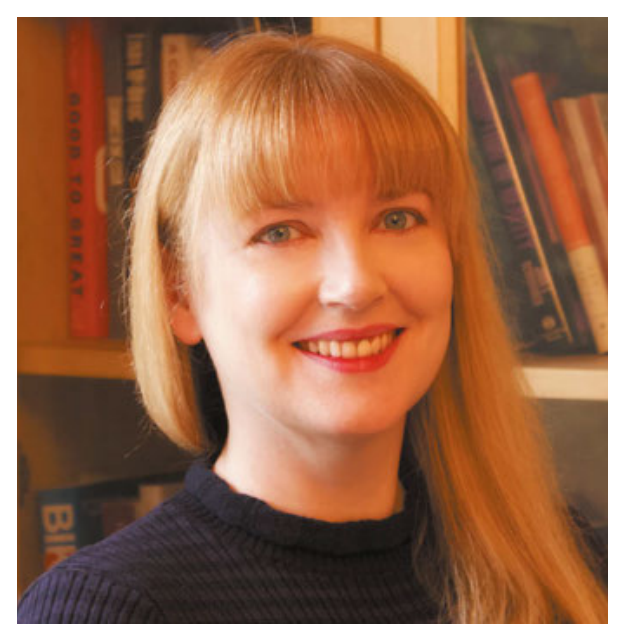

What do you value most about being a member of The Society?

I joined The Society as an Affiliate Member whilst a first-year PhD student at Trinity College Dublin. Since then, The Society has opened many doors for me. The first time I presented my PhD research was at a Physiological Society conference, and the rigorous questioning together with helpful comments helped hone both my presentation skills and research focus. I became a Full Member upon acquiring my first academic position and I learned first-hand the myriad of opportunities that membership brings.

I have attended and organised conferences, workshops, seminars and guest lecture series, all sponsored or co-sponsored by The Physiological Society. I have also received several travel awards that allowed me to attend conferences, present and receive feedback on my research, and broaden my peer support network.

Two of my colleagues and I were awarded a David Jordan Teaching Award, which has demonstrably enhanced our ability to carry out educational research. The support of The Society has been exceptionally important for my personal and career development. I am an Education and Teaching Theme Lead and this has given me a platform to reach out to members interested in best practice in physiology education, to discuss our practice and input into policy. I am delighted to be a Fellow Member of The Society. This accolade is recognised in my home institution but also worldwide as a marker of one's commitment, experience, and achievements in the field of physiology.

\section{How did completing a degree in physiology help you get to where you are now?}

I completed a degree in Natural Sciences in Trinity College Dublin. This degree was fantastically diverse in so far as I studied mathematics, chemistry and biology at first year and then branched into the different areas of chemical and biological sciences, including botany, zoology, ecology, genetics, microbiology, biochemistry and of course, physiology.

I especially enjoyed physiology and spent two years studying full-time as my specialist moderator subject. Together with completion of a lab-based research project, this training in physiology meant that I was equipped with the scientific knowledge and skills required to complete a PhD following graduation. My PhD focused on cardiovascular physiology, the autonomic nervous system and hormonal status. Completing a PhD in physiology meant that a career in academia was possible.

\section{What were the moments that had a decisive impact on your career trajectory?}

During the second year of my PhD studies, a position became available for a Postgraduate Student Physiology Teaching Scholar. The role involved teaching physiology to students in their $3^{\text {rd }}$ and $4^{\text {th }}$ years. Apart from supplementing my PhD stipend very nicely, which I confess was a serious consideration in my application for the post, this experience gave me immense personal satisfaction and reward and was fantastic for my own knowledge gain and career development.

"While we teach, we learn" the Roman philosopher Seneca is reported to have said, and I really did. I didn't know that I would enjoy teaching until I tried and I am glad I went for the opportunity when it presented itself. Consequently, although I was in a permanent position in a pharmaceutical consultancy company at the time, when a friend told me about an advertisement for a Lecturer (Education) position at Queen's University Belfast, I recognised the opportunity to combine two of my passions, and I was offered the job. I am someone who rarely says no when an opportunity presents itself and I think that has meant that I have gained experience and been offered roles that have ensured that I could progress my career during my time at Queen's.

What do you enjoy about the sector you work in, and what is challenging about it?

Job satisfaction is important to me. Currently no two days are alike, and I enjoy the variety; it maintains my motivation. In 2020, we launched a new medical curriculum at Queen's University Belfast and although it was a challenging time to do so, I enjoyed being a part of the first-year curriculum design team.

Meeting new students year on year keeps me enthusiastic and motivated; it is nice to know that I play a small part in their future. One of the most rewarding aspects of my job has been on the student support side. I was an Advisor of Studies for 9 years and during that time it was gratifying to meet with, support and mentor students as they progressed through their degree.

I remain up to date with educational innovations and actively contribute to these developments. I engage in physiology education research and scholarship and benefit from discovering new practices, feedback, and networking at conferences where I present my findings. My current research focuses on the use of ultrasound to teach basic cardiovascular concepts and the factors that influence STEM education in Northern Ireland.

I am Associate Director of my centre and of course, some decisions can be challenging, but this position gives me scope to have a say in how things evolve and help improve the university experience for students and staff alike. I love working as part of a team, I work with great people, both physiologists and non-physiologists, in a busy teaching centre that is responsible for educating the next generation of doctors, dentists, pharmacists, biomedical scientists and human biologists. Most of the time it is a lot of fun! 


\section{Dr Sue Deuchars}

University of Leeds, UK

What do you value most about being a member of The Society? Which member benefits have you found most useful over the years?

I certainly value the support of The Society over the years, right from when I was a PhD student giving my first oral communication. I appreciate the frank and useful advice that people have provided over the years about my research, career and how I can get involved with The Society. I have particularly welcomed the opportunities to act in my various roles as Trustee and on the Conferences Committee since working with the amazing staff and other members of The Society has made me so aware of all activities of The Society. These include grants, policy work, outreach work and conferences. I am also pleased to see how seriously The Society takes equality, diversity, and inclusion matters.

\section{What have you learned over the course of your work about how to balance productivity and mental health?}

I have always been an electrophysiologist, where it was important to stay in the lab while the experiments were running since you never knew if the next experiment would be a success. This meant that you have to be very flexible with time, which is especially hard when you have children and they need picking up! Therefore, I found that working parttime (which I did for 19 years) meant that I did not begrudge having long days in the lab since I had my days off with the children. It meant less money but better productivity on the days in the lab and a good work-life balance. Talking to others about problems in the lab also kept me sane - the physiology community is very friendly and people always try to give good advice to enhance your research.

\section{How did completing a degree in physiology help you get to where you are now?}

Gaining a degree in physiology opened the world of neurophysiology research to me - it allowed me to pursue a career in something that I feel passionate about, from researching new circuits in the central nervous system to learning about how production of new cells may be a useful therapeutic direction. To also be able to pass on knowledge to students is also a real privilege - their enthusiasm,

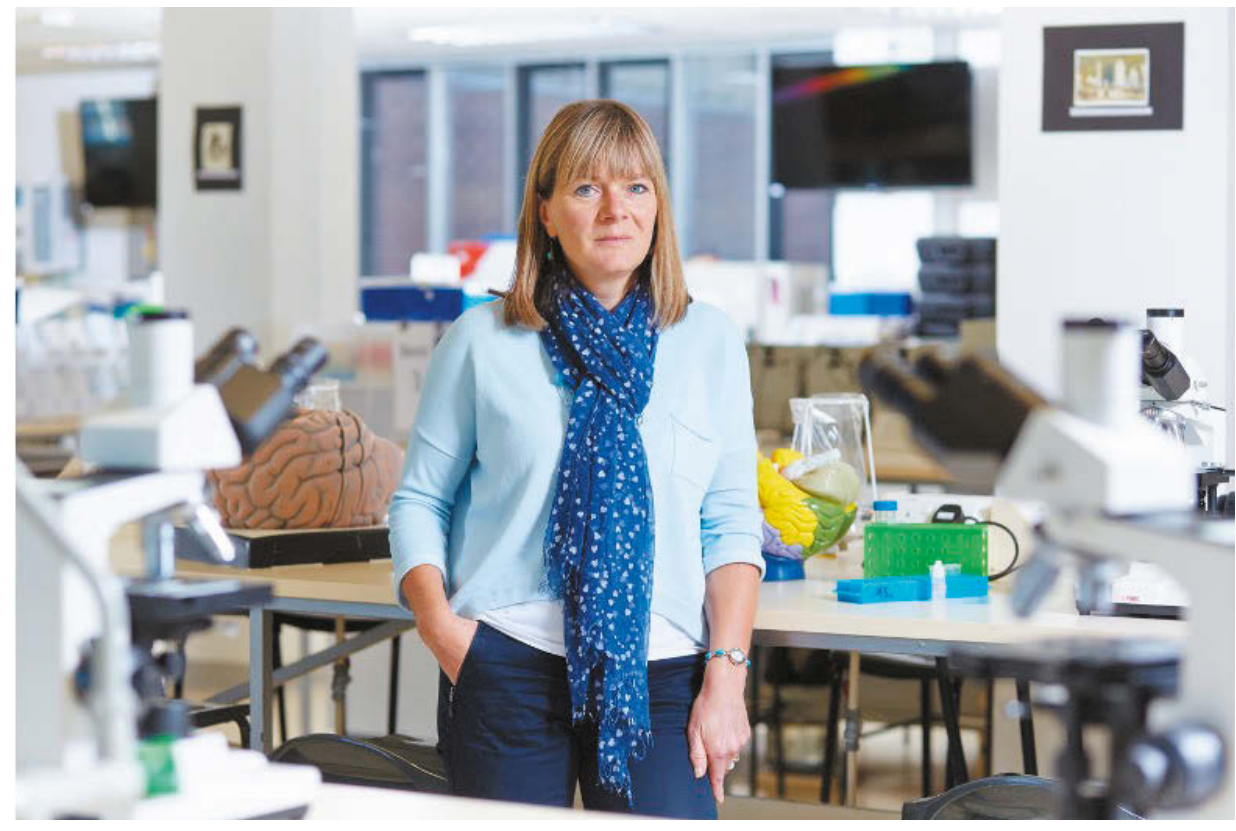

questions and sheer brilliance keep on inspiring us!

\section{How has your work/life changed due to COVID-19?}

My work has changed a lot due to COVID-19 in terms of delivery of teaching, gaining access to the research labs and a loss of those critical chats over a cup of coffee, poster viewing session or a glass of wine. It means that we have to be more inventive about how we discuss research directions but with online conferences evolving all the time, it has meant that we can "attend" conferences from all over the world. This is also really important to me as we all consider our carbon footprints. One of the most powerful talks that I heard recently was Professor Hugh Montgomery at our Extreme Environmental Physiology conference in 2019: he spoke eloquently and passionately about the impact of climate change. I think that moving forward, we all need to consider how we conduct and disseminate research to reduce the environmental impact.

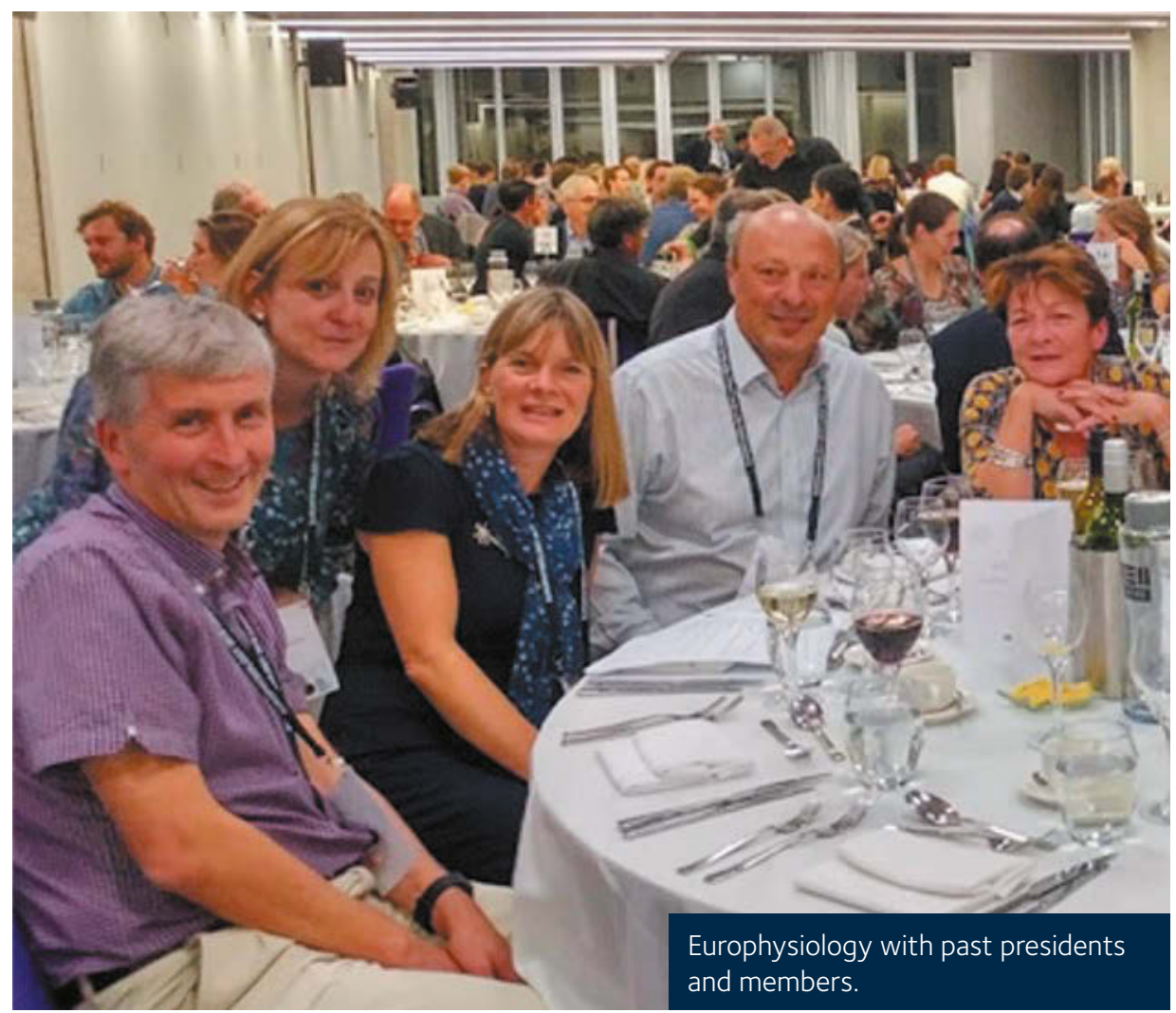




\section{Dr Alun Williams}

\section{Manchester Metropolitan University}

\section{What were the most difficult parts of running of your experiments?}

Most of my research has involved human subjects, which naturally depends on their willingness to participate. But many of my studies have involved elite athletes and that brings its own challenges. One of those is that the professional support staff (coaches/ medics/scientists) who work day to day with the athletes are often, quite understandably, wary of letting "strangers" near their athletes (precious commodities?). Their main concern, quite rightly, is making sure the athletes are ready to perform on the next Saturday or whenever their next competitive event is, and they don't want anything to disrupt their preparation. So from our point of view as researchers, it has sometimes been difficult to convince those professional support staff to allow us access to the athletes, and when they do see the value in what we're doing and agree, we have needed to be very flexible to fit in with their schedule so any inconvenience has been ours and not theirs. Sometimes we haven't been successful in gaining access to the athletes. But when we are, the relatively easy bit has then been gaining individual consent from the athletes - by the time we've reached that stage, most of the athletes are very interested and keen to take part, which is nice.

\section{Have you collaborated across different sectors, and if so, what lessons did you learn?}

I'm a physiologist, but also a sport scientist. Sport science research can be monodisciplinary, but more often than not is multior inter-disciplinary. So that has required, at a minimum, awareness and some reasonable knowledge of things like biomechanics and psychology, and as well as coaching, strength and conditioning principles, as well as sport rules and regulations. Frequently, input from biomechanists and psychologists has helped the design of protocols and studies in general, while input from coaches has helped make studies have practical relevance to the challenges they face in elite sport. Some of our current research addresses eligibility criteria for sex categories in sport, and for that it has certainly been important to have a broad view of the practical and ethical

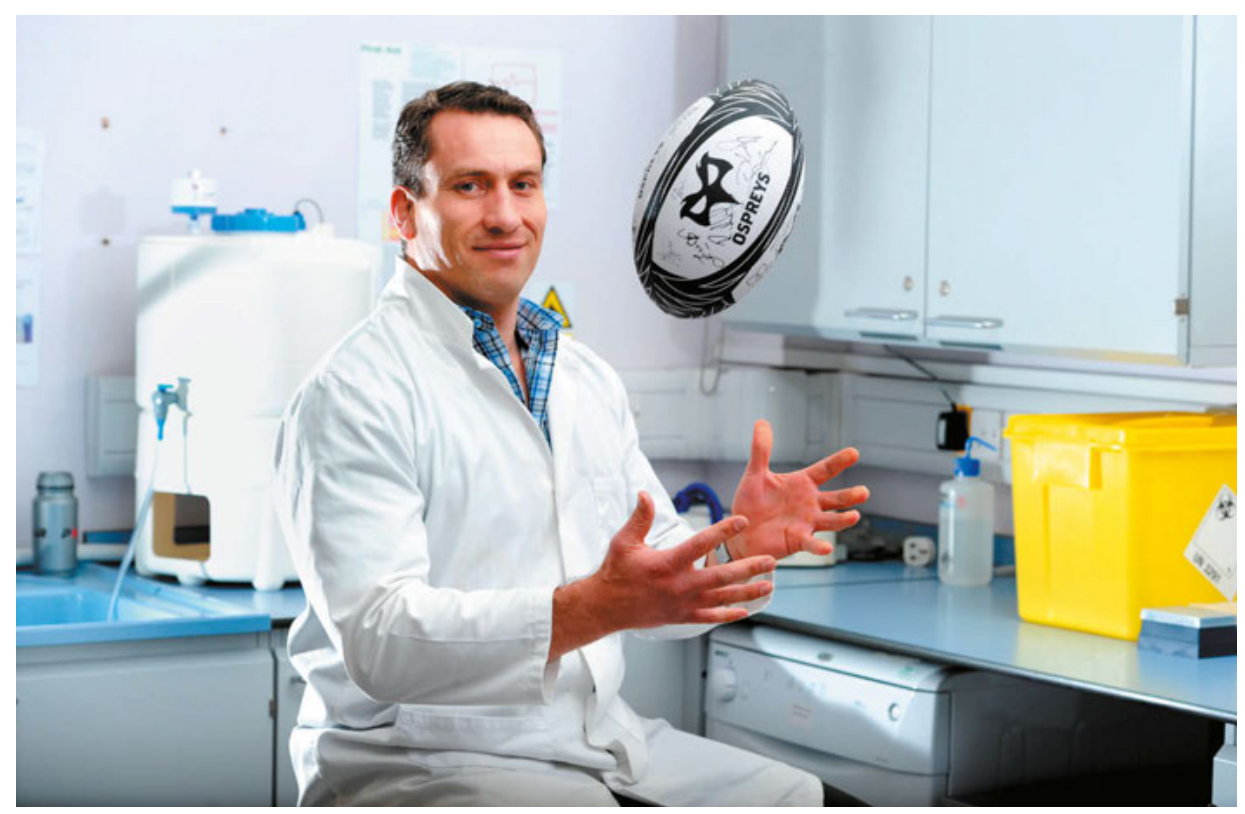

issues those topics raise, factoring them into experimental design where possible. So I've learned to educate myself outside of my home discipline to at least a level that, I hope/believe, lets me have sensible conversations with specialists from other sectors who know much more than I do about important things to consider when designing, conducting and reporting our research.

\section{How did completing a degree in physiology help you get to where you are now?}

I've mentioned that as well as a physiologist, I'm a sport scientist. My first degree was in sports science at the University of Brighton, which was a multi-disciplinary degree. However, I'm glad that the course at the time also let students specialise quite heavily in a particular discipline if they so wished, and for me that was certainly physiology. I'll forever be grateful for the dedication of the tutors there, their skills and knowledge, and the passion they showed for their subject. I remember them not being afraid to address big questions in their teaching, even if there was no clear answer that they were looking for - partly because there was no "right" answer to be found. I remember them addressing questions like the relative contributions of genes and environment on human physical performance (otherwise known as nature vs. nurture), and the relationship between exercise intensity and training response, sometimes taking concepts to their ridiculous extreme to make us think - e.g. what would the acute physiological responses and chronic training adaptations be if a running training session involved sprinting at 'maximum speed' for e.g. 4 minutes, i.e. maximum effort applied continuously, with no "pacing" involved. I don't recommend trying it! That first degree set me up well for an MSc and then a PhD that investigated different types of exercise training, which in turn helped me investigate how genetics and training are related.

\section{Is there a role model you aspire to be like?}

Not exactly one I aspire to be like, because I could never do that. But two scientists I've worked with are/were both utterly brilliant, though quite different to each other I would say. Professor David Jones, who I met at the University of Birmingham when he supervised my PhD, had a brilliant physiologist mind. He also openly asked simple questions about an idea or set of results: "So, what's the answer?" and "Show me the pictures" to cut immediately through to what mattered, and try not to make things more complicated than they actually were. I was delighted when, later in his career, David joined Manchester Metropolitan University where we worked together some more. Professor Hugh Montgomery, who introduced me to the study of the genetics of physical fitness, also has a brilliant physiologist mind. He always seems to be one or two steps ahead of everyone else in terms of ideas, and is a brilliant communicator. Hopefully I can echo some of their qualities, on my good days at least. 


\section{Professor Eric Flitney}

\section{Retired, Previously Northwestern University}

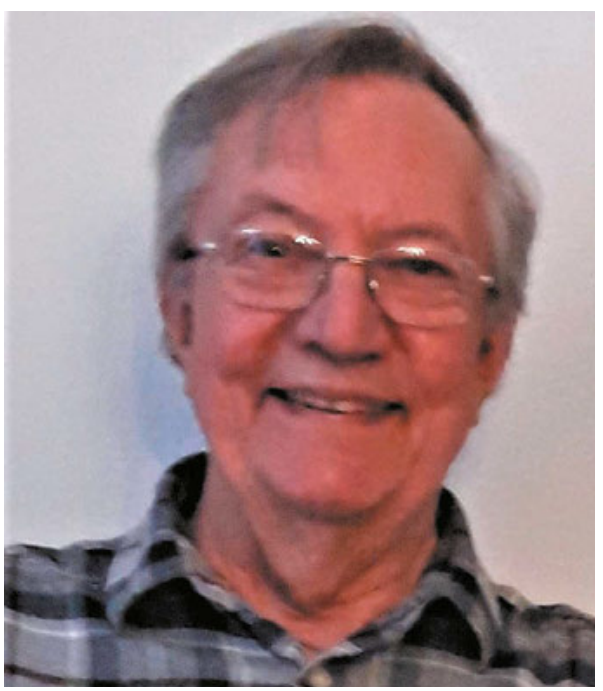

\section{What were the moments that had a decisive impact on your career trajectory?}

I first became interested in becoming a physiologist over half a century ago, while still an undergraduate student attending a field course at the Gatty Marine Biology Laboratory in St Andrews. I was in the laboratory one evening when one of the PhD students called out from a dimly-lit side room to ask if I would like to watch his demonstration. When I peered inside, I could see that he was crouched inside a wire cage recording the electrical activity of a crab nerve.

I had read about the ionic basis of the action potential as part of my undergraduate studies but I had never seen real action potentials propagating along a living nerve. I was fascinated by what I saw that night: with each pulse of the stimulating electrode the oscilloscope beam swept across the screen, briefly illuminating the room and leaving an image of the change in nerve membrane potential in its wake.

Hodgkin and Huxley had shown that the action potential was caused by precisely coordinated changes in the movement of $\mathrm{Na}^{+}$and $\mathrm{K}^{+}$ions across the axonal membrane. These movements were thought to result from the opening and closing of specialised areas of membrane, called gates, but nothing was known of their molecular structure, so the nature of the conformational changes responsible for choreographing the gating process could only be surmised.

It occurred to me that here was an important problem that should be addressed, so with the audacity of youth and little else, I promised myself that when I became a physiologist, I would be the one to solve it! In the fullness of time I did became a physiologist, but I added nothing to the body of knowledge about ion gating because I decided to spend my career studying muscle instead. Some years later I met again with the PhD student whose enthusiasm had first ignited my interest in physiology; his name was Professor Reginald Chapman who served on the Executive Committee of The Society for many years and eventually became one of its senior officers.

The notion of becoming a physiologist was reinforced during my first encounter with The Society. The occasion was engineered by my friend and mentor Professor D K Hill, who invited me to be his guest at one if its scientific meetings, this one at UCL. I was then a 20-something PhD student and the event was to leave a lasting impression on me. I was fortunate to see several luminaries of my chosen field, two of whom were Nobel Laureates, describe their most recent findings on muscle.

The opportunity to meet people afterwards at the traditional Society dinner and discuss their experiments informally was a bonus and I remember being surprised when they showed as much interest in my work as I had in theirs. I realised later that one of the assets of The Society was the willingness of its older, more experienced members to advise and encourage the younger ones. Looking back, I think my introduction to The Society at the UCL meeting was pivotal in my decision to become a physiologist.

\section{What are the main challenges you've encountered during your career?}

As a newly-appointed lecturer I realised that the time available for my research might not be as much as I would have liked, given that I would be doing my share of the department teaching and administrative loads as well. My head of department at the time was Professor J F Lamb, whose aim was to raise the research profile of the department within the wider community of physiologists. This was reflected in the way he allocated our duties: those active in research received somewhat lighter teaching and administrative loads than those who were not so interested, or else had expressed a preference for teaching, or were good administrators.

This arrangement helped mitigate the problem somewhat, but it was not ideal. Realistically, the situation could only by improved by increasing the total number of hours worked, over and above any contractual obligations, which meant working some evenings and weekends, and that is what many of us did.

The necessity to obtain sufficient funding to continue with research was a challenge that persisted throughout my career. The department had set aside a sum for new appointees to help them kick-start their research, so that they would have preliminary results to support a grant application.

I benefited from the scheme in my first year, to the tune of a storage oscilloscope and a hard-wired instrument for signal averaging. I found getting modest sums of research funding relatively easy in the early stage of my career. The research charities in particular were especially supportive of new appointees. It might surprise younger members of The Society today to know that a reasonable idea, supported by a few preliminary results and presented in a succinct manner, would be more likely to succeed than not. I recall one occasion when an application I had made was returned to me, with a note expressing interest in the proposal and offering suggestions on how to amend it to increase its chances of success. It seemed like I was taking an exam after having been given all the answers to the questions!

The need to maintain continuous funding for an on-going programme of research, particularly one in which individuals were employed on soft money, was more challenging and required considerable time and effort. The burgeoning cost of research in the 1980s exacerbated the problem and led to a substantial rise in the number of grant applications. Competition for support increased accordingly; the result of a straw poll among colleague suggested the success rate could be as low as 1 in 5 applications. This result was alarming, but as the funding situation worsened, a $20 \%$ success rate would come to seem "pretty good", which was even more disturbing. The inevitable result was that inordinate time and energy was swallowed up writing lengthy grant proposals and less on conducting research, which was very wasteful. Predictably, this caused morale to plunge, and some colleagues for whom I had high regard decided that the struggle was not worth the risk to their health and gave up research altogether. 


\section{From exercise physiology to the Olympics, England Athletics and beyond: A Fellow Member tells the story of her illustrious career}

\author{
Professor Myra Nimmo \\ Emeritus Professor of Metabolic \\ Physiology, University of \\ Birmingham, UK
}

Myra Nimmo is an Olympic long jump athlete, who held the Scottish long jump record for 39 years. Her academic career as an exercise physiologist included being a professor at the University of Strathclyde, Pro Vice-Chancellor Research at Loughborough University, and both Pro Vice-Chancellor and Head of College of Life and Environmental Sciences at the University of Birmingham. In 2016, Nimmo was appointed the Chair of England Athletics, and she retired from her time in this post earlier this year.

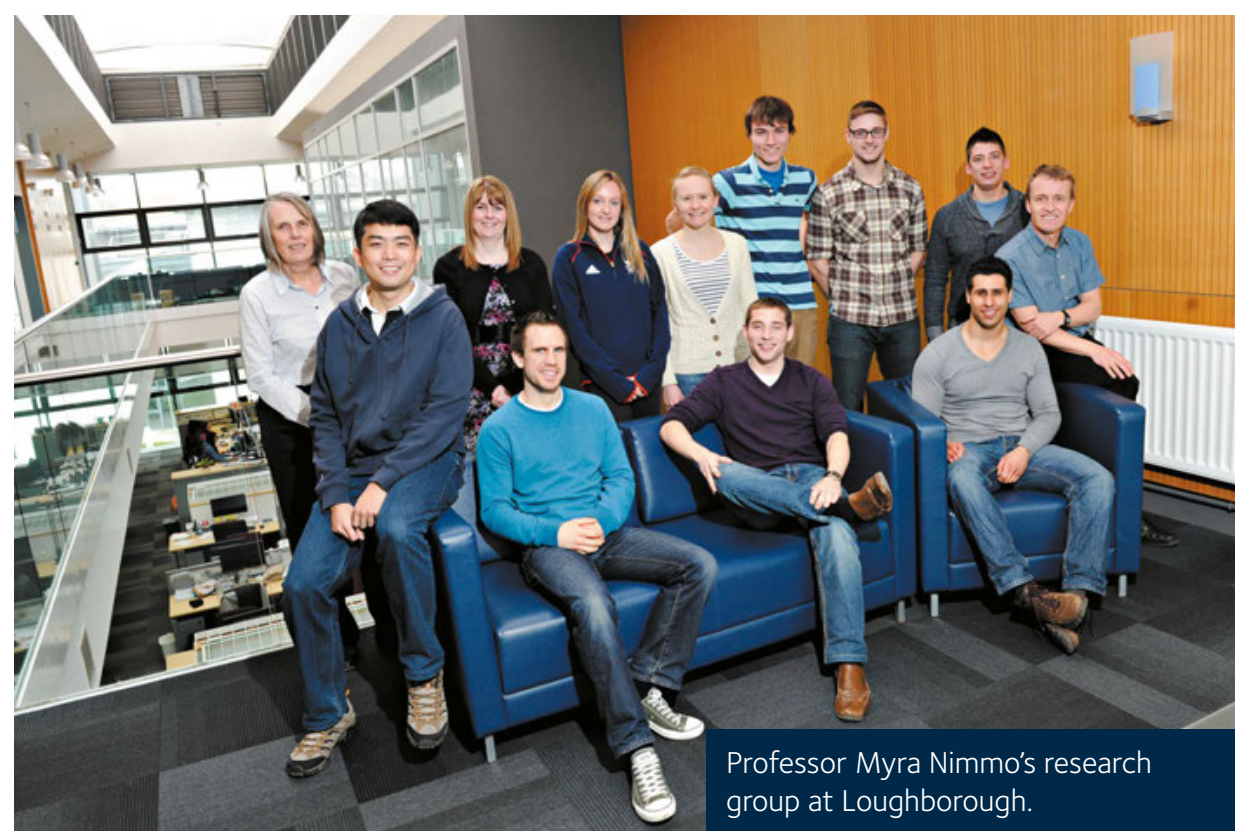

What have you valued most about membership of The Physiological Society over the years?

Initially, I became a member of The Physiological Society in 1984. At this time, of course, The Society was very different. To become a member, your name was placed in a book for others to sign and support. This early part of my career was when I found an enormous amount of benefit from The Society.

The benefit of being a member back when I was an academic came from being able to present before the study was complete and to share preliminary data. It was common for the author when asked "Do you wish this to be published?" to answer "No" as the value and the reason for presenting was to gain insight from those in the audience as to how best to progress or interpret unexpected findings.

As students received free accommodation and attendance, it was also hugely beneficial for my group to be away from their home university and to meet, discuss their work and socialise with others in their field. My students, all of whom presented and became members of The Society benefited hugely in the skill of how to present with the traffic light system being used on timings and the number of slides allowed. To this day, as I sit through some lengthy presentations, I wish many more had experienced that training regimen!
Tell us a bit about the projects you were involved in during your years as a physiologist.

I was fortunate to be involved in many aspects where my work as a physiologist allowed me to lead on a number of national projects including the establishment of the National Centre for Sport and Exercise Medicine, a joint project based at Loughborough University, University College London and Leeds. The National Centre is a legacy project from the 2012 Olympic Games that aims to foster world-class research that will lead to long-term systemic changes to benefit England.

At Loughborough and Birmingham, I was fortunate to work with military colleagues in the development and shape of the Defence and National Rehabilitation Centre, a stateof-the-art clinical facility for injured service men and women. The programme also includes the potential to develop a national clinical rehabilitation facility where the expertise that exists within defence medicine could be shared for the benefit of England.

England Athletics (EA) is the Governing Body for grass roots activity to competitive level at Commonwealth Games in England. It is therefore necessary for EA to work closely with our partner UK Athletics who is responsible for teams from all the Home Nations. This allowed a smooth transition 


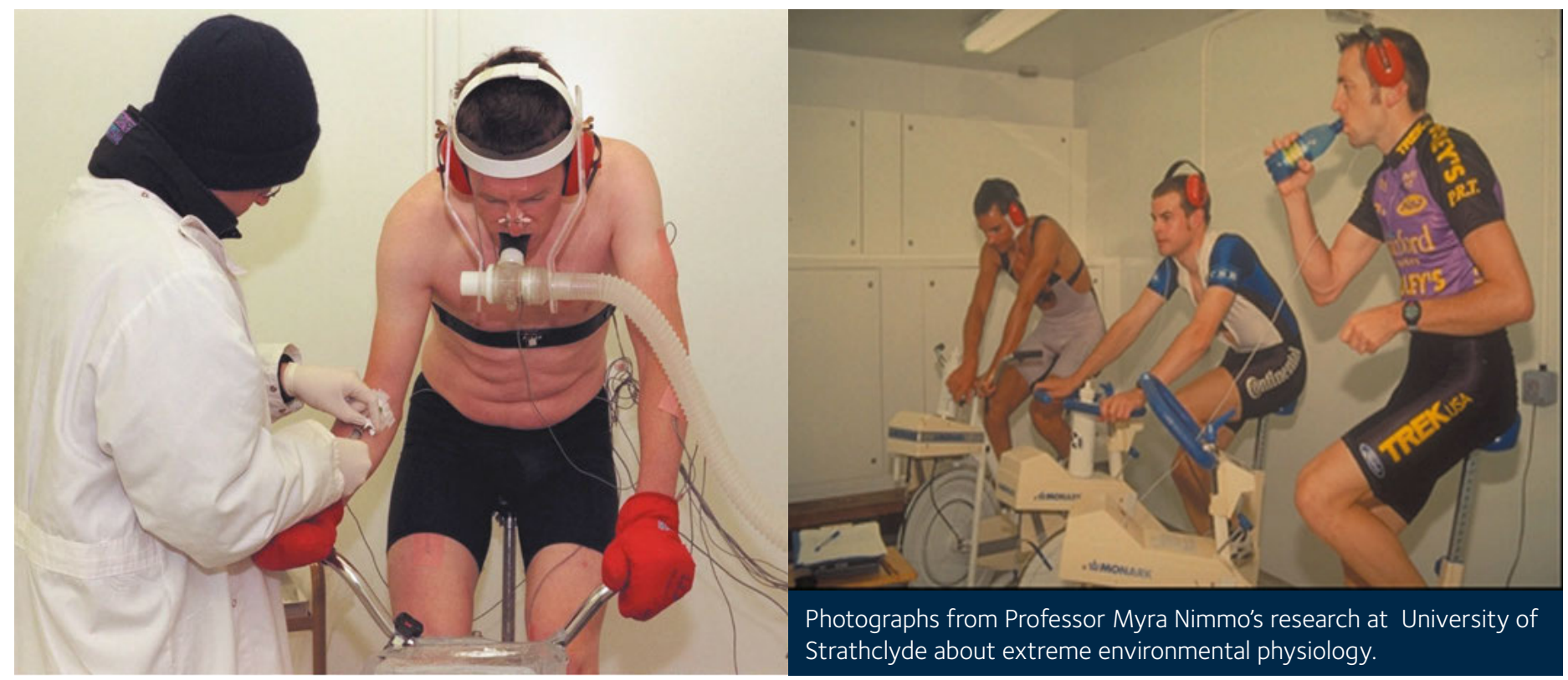

from young athlete to elite. EA is very much smaller than the latter two universities I worked at and had considerably smaller numbers of support staff. No large HR or Development funding departments but the functions and expertise are still required. The sport, as a whole, is dependent on volunteers and therefore leading the Board and the executive is much closer to my role at Loughborough as Pro Vice-Chancellor Research, where I had little or no budget and had to drive the progress through collaborative working with the Deans and working through influencing and persuading staff of the direction of travel. Similarly, the matrix management required to deliver inter-university research projects was paramount in our work with UK Athletics. Essentially different organisations, different cultures with staff paid by different masters, but on any specific topic working as a team.

\section{What were the most difficult parts of running of your experiments?}

My PhD studies were on thoroughbred racehorses and the most difficult part of these experiments was not getting kicked or bitten as you tried to draw blood or take muscle biopsies from these beautiful animals. Doing research on humans was no less demanding but getting bitten or kicked was not usually an issue!

Most of our exercise experiments on humans required participants to be fasted and by default started early in the morning for the subjects and even earlier for the researchers. An empathy for the subjects was of course paramount whether they were elite athletes or obese or elderly people. Our experiments were invasive and demanding for the subjects and it was always of concern to ensure that they were as comfortable as they could be.

\section{What have you learned over the course of your work about how to balance productivity and mental health?}

As an athlete, I have always relied on exercise to relieve stress. Training for the Olympics and preparing for my finals at the University of Glasgow at the same time was perversely ideal for me. I was usually fortunate enough that if one aspect was not going well, I could disappear into the other for a few hours.

\section{Have you collaborated across different sectors, and if so, what lessons did you learn?}

Working in exercise physiology it was imperative that I engaged with other fields. The first obvious observation is how differently sectors work and communicate. I found, as a generalisation, clinicians were very big team orientated, with access to specialist laboratory and technical facilities.

Much of my own group's work was contained within our own laboratories - if a new assay was needed, we set about developing and validating it, rather than request a central laboratory to analyse the samples or similarly running the data. This alternative way of working opened up enormous opportunities but required that as a physiologist I still fully understood exactly what was done and what the statistics were telling me.

The largest collaboration ( $£ 4.5 \mathrm{M}$ from the National Institute of Health Research) was as the Loughborough lead in the Biomedical Research Unit (BRU) jointly with the University Hospitals of Leicester NHS Trust. The BRU was entitled Diet, Lifestyle and Physical Activity and investigated interventions to manage chronic disease. My colleagues at Leicester, led by Professor Melanie Davies were experts in diabetes but we also engaged under this topic with experts in fatty liver disease and renal disease.

\section{What advice would you give to yourself as an A-level student?}

I started University studying mathematics and statistics, but my athletics career made me curious about biology and in second year I switched over to biological sciences with no firm career plan in mind. I think I was surprised with my progress in academe. I had never anticipated undertaking a PhD when I started my degree, nor anticipating winning a postdoctoral Wellcome Fellowship following the PhD. Throughout my career I hope I made the most of the opportunities that I was given and pursued activities that I enjoyed. This was probably best illustrated when after years working in Scotland, and achieving my Chair, I believed that I would remain in Glasgow until retirement. I have never regretted responding to the post at Loughborough and then Birmingham- which were certainly not pre-planned.

\section{What are the main challenges you've encountered during your career?}

Not dissimilar to many lab-based academic researchers who are carers, it is difficult to be flexible. When my sons were young it was just not possible to travel to conferences or to spend time in international labs - the Physiological Society conference in the UK was vital to keep networks alive as there was always the highest quality work being discussed.

What do you enjoy about the sector you work in, and what is challenging about it?

The joy is that physiology gives you such a broad base and allows you to work across many domains from the genomic level to applications to elite athletes' training programmes. I think I have had the chance to work across all these levels, and this kept my science relevant and alive. 


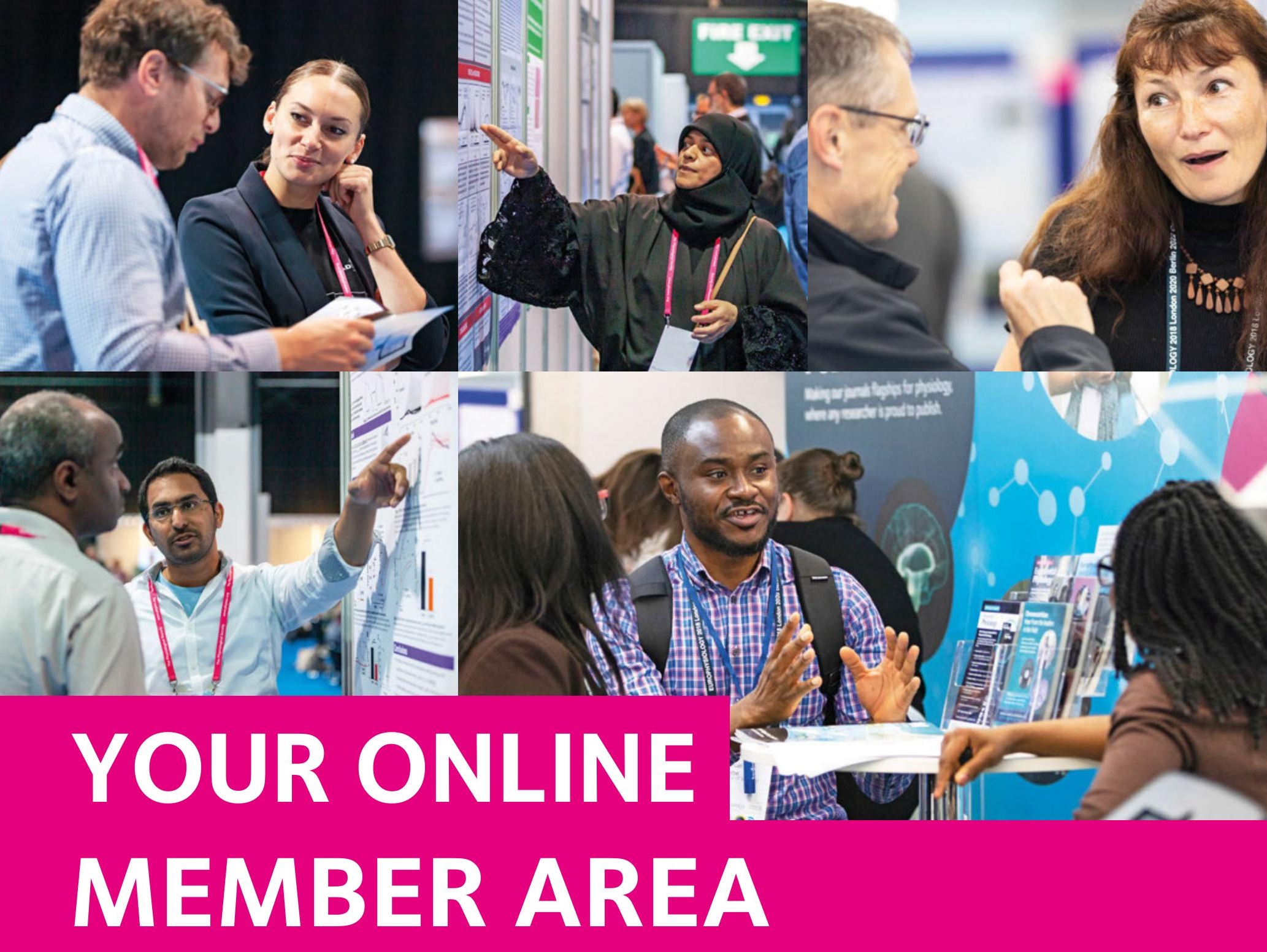

Join physiologists from across the world to discuss, learn and share ideas using our new online Member Community.

תֵ

Build supportive relationships and grow your network with physiologists across career stages and interests

Expand the reach of your research with our lively, global community

Share your ideas and explore new $\circ$ approaches to research and teaching in a friendly, supportive environment
Denelop your career through memberonly professional development webinars and resources

ooo Continue the conversation beyond our conferences and webinars

Log on and join in the conversation: www.physoc.org

D. The

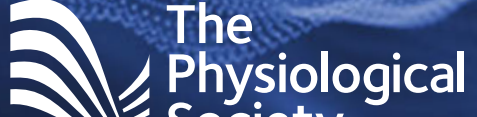

D.IE Society 